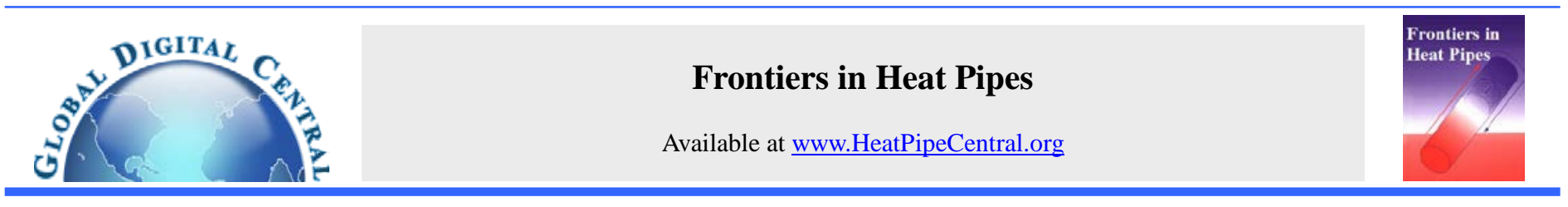

\title{
HEAT PIPES: REVIEW, OPPORTUNITIES AND CHALLENGES
}

\author{
Amir Faghri* \\ Department of Mechanical Engineering, University of Connecticut, Storrs, CT 06269, U.S.A.
}

\begin{abstract}
A detailed overview of heat pipes is presented in this paper, including a historical perspective, principles of operations, types of heat pipes, heat pipe performance characteristics, heat pipe limitations, heat pipe frozen startup and shutdown, heat pipe analysis and simulations, and various applications of heat pipes. Over the last several decades, several factors have contributed to a major transformation in heat pipe science and technology . The first major contribution was the development and advances of new heat pipes, such as loop heat pipes, micro and miniature heat pipes, and pulsating heat pipes. In addition, there are now many new commercial applications that have helped contribute to the recent interest in heat pipes, especially related to the fields of electronic cooling and energy. For example, several million heat pipes are now manufactured each month since all modern laptops use heat pipes for CPU cooling. Numerical modeling, analysis, and experimental simulation of heat pipes have also significantly progressed due to a much greater understanding of various physical phenomena in heat pipes, as well as advances in computational and experimental methodologies.
\end{abstract}

Keywords: heat pipes, performance characteristics, types of heat pipes, numerical modeling, heat pipe applications

\section{INTRODUCTION}

The heat pipe (Faghri, 1995) is a highly effective passive device for transmitting heat at high rates over considerable distances with extremely small temperature drops, exceptional flexibility, simple construction, and easy control with no external pumping power. Engineers, scientists and graduate students interested in heat pipe science often times struggle and spend considerable time poring through archival publications or the contents of heat pipe books in order to understand and predict a heat pipe system. Being aware of this situation, this review is a self-contained document of the state-of-the-art heat pipe science and technology. The physical significance and performance characteristics, as well as the technological and experimental issues related to this technology are covered in this review. The purpose of this review article is also to make a thorough presentation of the basic and advanced techniques for analyzing various heat pipe systems under a variety of operating conditions and limitations.

The subject of heat pipe science has immense importance in a large variety of traditional engineering disciplines. The sub-discipline of heat pipe science has its foundation in several classical fields, such as fluid mechanics, heat transfer, thermodynamics and solid mechanics. Heat pipe science also provides an opportunity for scientists and engineers to apply a variety of complex physical phenomena and fundamental laws in the thermal-fluids area to a relatively simple system, such as the heat pipe. This includes the steady and unsteady forced laminar and turbulent convective heat and mass transfer, compressible vapor effects, phase-change phenomena, boiling, condensation/evaporation, two-phase flow, rotating flows, thin film flows, liquid flow in porous media, rarefied gases, interfacial heat and mass transfer, magneto-hydrodynamic flows, and conjugate heat transfer effects.

This review provides detailed information about the following topics related to heat pipe science and technology:
Section 2: Historical Development of Heat Pipes

Section 3: Principles of Operations

Section 4: Types of Heat Pipes

Section 5: Working Fluids and Temperature Ranges

Section 6: Capillary Wick Designs and Structures

Section 7: Heat Transfer Limitations

Section 8: Heat pipe Start Up

Section 9: Heat Pipe Characteristics

Section 10: Heat Pipe Analysis and Simulation

Section 11: Heat Pipe Applications

Section 12: Conclusions

\section{HISTORICAL DEVELOPMENT OF HEAT PIPES}

Of the many different types of systems which transport heat, the heat pipe (Faghri, 1995) is one of the most efficient systems known today. The advantage of using a heat pipe over other conventional methods is that large quantities of heat can be transported through a small crosssectional area over a considerable distance with no additional power input to the system. Furthermore, design and manufacturing simplicity, small end-to-end temperature drops, and the ability to control and transport high heat rates at various temperature levels are all unique features of heat pipes.

The predecessor of the heat pipe, the Perkins tube, was introduced by the Perkins family from the mid-nineteenth to the twentieth century through a series of patents in the United Kingdom. Most of the Perkins tubes were wickless gravity-assisted heat pipes (thermosyphons), in which heat transfer was achieved by a change of phase (latent heat of evaporation). The Perkins tube design closest to the present heat pipe was patented by Jacob Perkins (1836). This design was a closed tube containing a small quantity of water operating as a two-phase cycle.

The introduction of the heat pipe was first conceived by Gaugler (1944) of the General Motors Corporation in the U.S. Patent No. 2350348. Gaugler, who was working on refrigeration problems at that time, envisioned a device which would evaporate a liquid at a point above the place where condensation would occur without requiring any

\footnotetext{
*Email: faghri@engr.uconn.edu
} 
additional work to move the liquid to the higher elevation. His device consisted of a closed tube in which the liquid would absorb heat at one location causing the liquid to evaporate. The vapor would then travel down the length of the tube, where it would recondense and release its latent heat. It would then travel back up the tube via capillary pressure to start the process over. In order to move the liquid back up to a higher point, Gaugler suggested the use of a capillary structure consisting of a sintered iron wick. A refrigeration unit proposed by Gaugler used a heat pipe to transfer the heat from the interior of a compartment to a pan of crushed ice below. His idea, however, was not used by General Motors for the refrigeration problem.

In 1962, Trefethen (1962) resurrected the idea of a heat pipe in connection with the space program. Serious development started in 1964 when the heat pipe was independently reinvented and a patent application was filed by Grover at Los Alamos National Laboratory in New Mexico. Grover et al. (1964) and Grover (1966) built several prototype heat pipes, the first of which used water as a working fluid, and was soon followed by a sodium heat pipe which operated at 1100 $\mathrm{K}$. Grover and his co-workers also demonstrated the effectiveness of heat pipes as a high performance heat transmission device and proposed several applications for their use. In a U.S. patent application filed by Grover on behalf of the U.S. Atomic Energy Commission, Grover (1966) coined the phrase "heat pipe" and described a device almost exactly the same as Gaugler's, stating, "with certain limitations on the manner of use, a heat pipe may be regarded as a synergistic engineering structure which is equivalent to a material having a thermal conductivity greatly exceeding that of any known metal.” In the patent application, Grover (1966) gave a very limited theoretical analysis of heat pipes, but presented experimental results obtained from stainless steel heat pipes that incorporated a screen wick with sodium, silver and lithium as working fluids.

The recognition of the heat pipe as a reliable thermal device was initially due to the preliminary theoretical results and design tools that were reported in the first publication on heat pipe analysis by Cotter (1965). Following this publication, research began worldwide. The United Kingdom Atomic Energy Laboratory at Harwell started experimenting with sodium heat pipes to use as thermionic diode converters. In addition, scientists started conducting similar work at the Joint Nuclear Research Center in Ispra, Italy, which soon became the most active research center outside the U.S. Shortly thereafter, other countries such as Germany, France, and the former USSR initiated efforts in this regard.

The early development of terrestrial applications of heat pipes proceeded at a slow pace. Due to capillary action, heat pipes can operate in microgravitational fields without any external force field or pump. Because of this, most early efforts were directed toward space applications. However, due to the high cost of energy, especially in Japan and Europe, the industrial community began to appreciate the significance of heat pipes and thermosyphons in energy savings applications. Today, all developed countries have been actively involved in research, development, and commercialization of heat pipes.

Within the last decade, a major transformation regarding heat pipe technology and application has occurred due to the critical need of electronic cooling and energy systems, as well as the invention of new heat pipes. Several million heat pipes per month are now being manufactured since all modern laptop computers use heat pipe technology to transfer heat away from the processor. Furthermore, research and development for new heat pipes such as loop heat pipes, micro and miniature heat pipes, and pulsating heat pipes, has matured enough for use in various applications.

There is a wealth of published literature: several heat pipe books and monographs, as well as the proceedings of eleven international heat pipe symposiums and seventeen international heat pipe conferences. In addition, there are a large number of archival and non-archival publications and reports related to heat pipes, dating back over the last four decades. A significant amount of basic and applied research \& development has been performed since 1985 in the area of heat pipes due to the great potential use of this technology for various applications.

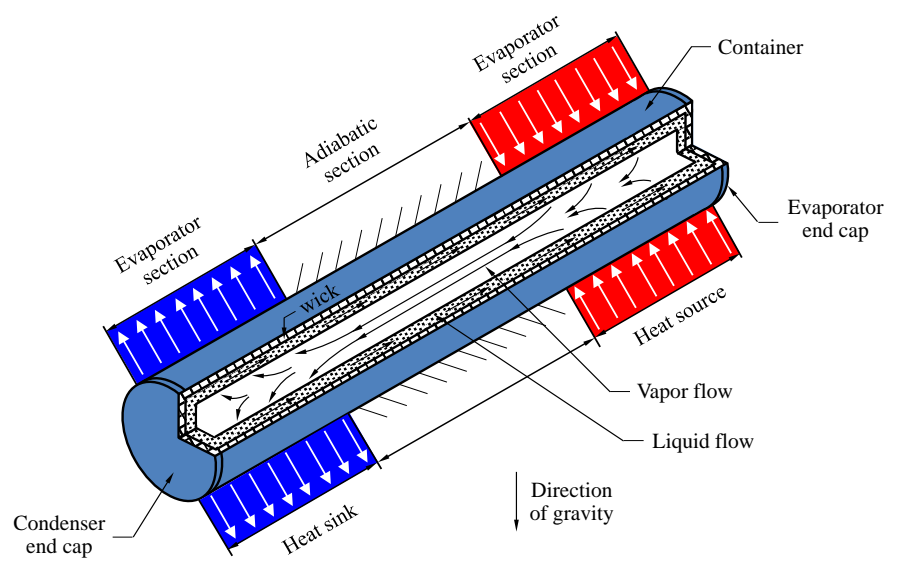

Fig. 1 Schematic of a conventional heat pipe showing the principle of operation and circulation of the working fluid.

\section{PRINCIPLES OF OPERATION}

The operation of a heat pipe (Faghri, 1995) is easily understood by using a cylindrical geometry, as shown in Fig. 1. However, heat pipes can be of any size or shape. The components of a heat pipe are a sealed container (pipe wall and end caps), a wick structure, and a small amount of working fluid which is in equilibrium with its own vapor. Different types of working fluids such as water, acetone, methanol, ammonia or sodium can be used in heat pipes based on the required operating temperature. The length of a heat pipe is divided into three parts: the evaporator section, adiabatic (transport) section and condenser section. A heat pipe may have multiple heat sources or sinks with or without adiabatic sections depending on specific applications and design. Heat applied externally to the evaporator section is conducted through the pipe wall and wick structure, where it vaporizes the working fluid. The resulting vapor pressure drives the vapor through the adiabatic section to the condenser, where the vapor condenses, releasing its latent heat of vaporization to the provided heat sink. The capillary pressure created by the menisci in the wick pumps the condensed fluid back to the evaporator section. Therefore, the heat pipe can continuously transport the latent heat of vaporization from the evaporator to the condenser section. This process will continue as long as there is a sufficient capillary pressure to drive the condensate back to the evaporator.

The menisci at the liquid-vapor interface are highly curved in the evaporator section due to the fact that the liquid recedes into the pores of the wick. On the other hand, during the condensation process, the menisci in the condenser section are nearly flat. A capillary pressure exists at the liquid-vapor interface due to the surface tension of the working fluid and the curved structure of the interface. The difference in the curvature of the menisci along the liquid-vapor interface causes the capillary pressure to change along the pipe. This capillary pressure gradient circulates the fluid against the liquid and vapor pressure losses, and adverse body forces such as gravity or acceleration.

The vapor pressure changes along the heat pipe are due (Faghri, 1995) to friction, inertia and blowing (evaporation) and suction (condensation) effects, while the liquid pressure changes mainly as a result of friction. The liquid-vapor interface is flat near the condenser end cap corresponding to a zero local pressure gradient at very low vapor flow rates. A typical axial variation of the shape of the liquidvapor interface and the liquid and vapor pressures for low vapor flow rates are shown in Figs. 2(a) and 2(b), respectively. 


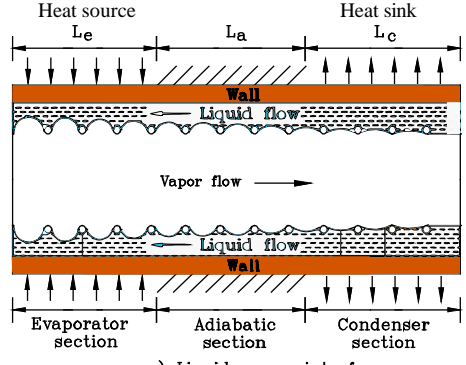

a) Liquid-vapor interface

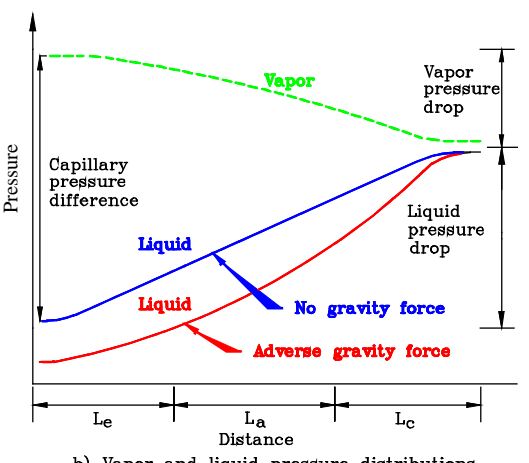

b) Vapor and liquid pressure distributions

Fig. 2 Axial variation of the liquid-vapor interface, and the vapor and liquid pressures along the heat pipe at low vapor flow rates.

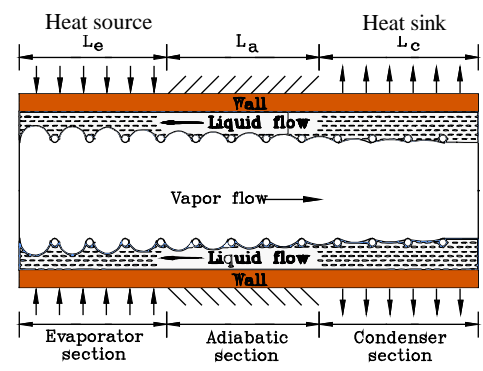

a) Liquid-vapor interface

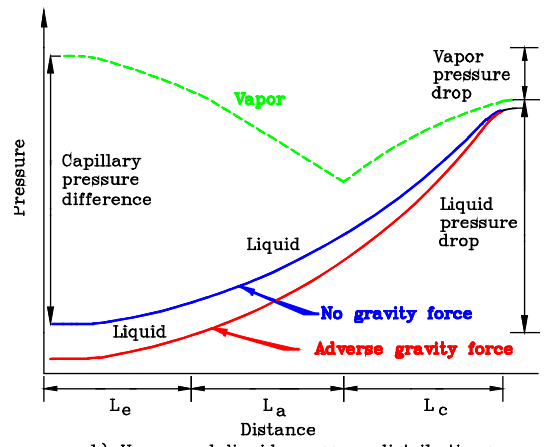

b) Vapor and liquid pressure distributions

Fig. 3 Axial variation of the liquid-vapor interface, and the vapor and liquid pressures along the heat pipe at moderate vapor flow rates.

The maximum local pressure difference occurs near the evaporator end cap. This maximum local capillary pressure should be equal to the sum of the pressure drops in the vapor and the liquid across the heat pipe in the absence of body forces. When body forces are present, such as an adverse gravitational force, the liquid pressure drop is greater, indicating that the capillary pressure must be higher in order to return the liquid to the evaporator for a given heat input. At moderate vapor flow rates, dynamic effects cause the vapor pressure drop and recovery along the condenser section, as shown in Fig. 3(b).

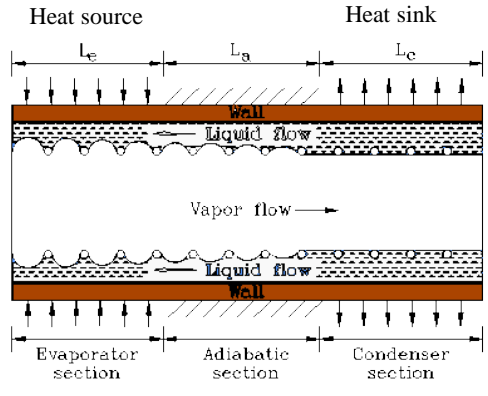

a) Liquid-vapor interface

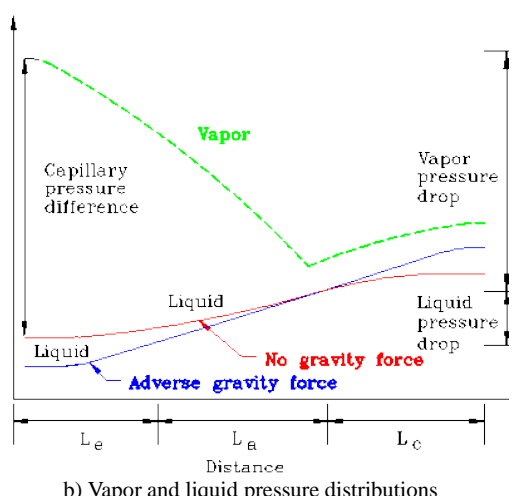

Fig. 4 Axial variation of the liquid-vapor interface, and the vapor and liquid pressures along the heat pipe at high vapor flow rates.

The local liquid-vapor pressure difference is small, but this pressure gradient approaches zero at the condenser end cap similar to the low vapor flow rate case. Again, the capillary pressure difference at the evaporator end cap should be balanced by the sum of the total pressure drop in the vapor and liquid across the heat pipe.

The general trend at high vapor flow rates with low liquid pressure drops is different from the other two cases. The vapor pressure drop can exceed the liquid pressure drop in the condenser section. In such a case, the liquid pressure would be higher than the vapor pressure in the condenser section if the pressure in the liquid and vapor are equal at the condenser end cap. In reality, the wet point is not situated at the condenser end cap as shown in 4(b), and the menisci at the liquid-vapor interface in the condenser are curved.

Traditionally, heat pipe theory consists of fundamental analyses related to hydrodynamic and heat transfer processes. Fluid mechanics theory is generally used to describe the axial liquid pressure drop in the wick structure, the maximum capillary pumping head and the vapor flow in the vapor channel. Heat transfer theory is used to model the transfer of heat into and out of the heat pipe. Phenomena such as conjugate heat conduction in the wall and wick, evaporation and condensation at the liquid-vapor interface, and forced convection in the vapor channel and wick structure are described. The various thermal resistances or elements in a conventional heat pipe are shown in Fig. 5. The thermal processes such as solidification and liquefaction, and those related to rarefied gases can play important roles in modeling transient heat pipe operation during startup from the frozen state.

Fundamentally, one expects to analyze the internal thermal processes of a heat pipe as a thermodynamic cycle subject to the first and second laws of thermodynamics (Zuo and Faghri, 1998; Khalkhali et al., 1999). Zuo and Faghri (1998) predicted the transient heat pipe performance by using a simple thermal resistance model similar to that of Fig 5. However, classical heat pipe theory does not consider a thermodynamic approach. The idealized cycle is shown in Fig. 6(a). A quantity of heat, $\mathrm{Q}_{\mathrm{in}}$, is applied to the heat pipe system at an average evaporator temperature, $\mathrm{T}$. Under steady operation, the same quantity 
of heat is rejected at a lower average condenser temperature $T_{c}$. Work is produced inside the heat pipe, but is then completely used in overcoming the hydrodynamic losses of the system. The thermal energy is converted to mechanical energy due to phase change at the liquidvapor interface by producing a pressure head.

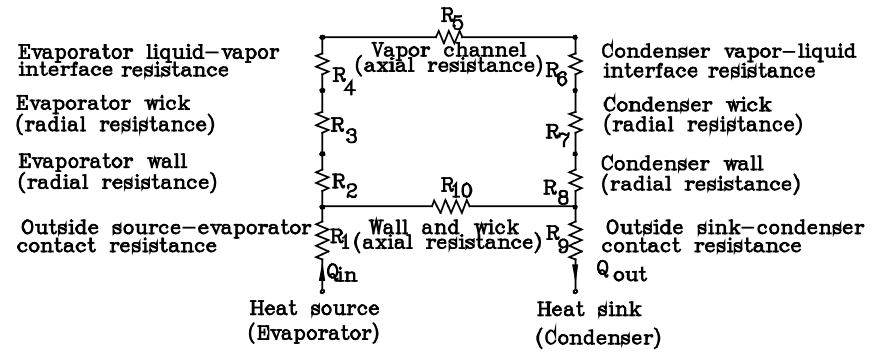

Fig. 5 Thermal resistance model of a typical heat pipe.

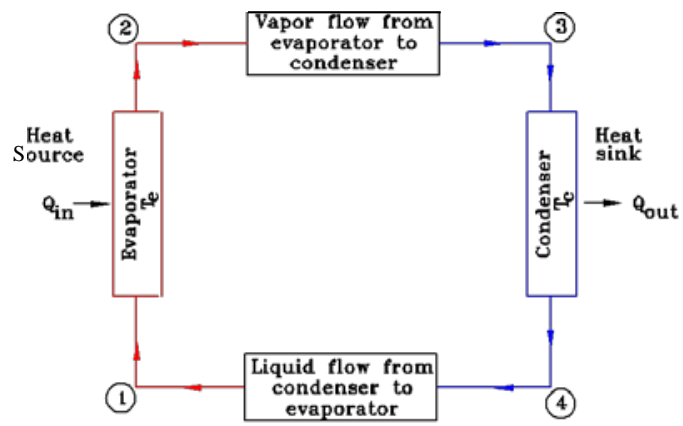

a) Various components

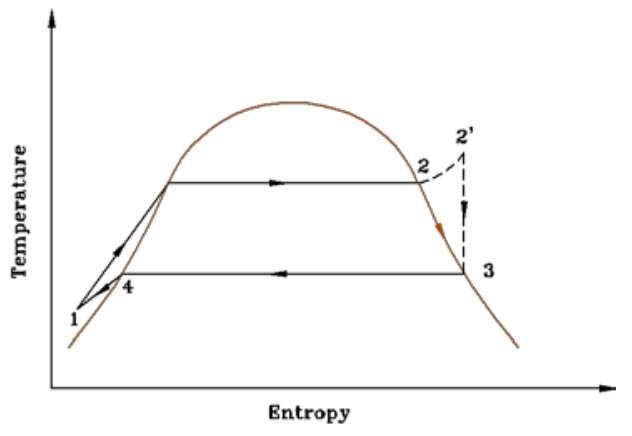

b) Temperature-Entropv diagram

Fig. 6 Thermodynamic cycle of a typical heat pipe.

The thermodynamic cycle of the heat pipe is shown in Fig. 6(b) (Khalkhali et al., 1999). The fluid enters the evaporator as a compressed liquid at temperature T1 and leaves at temperature T2 or $\mathrm{T} 2^{\prime}$ as saturated or superheated vapor, respectively. The vapor flows through the vapor channel from the evaporator to condenser due to the vapor pressure differential in the evaporator and condenser sections (23 , or $\left.2-2^{\prime}-3\right)$. The vapor enters the condenser section as a saturated vapor or mixture. The condensate enters the adiabatic section as a saturated liquid (4). Finally, the liquid leaves the adiabatic section to enter the evaporator as a compressed liquid to complete the cycle. The work done on the working fluid during its circulation through the heat pipe is the area enclosed by the temperature versus entropy diagram shown in Fig. 6(b). As expected from the second law of thermodynamics, the conversion of thermal energy to kinetic energy is associated with heat rejection at a temperature below the high temperature reservoir in the system with efficiency less than $100 \%$. It should be noted that in most heat pipes, the end-to-end temperature difference is small compared to other conductive systems. Nevertheless, the most ideal heat pipe can never be completely isothermal because this would violate the second law of thermodynamics. The capability of the simple thermodynamic analysis is very limited. In most cases, the heat transfer and fluid mechanics methodologies are needed to solve a heat pipe problem, especially when a quantitative solution is required.

\section{TYPES OF HEAT PIPES}

Heat pipes have been designed and built with various crosssectional areas as small as $30 \mu \mathrm{m}$ width $\times 80 \mu \mathrm{m}$ depth and $19.75 \mathrm{~mm}$ in length (micro heat pipes), and heat pipes as large as $100 \mathrm{~m}$ in length. All heat pipes have an evaporator and condenser section where the working fluid evaporates and condenses, respectively. Many heat pipes also have a transport or adiabatic section which separates the evaporator and condenser sections by an appropriate distance, intended to satisfy the heat pipe limitations and/or the design constraints of the application. A given heat pipe may have multiple evaporators, condensers and adiabatic sections. The working fluid is usually circulated by capillary forces in a wick. However, gravitational, centrifugal, electrostatic, and osmotic forces can also be used to return the liquid from the condenser to the evaporator.

For simplicity of design and manufacturing, heat pipe containers are generally circular cylinders. Other shapes, however, such as rectangular (flat heat pipes), conical (rotating heat pipes), corrugated flexible heat pipes, and nosecap (leading edge heat pipes) geometries have been studied.

\section{Two-Phase Closed Thermosyphon}

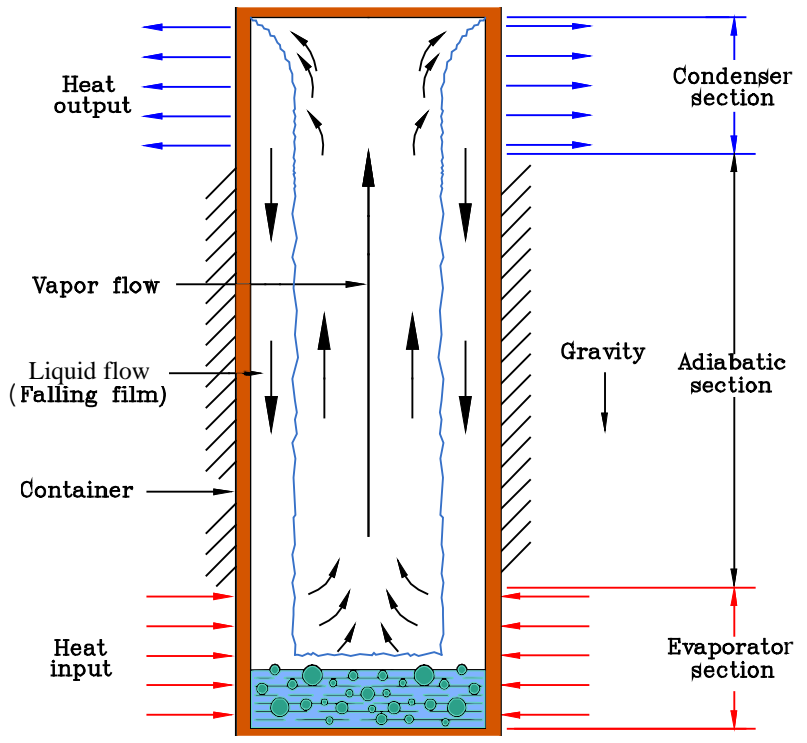

Fig. 7 Gravity-assisted wickless heat pipe (two-phase closed thermosyphon).

A two-phase closed thermosyphon (Faghri, 1995) is a gravityassisted wickless heat pipe (Fig. 7) (Faghri et al., 1989a). The condenser section is located above the evaporator so that the condensate is returned by gravity. The sonic and vapor pressure limits are constraints to the operation of the thermosyphon as with capillarydriven heat pipes. The entrainment limit is more profound in the thermosyphon than in capillary-driven heat pipes due to the free liquid surface. The counterpart of the entrainment limit in thermosyphons is called flooding (Faghri et al., 1989a), which is the most severe limitation in the operation of these systems. A sudden oscillating wall temperature and vapor pressure rise will occur at the flooding limit. The boiling limit in thermosyphons is due to film boiling, rather than nucleate boiling as in capillary-driven heat pipes. The boiling limit in 
thermosyphons occurs when a vapor film forms between the pipe wall and the liquid in the evaporator section of the heat pipe. For small liquid fill volumes, the dryout limit may be reached, where all of the working fluid is held in the liquid film, and no liquid pool exists. In this case, any further increase in the input heat will cause a severe temperature increase at the bottom of the evaporator section.

The operation of the thermosyphon is sensitive to the working fluid fill volume. For thermosyphons without wicks, it has been shown experimentally that the maximum rate of heat transfer increases with the amount of the working fluid up to a certain value. A wick structure is sometimes included in the design of thermosyphons to postpone flooding and improve the contact between the wall and the liquid. The capillary limit is generally of no concern in the operation of the thermosyphon due to the fact that gravity is the major driving force for condensate return.

\section{Capillary-Driven Heat Pipe}

The capillary-driven heat pipe (conventional heat pipes) consists of a sealed container, in which a wick is placed on the inner radius of the pipe wall (Fig. 8). The purpose of the wick is to provide a capillarydriven pump for returning the condensate to the evaporator section. Enough working fluid is placed inside the sealed pipe to saturate the wick with liquid. The operation of the capillary-driven heat pipe is as follows. Heat input to the evaporator section evaporates the liquid in the wick. The vapor then enters the vapor space and travels to the condenser section due to the higher vapor pressure in the evaporator. Heat removal from the condenser causes the vapor to condense, releasing its latent heat of vaporization. The condensate is then pumped back to the evaporator section by the capillary force generated at the liquid-vapor interfaces of the pores in the wick. Due to the two-phase nature of the capillary heat pipe, it is ideal for transferring heat over long distances with a very small temperature drop, and for creating a nearly isothermal surface for temperature stabilization. Generally, the most commonly encountered limitation to the performance of a capillary-driven heat pipe is the capillary limit. This occurs when the wick cannot return enough liquid to the evaporator section to keep it saturated. At this point, the evaporator wall experiences a sudden, continuous increase in temperature. Conventional capillary heat pipes are used in almost all laptop/notebook computers nowadays to channel heat away from the processors. The capillary heat pipe has also been widely applied to various commercial and aerospace applications.

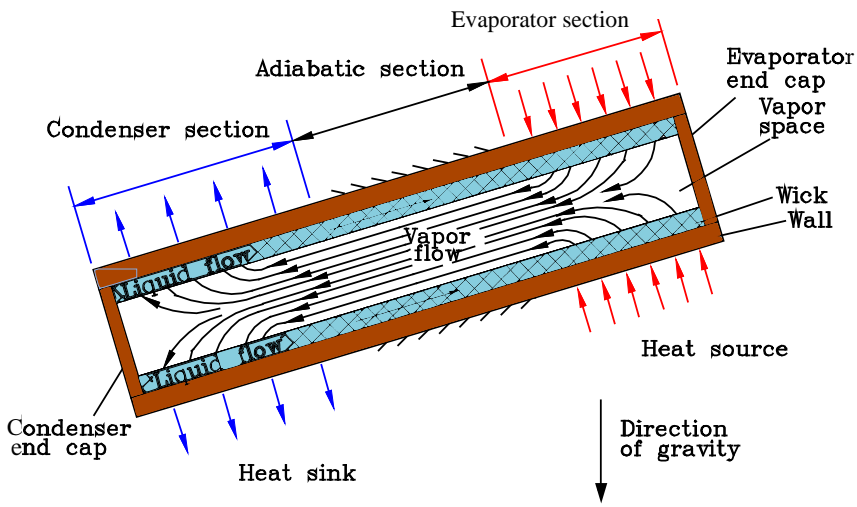

Fig. 8 Conventional capillary-driven heat pipe.

\section{Annular Heat Pipe}

The annular heat pipe is similar to the conventional capillary-driven heat pipe in many ways. The main difference between the two is that the cross-section of the vapor space in an annular heat pipe is annular instead of circular (Fig. 9) (Faghri and Thomas, 1989; Faghri, 1989). This enables the designer to place wick material both on the inside of the outer pipe and on the outside of the inner pipe. In this manner, the surface area for heat input and output can be significantly increased without increasing the outer diameter of the pipe. Therefore, the capillary limit of the annular heat pipe is greater than that of a conventional heat pipe having the same outer dimensions. The annular heat pipe has been used as an isothermal furnace, with excellent results due to its temperature flattening capabilities and fast response time to a cold charge. This type of heat pipe can also be used to connect two circular cross-section heat pipes end-to-end by inserting the circular heat pipe into the inner pipe.
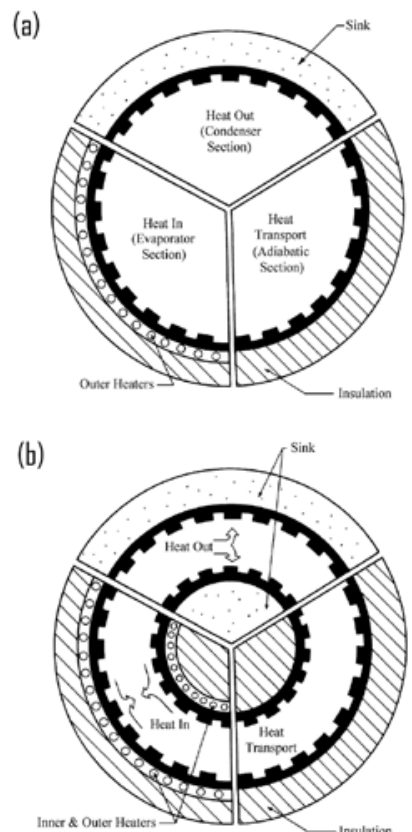

Fig. 9 Conventional and concentric annular heat pipe design: (a) conventional; (b) concentric annular.

\section{Vapor Chamber}

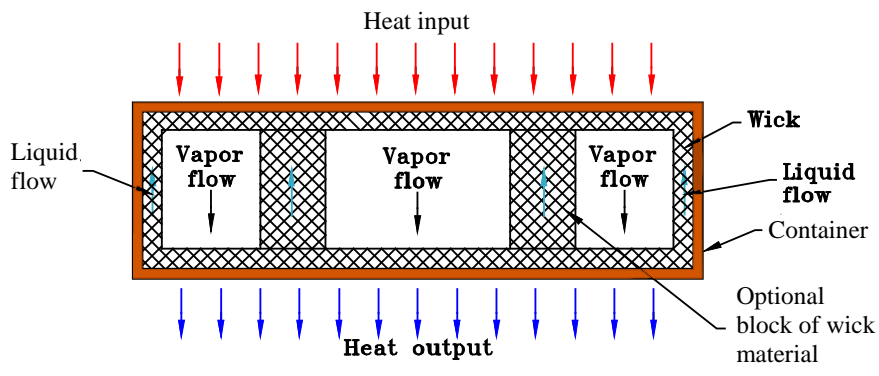

Fig. 10 Vapor chamber.

The vapor chamber is a capillary-driven planar (flat-plate heat pipe in a rectangular or disk-shaped) with a small aspect ratio (Faghri, 1995; Mochizuki et al., 2006; Mochizuki et al., 2007; Xiao and Faghri, 2008), as shown in Fig. 10. Additional wick blocks between the evaporator and condenser aid in condensate return, especially when the condenser is below the evaporator in a gravity field. If the condenser is above the evaporator, there is no need to have a wick in the condenser section, since the condensate on the upper plate will drip back to the evaporator. A wick is needed over the evaporator section, however, in order to uniformly distribute the liquid over the entire surface so to prevent dryout. The vapor chamber is an excellent candidate for use in electronic cooling applications especially with high heat flux applications, including desktops and servers. Vapor chambers are preferred over conventional heat pipes (CHP) for electronic cooling with heat fluxes higher than $50 \mathrm{~W} / \mathrm{cm}^{2}$, since heat flow is two or three dimensional, compared to one dimensional in CHPs. Furthermore, 
vapor chambers can be placed in direct contact with CPUs using thermal interface materials, thereby reducing the overall thermal resistance of heat sinks.

\section{Rotating Heat Pipe}

Rotating heat pipes can be designed in two configurations (Gray, 1969; Faghri, 1995). First, the heat pipe can be in the shape of a circular cylinder with or without an axial taper, which rotates either about its own axis of symmetry or revolves off-axis. Secondly, the heat pipe can be manufactured in the shape of a disk, where two parallel disks are joined together at the outer and inner radii to form the vapor space (Fig. 11). Cylindrical rotating heat pipes operate in the same manner as conventional cylindrical heat pipes except that internal tapers are commonly used to aid in returning the condensate to the evaporator by centrifugal force. With disk-shaped heat pipes, heat is input at the outer radii and extracted at the inner radii, which allows the condensate to be driven back to the evaporator by centrifugal force with the aid of an internal taper. Therefore, capillary wicks are not used in rotating heat pipes. Cylindrical rotating heat pipes have been used to cool the rotating parts of electric motors and metal-cutting tools such as drill bits and end mills. Disk-shaped heat pipes have been proposed to effectively cool turbine components and automobile brakes.

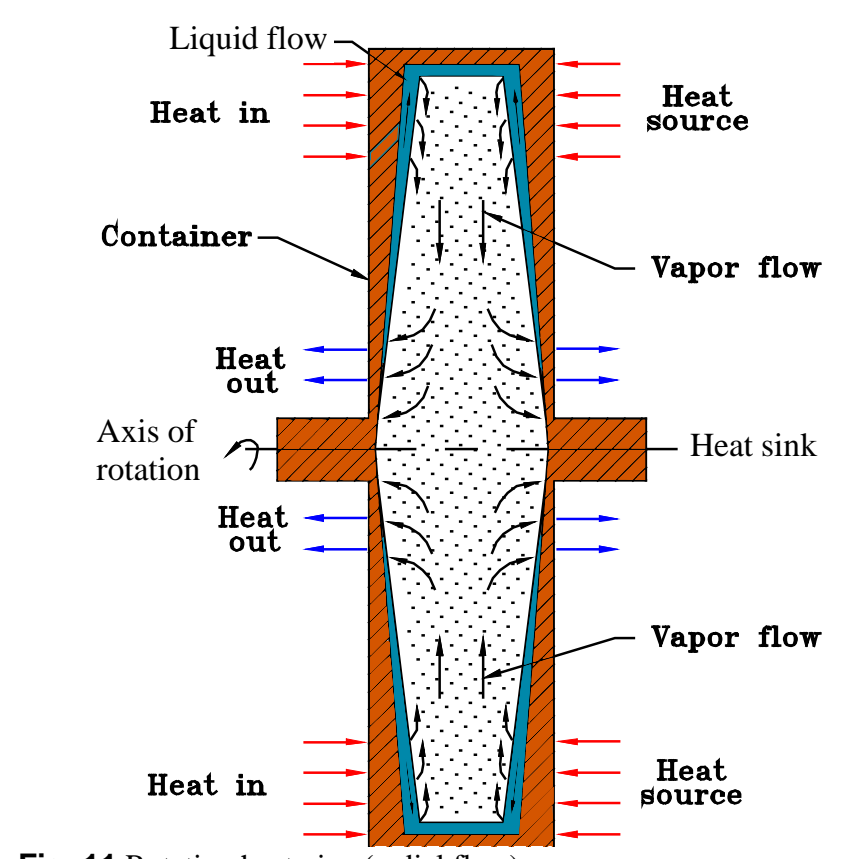

Fig. 11 Rotating heat pipe (radial flow).

\section{Gas-Loaded Heat Pipe}

Gas-loaded heat pipes are one type of variable conductance heat pipes. The gas-loaded heat pipe, shown in Fig. 12, is the same as the capillarydriven heat pipe or the two-phase thermosyphon except that a noncondensing gas is introduced into the vapor space. During operation, this gas is swept down the length of the heat pipe by the working fluid vapor to the condenser section. Since condensation of the working fluid does not take place where the noncondensing gas is present, a portion of the condenser is blocked from transferring heat to the heat sink (Fig. 12(a)). If the heat input to the evaporator section is increased, the vapor and gas temperatures both increase, which leads to the compression of the inert gas. This in turn increases the amount of condenser surface area available to transfer heat (Fig. 12(b)). This phenomenon results in the gas-loaded heat pipe being able to maintain a nearly constant evaporator temperature regardless of the heat input. Gas-loaded heat pipes have been used in the annular arrangement previously mentioned for an isothermal furnace and for electronic cooling.

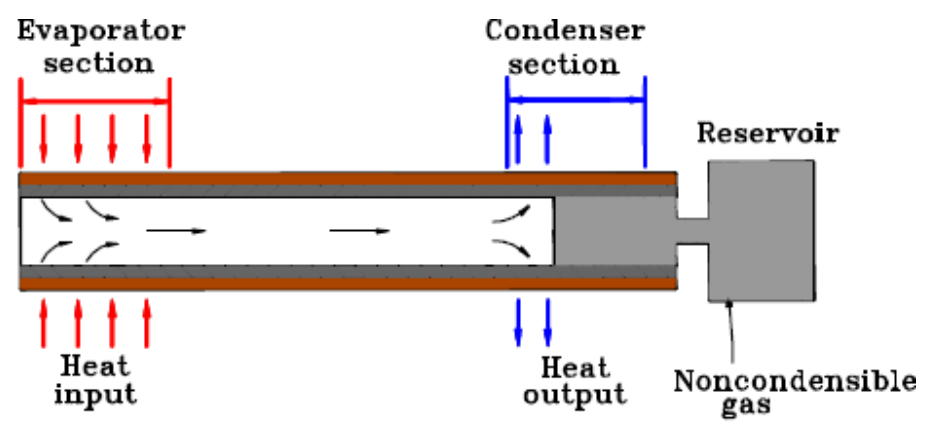

a) Condenser partially active

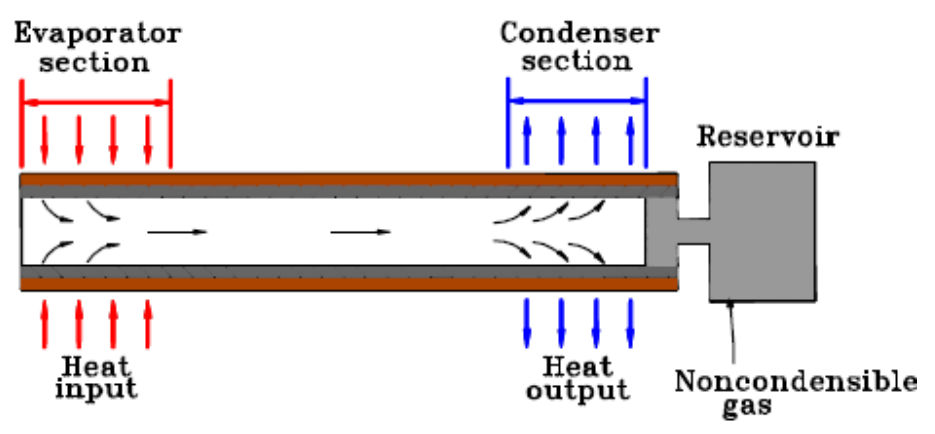

b) Condenser fully active

Fig. 12 Operation of a gas-loaded variable conductance heat pipe.

\section{Loop Heat Pipe}

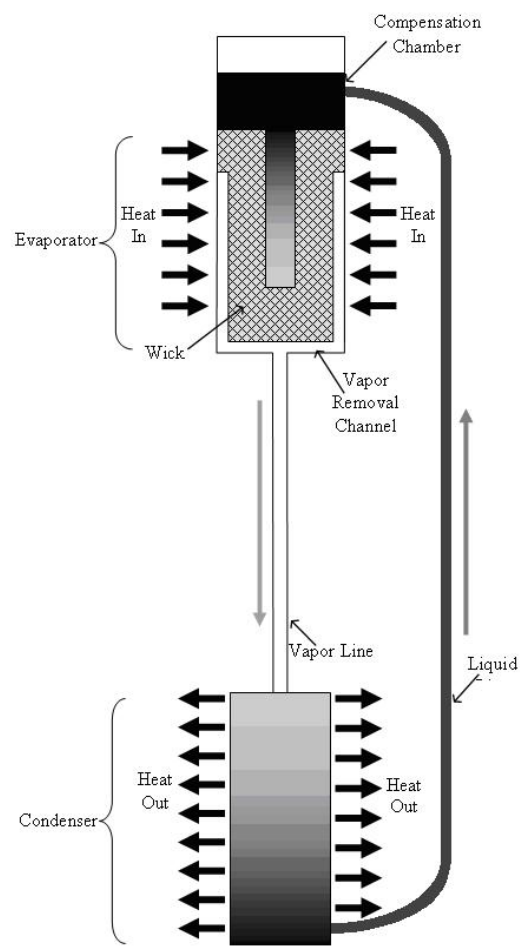

Fig. 13 Loop heat pipe (LHP).

The loop heat pipe (LHP) (Faghri, 1995; Maydanik, 2005) was invented in Russia in 1971 by Gerasimov and Maydanik (Maydanik et al., 1991). The LHP is based on the same physical processes (evaporation and condensation) as those of conventional heat pipes. 
The LHP in its simplest form (Fig. 13) consists of a capillary pump (or evaporator), a compensation chamber (or reservoir), a condenser, and liquid and vapor lines. The wicks are only present in the evaporator and compensation chamber. The high capillary force is created in the evaporator due to fine-pored wicks (primary wicks) such as sintered nickel, titanium and copper powder with an effective pore radius of 0.7 $15 \mu \mathrm{m}$ and a porosity of $55-75 \%$. The compensation chamber is an important component in the LHP and is often an integral part of the evaporator. The purpose of the compensation chamber is to accommodate excess liquid in an LHP during normal operation. A secondary wick (usually made of larger pores) physically connects the evaporator to the compensation chamber in order to supply the primary wick with liquid, particularly when the compensation chamber is below the evaporator, or when the LHP is operating in microgravity conditions. The motion of vapor and liquid flow in the primary wick proceeds mainly in a radial direction. The evaporator meniscus is inverted down toward the wall being heated. Both the liquid and vapor lines are made of small diameter tubing with no wicks. LHPs can be made flexible and bendable. LHPs provide heat removal over long distances without sensitivity to gravity. Several factors make the LHP an attractive option for spacecraft cooling over conventional heat pipes. Since the wick structure is only in the evaporator, the rest of the container walls can be smooth, which reduces pressure drops in the vapor and liquid flows. The pressure drops throughout the system are also reduced because the vapor and liquid flow are co-current, as opposed to the counter-current flow in conventional heat pipes. For these reasons, the LHP is a more effective thermal bus, and the heat source and sink can be separated by a longer distance than with conventional heat pipes.

\section{Capillary Pumped Loop Heat Pipe}

Spacecraft and electronic systems require heat rejection systems which can remove quantities of heat on the order of 10 to 100 times that which present single-phase systems can reject. Another special type of heat pipe has been proposed and extensively tested for this purpose, the capillary pumped loop (CPL) (Faghri, 1995). The CPL was first proposed by Stenger (1966) at the NASA Lewis Research Center. A basic schematic of the CPL is given in Fig. 14. Heat is applied to the evaporator component, which consists of a hollow rod of wick material capped at one end and force fitted into an internally axially-grooved pipe. The heat applied to the outer surface of the evaporator vaporizes the liquid working fluid, which then travels down the length of the axially-grooved vapor channels and into the vapor header. The vapor travels to the condenser, where it is condensed first as a film on the inner wall of the pipe, and then as a liquid slug flow. Before reaching the evaporator, the liquid passes through a subcooler to collapse any remaining vapor bubbles as well as to provide additional subcooling if necessary. The capillary pressure generated in the wick structure continuously pumps the working fluid through the cycle. A two-phase reservoir is provided to control both the working fluid through the cycle and the working temperature of the system, which is similar in function to the variable conductance heat pipe. For multiple evaporator systems, isolators are provided to prevent the depriming of one evaporator from depriming the other evaporators. Despite the wide use of the CPL and LHP in space technology, fundamental confusion still exists regarding their similarities and distinctions in operation, as well as the limitations of these two devices.

\section{Pulsating Heat Pipe}

The pulsating heat pipe (PHP) (Faghri, 1995) is made from a long capillary tube bent into many turns, with the evaporator and condenser sections located at these turns. There are two main types of PHPs-looped and unlooped (Fig. 15) — which are classified according to whether or not the two ends of the PHP connect.

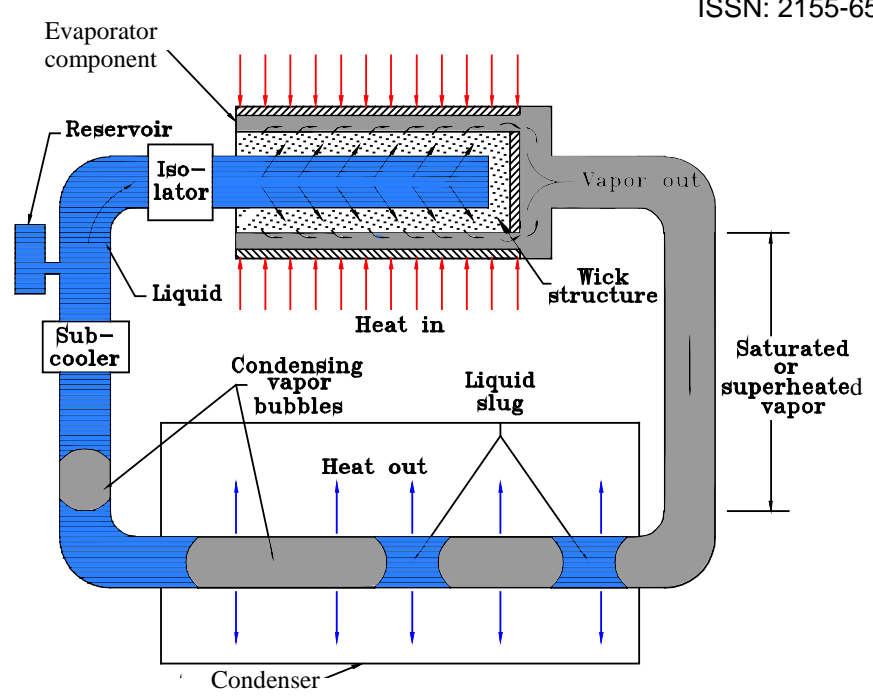

Fig. 14 Capillary pumped looped heat pipe (CPL).

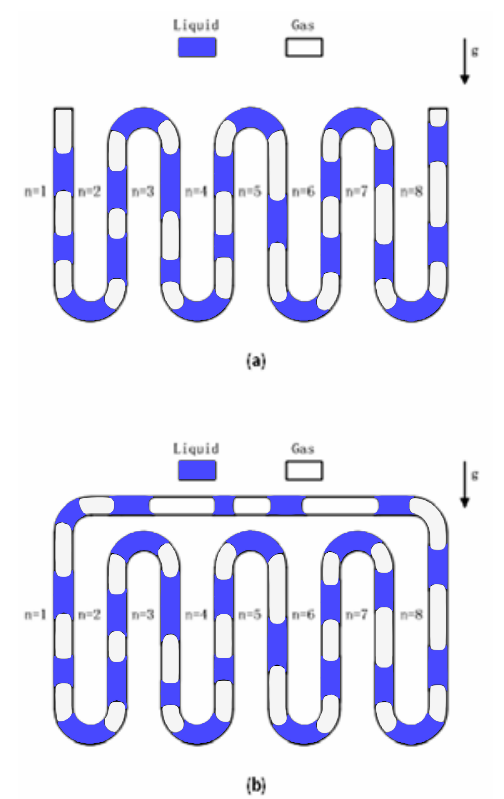

Fig. 15 Pulsating heat pipe (a) unlooped, (b) looped.

A PHP is usually partially charged with a working fluid, with a charge ratio between $40 \%$ and $60 \%$. Since the diameter of a PHP is very small (less than $5 \mathrm{~mm}$ ), vapor plugs and liquid slugs are formed as a result of capillary action. Heat input either causes evaporation or boiling, which increases the pressure of the vapor plug in the heating section. Simultaneously, the pressure in the cooling section decreases due to condensation. This pressure difference pushes the liquid slug and vapor plug into the cooling section. The liquid slug and vapor plug in the cooling section are then pushed into the next heating section, which will push the liquid slug and vapor plug back to the cooling section. This process enables the self-excited oscillatory motion of liquid slugs and vapor plugs. Heat is transported from the heating section to the cooling section via the pulsation of the working fluid in the axial direction of the tube.

The unique feature of PHPs, compared to conventional heat pipes, is that there is no wick structure returning the condensate to the heating section. There is therefore no countercurrent flow between the liquid and vapor. The entrainment limit in the conventional heat pipe does not have any effect on the capacity of heat transport by a PHP. With this simple structure, the PHP weighs less than a conventional heat pipe, making it an ideal candidate for space applications. Since the diameter of the PHP is very small, surface tension plays a greater role in the 
dynamics of the PHP than gravitational force does, enabling successful operation in a microgravity environment. Other applications of PHPs include thermal control of electrical and electronic devices and components, as well as thyristors, diodes and ceramic resistors. Zhang and Faghri (2008) made a comprehensive review related to existing experimental and theoretical research in pulsating heat pipes.

\section{Monogroove Heat Pipe}

The monogroove heat pipe developed by Grumman utilizes an extruded cross section which separates the vapor space from the liquid return path (Fig. 16) (Alario et al., 1981; Alario, 1984). Heat input and output are through the flat face on top of the vapor space. Since heat is not conducted through the wall of the liquid return path, the chance of arterial blockage due to vapor bubbles is significantly reduced. Wick structures are placed along the interior walls to deliver condensate from the artery to the evaporator. Monogroove heat pipes are proposed to be used for multi-kilowatt space radiator heat rejections systems.

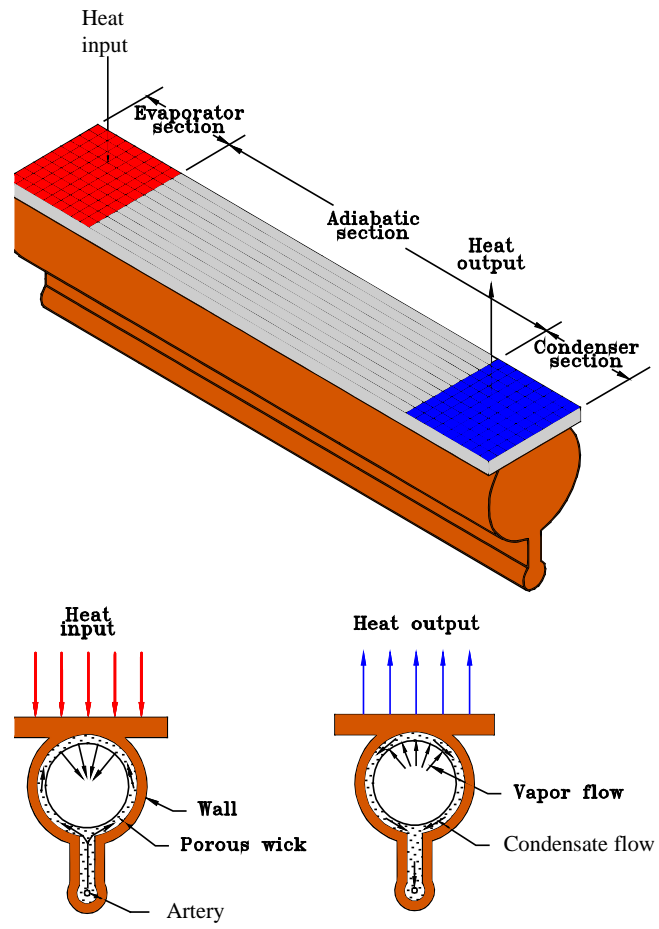

Fig. 16 Monogroove heat pipe.

\section{Micro and Miniature Heat Pipes}

Cotter (1984) was the first to propose the micro heat pipe concept for cooling of electronic devices. The micro heat pipe was defined as a heat pipe in which the mean curvature of the liquid vapor interface is comparable in magnitude to the reciprocal of the hydraulic radius of the total flow channel. Typically, micro heat pipes (Fig. 17) have convex but cusped cross sections (Peterson, 1992) (for example, a polygon), with hydraulic diameter in range of 10 to $500 \mu \mathrm{m}$ (Cao and Faghri, 1994a). Miniature heat pipe is defined as a heat pipe with a hydraulic diameter in the range of 0.5 to $5 \mathrm{~mm}$ (Hopkins et al., 1999).

References to micro and miniature heat pipes in open literature are sometimes not properly differentiated as defined above. For example, miniature heat pipes with micro grooves are sometimes improperly referred to as micro heat pipes. It is also worth noting the other structural differences between micro and miniature heat pipes in addition to the size ranges noted above. A true micro heat pipe, for both metallic and silicon applications, has a single non-circular channel for both liquid and vapor phases where the liquid return from condenser to evaporator by capillary force occurs in the sharp corner of the channel.
These types of micro heat pipes are generally placed in an array of parallel micro heat pipes on the substrate surface in order to increase the overall heat transfer area. Miniature heat pipes can be designed based on micro axially grooved structure (1D capillary structure), meshes or cross grooves (2D capillary structure).

Attempts have been made to etch micro heat pipes directly into the silicon and use them as thermal spreaders (Peterson and Ma, 1999; Le Berre et al., 2003; Launay et al., 2004a). The performance characteristics of the micro heat pipes are different from those conventional heat pipes (Khrustalev and Faghri, 1994; Launay et al., 2004a).
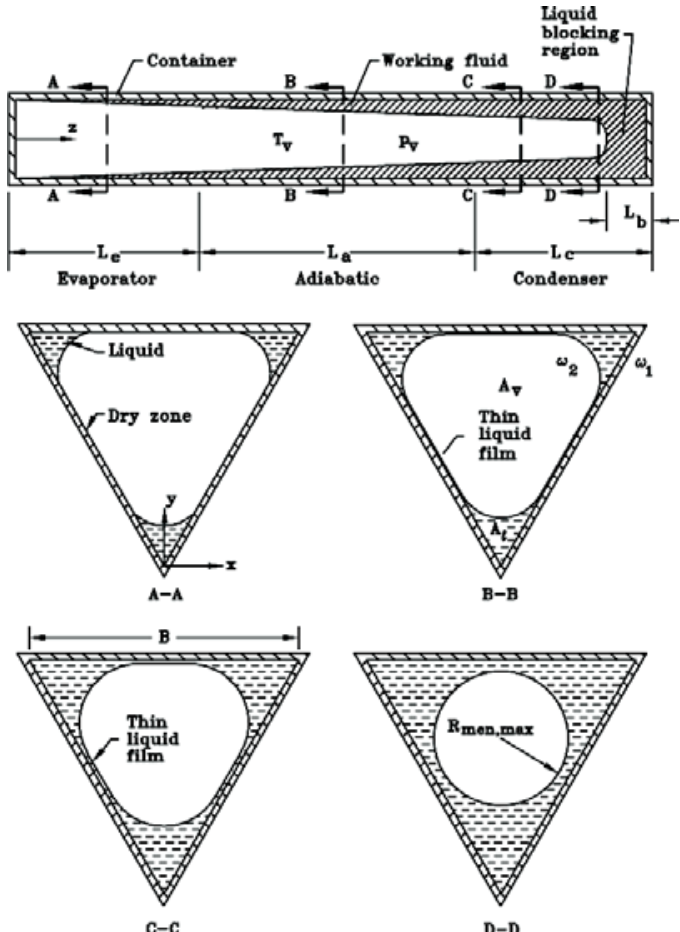

Fig. 17 Schematic of the micro heat pipe

In order for the micro heat pipe to find more commercial applications in microelectric cooling, it must compete with other cooling methods, such as forced convection, impingement and two phase direct cooling in areas such as manufacturing cost and reliability. Because of the extremely small dimensions of micro heat pipes, difficulties in manufacturing and the subsequent degassing and charging are expected. Furthermore, the "true" micro heat pipe built directly into the silicon must compete with the miniature heat pipe attached on the chip surface in this area, which is much less costly.

Miniature heat pipes with micro axial grooves can be successfully used in electronic components cooling systems. Fabrication and experimental data on the performance characteristics of the flat watercopper heat pipe with external dimensions $2 \times 7 \times 120 \mathrm{~mm}$ have been reported by Hopkins et al. (1999) with radial heat fluxes of $90 \mathrm{~W} / \mathrm{cm}^{2}$ and $150 \mathrm{~W} / \mathrm{cm}^{2}$ for horizontal and vertical applications, respectively.

\section{Inverted Meniscus Heat Pipe}

Advanced miniature heat pipes are needed to meet the demand for dissipating high heat fluxes (over $100 \mathrm{~W} / \mathrm{cm}^{2}$ ) for electronic components. Several techniques were proposed in this regard, including ivadizing (Khrustalev and Faghri, 1996a), which is the deposit of a porous structure on the top of the lands between the grooves or "inverted meniscus scheme" (Khrustalev and Faghri, 1995c; Khrustalev and Faghri, 1996b).

With extremely high heat fluxes, a vapor blanket appears inside the uniform structure in the evaporator along the heated solid surface (Khrustalev and Faghri, 1996b), as shown in Figs. 18(a) and 18(b). In 
this case, evaporation takes place in the dry region of the porous structure at the liquid-vapor interface, the location of which shifts depending on the operational conditions. The heat is conducted to this interface from the heated surface through the dry region of the porous element, and the vapor flows mainly along the solid surface through this porous region towards the triangular vapor channel. The vapor flow is provided by the capillary pressure gradient due to the difference in the curvature of the menisci along the liquid-vapor interface inside the porous structure. Therefore, with high heat fluxes, part of the capillary pressure is spent on the compensation of the pressure drop in the vapor flow through the dry porous region. Hence, the maximum heat flux for this configuration should be calculated with respect to the formation of this vapor blanket and can be less than that estimated from the traditional capillary limit. Numerical results show that miniature copper water heat pipes with an inverted meniscus type evaporator of estimated dimensions of 2x7x120 mm is capable of withstanding high heat fluxes on the evaporator wall, which can be about $200 \mathrm{~W} / \mathrm{cm}^{2}$ for horizontal orientation at $120^{\circ} \mathrm{C}$ (Khrustalev and Faghri, 1996b).

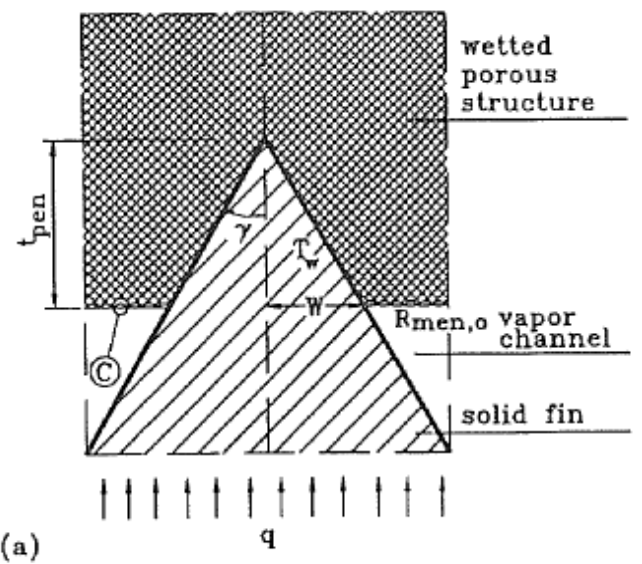

(a)

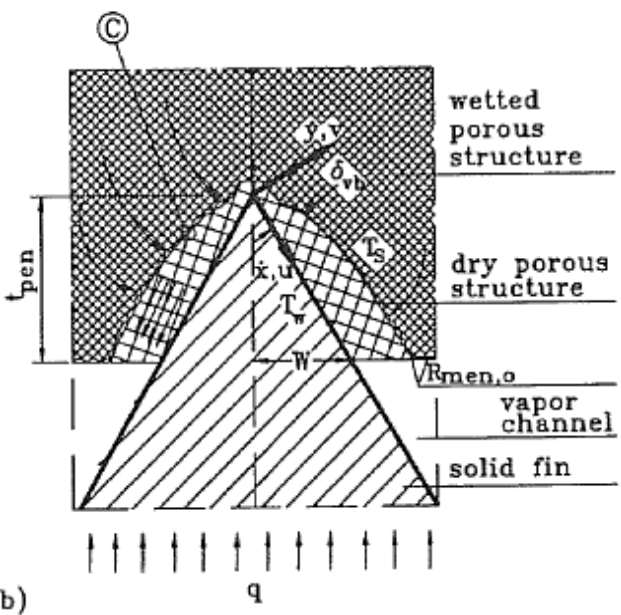

Fig. 18 Schematic of an inverted meniscus type evaporator with the triangular fin: (a) with low heat fluxes; (b) with high heat fluxes.

\section{Nonconventional Heat Pipes}

While the majority of heat pipes have a cylindrical or rectangular cross section, specific applications require the use of heat pipes with other geometries. Examples include heat pipe cross sections with polygonal shapes, such as micro/miniature heat pipes, or cross sections that vary along the length of the heat pipe. An example of this latter type of cross section is shown in Fig. 19, where nosecap and leading edge heat pipes are shown schematically. Another example that standard coordinate systems, such as Cartesian or cylindrical coordinates, are not applicable is heat pipe turbine vane cooling (Zuo et al., 1998) as shown in Fig. 20.

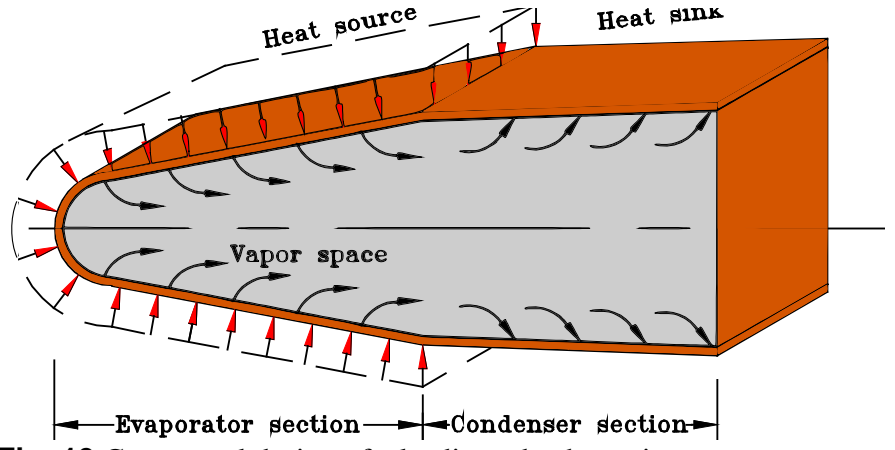

Fig. 19 Conceptual design of a leading edge heat pipe.

The leading edge heat pipe has been proposed to cool the leading edges of future hypersonic aircraft and reentry vehicles (Fig. 19) (Cao and Faghri, 1991). The heat pipe will cover the leading edges of the wings and engine nacelles, where the aerodynamic heating is the most intense. The heat will be absorbed and transported through the heat pipe to the condenser, where it will be rejected by radiation and/or convection. The extremely high heat fluxes and temperatures which will be experienced by the proposed leading edge heat pipe will make its design and manufacturing one of the most challenging design problems faced by heat pipe engineers to date.

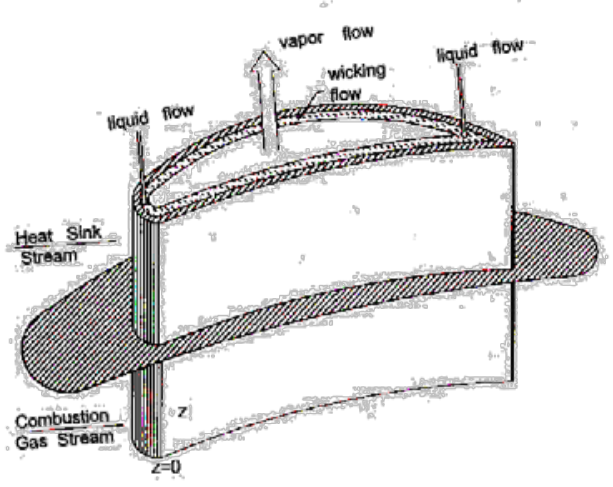

(a) heat pipe turbine vane cooling

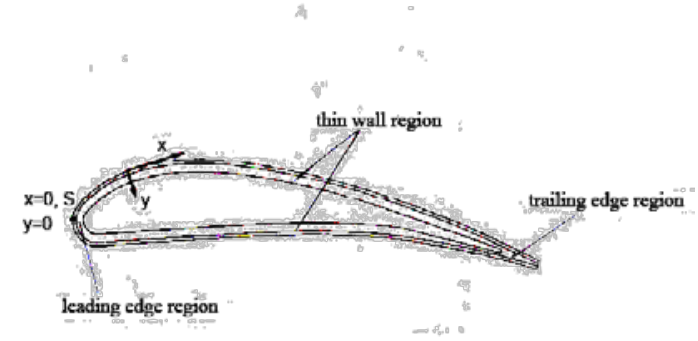

(b) representative vane cross-section

Fig. 20 A sketch of the heat pipe turbine vane: (a) heat pipe turbine vane cooling; (b) representative vane cross section.

\section{WORKING FLUIDS AND TEMPERATURE RANGES}

Each heat pipe application has a particular temperature range in which the heat pipe needs to operate. Therefore, the design of the heat pipe must account for the intended temperature range by specifying the proper working fluid. Table 1 (Faghri, 1995) lists some of the commonly used and proposed working fluids, their melting and boiling points at atmospheric pressure, and their useful ranges. As a rule of thumb, the useful range extends from the point where the saturation pressure is greater than $0.1 \mathrm{~atm}$ and less than $20 \mathrm{~atm}$. Below $0.1 \mathrm{~atm}$, the vapor pressure limit may be approached. Above 20 atm, the 
Table 1 Working fluids and temperature ranges of heat pipes

\begin{tabular}{|c|c|c|c|}
\hline Working Fluid & $\begin{array}{l}\text { Melting Point, } \\
\mathrm{K} \text { at } 1 \mathrm{~atm}\end{array}$ & $\begin{array}{l}\text { Boiling Point, } \\
\text { K at } 1 \text { atm }\end{array}$ & $\begin{array}{l}\text { Useful } \\
\text { Range, } \mathrm{K}\end{array}$ \\
\hline Helium & 1.0 & 4.21 & $2-4$ \\
\hline Hydrogen & 13.8 & 20.38 & $14-31$ \\
\hline Neon & 24.4 & 27.09 & $27-37$ \\
\hline Nitrogen & 63.1 & 77.35 & 70-103 \\
\hline Argon & 83.9 & 87.29 & $84-116$ \\
\hline Oxygen & 54.7 & 90.18 & $73-119$ \\
\hline Methane & 90.6 & 111.4 & $91-150$ \\
\hline Krypton & 115.8 & 119.7 & $116-160$ \\
\hline Ethane & 89.9 & 184.6 & $150-240$ \\
\hline Freon 22 & 113.1 & 232.2 & $193-297$ \\
\hline Ammonia & 195.5 & 239.9 & 213-373 \\
\hline Freon 21 & 138.1 & 282.0 & $233-360$ \\
\hline Freon 11 & 162.1 & 296.8 & 233-393 \\
\hline Pentane & 143.1 & 309.2 & 253-393 \\
\hline Freon 113 & 236.5 & 320.8 & $263-373$ \\
\hline Acetone & 180.0 & 329.4 & 273-393 \\
\hline Methanol & 175.1 & 337.8 & 283-403 \\
\hline Flutec PP2 & 223.1 & 349.1 & 283-433 \\
\hline Ethanol & 158.7 & 351.5 & 273-403 \\
\hline Heptane & 182.5 & 371.5 & $273-423$ \\
\hline Water & 273.1 & 373.1 & $303-550$ \\
\hline Toluene & 178.1 & 383.7 & $323-473$ \\
\hline Flutec PP9 & 203.1 & 433.1 & $273-498$ \\
\hline Naphthalene & 353.4 & 490 & $408-623$ \\
\hline Dowtherm & 285.1 & 527.0 & 423-668 \\
\hline Mercury & 234.2 & 630.1 & $523-923$ \\
\hline Sulphur & 385.9 & 717.8 & $530-947$ \\
\hline Cesium & 301.6 & 943.0 & 723-1173 \\
\hline Rubidium & 312.7 & 959.2 & $800-1275$ \\
\hline Potassium & 336.4 & 1032 & 773-1273 \\
\hline Sodium & 371.0 & 1151 & 873-1473 \\
\hline Lithium & 453.7 & 1615 & 1273-2073 \\
\hline Calcium & 1112 & 1762 & $1400-2100$ \\
\hline Lead & 600.6 & 2013 & $1670-2200$ \\
\hline Indium & 429.7 & 2353 & $2000-3000$ \\
\hline Silver & 1234 & 2485 & $2073-2573$ \\
\hline
\end{tabular}

container thickness must increase to the point where the heat pipe becomes limited by the thermal resistance through the container.

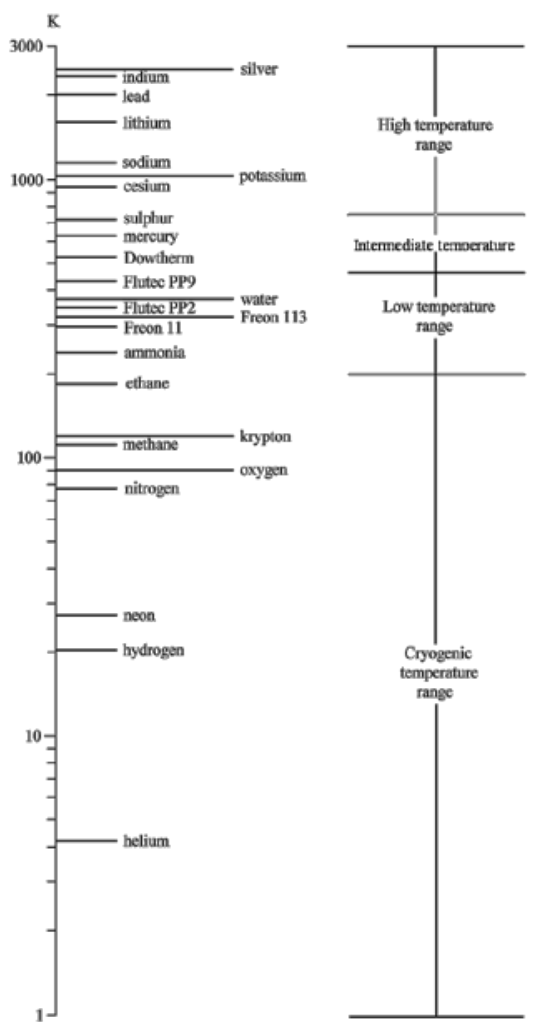

Fig. 21 Operating temperature ranges of various working fluids on a logarithmic temperature scale.

Longevity of a heat pipe can be assured by selecting a container, a wick and welding materials that are compatible with one another and with the working fluid of interest. Performance can be degraded and failures can occur in the container wall if any of the parts (including the working fluid) are not compatible. For instance, the parts can react chemically or set up a galvanic cell within the heat pipe. Additionally, the container material may be soluble in the working fluid or may catalyze the decomposition of the working fluid at the expected operating temperature. A compilation of the most up-to-date information concerning the compatibility of metals with working fluids for heat pipes is given in Table 2 (Faghri, 1995). Figure 21 presents various working fluid boiling points and classifies them into four categories: cryogenic, low, intermediate and high temperature ranges. The working-fluid inventory of a heat pipe is the sum of the masses of the vapor and liquid phases, assuming the wick is full of liquid. This criterion is slightly over the optimum requirement because the meniscus recedes into the evaporator wick during normal operation. However, this situation is more advantageous than underfilling the heat pipe,

which may significantly reduce the maximum heat transfer. With extreme overfill, however, any excess fluid might collect as liquid in the condenser section and increase the thermal resistance, thereby decreasing the heat transport capability of the heat pipe.

Heat pipe fabrication, processing, and testing involve several detailed procedures which are recommended to be strictly followed in order to achieve the highest quality possible. Faghri (1995) provided a detailed procedure for the fabrication, processing, and testing of low, moderate, and high temperatures.

\section{Cryogenic Temperature Range}

Cryogenic heat pipes operate between 4 to $200 \mathrm{~K}$. Typical working fluids include helium, argon, oxygen, and krypton. The amount of heat that can be transferred for cryogenic heat pipes is quite low due to the 
small heats of vaporization, high viscosities, and small surface tensions of the working fluids.

Table 2 Generalized results of experimental compatibility tests

\begin{tabular}{|c|c|c|}
\hline Working Fluid & Compatible Material & $\begin{array}{c}\text { Incompatible } \\
\text { Material }\end{array}$ \\
\hline Water & $\begin{array}{l}\text { Stainless Steel }^{\mathrm{a}} \text {, } \\
\text { Copper, Silica, } \\
\text { Nickel, Titanium }\end{array}$ & Aluminum, Inconel \\
\hline Ammonia & $\begin{array}{l}\text { Aluminum, Stainless } \\
\text { Steel, Cold Rolled } \\
\text { Steel, Iron, Nickel }\end{array}$ & \\
\hline Methanol & $\begin{array}{l}\text { Stainless Steel, Iron, } \\
\text { Copper, Brass, Silica, } \\
\text { Nickel }\end{array}$ & Aluminum \\
\hline Acetone & $\begin{array}{l}\text { Aluminum, Stainless } \\
\text { Steel, Copper, Brass, } \\
\text { Silica }\end{array}$ & \\
\hline Freon-11 & Aluminum & \\
\hline Freon-21 & Aluminum, Iron & \\
\hline Freon-113 & Aluminum & \\
\hline Heptane & Aluminum & \\
\hline Dowtherm & $\begin{array}{l}\text { Stainless Steel, } \\
\text { Copper, Silica }\end{array}$ & \\
\hline Lithium & $\begin{array}{l}\text { Tungsten, Tantalum, } \\
\text { Molybdenum, } \\
\text { Niobium }\end{array}$ & $\begin{array}{l}\text { Stainless Steel, } \\
\text { Nickel, Inconel, } \\
\text { Titanium }\end{array}$ \\
\hline Sodium & $\begin{array}{l}\text { Stainless Steel, } \\
\text { Nickel, Inconel, } \\
\text { Niobium }\end{array}$ & Titanium \\
\hline Cesium & $\begin{array}{l}\text { Titanium, Niobium, } \\
\text { Stainless Steel, } \\
\text { Nickel-based } \\
\text { superalloys }\end{array}$ & \\
\hline Mercury & Stainless Steel $^{\mathrm{b}}$ & $\begin{array}{l}\text { Molybdenum, Nickel, } \\
\text { Tantalum, Inconel, } \\
\text { Titanium, Niobium }\end{array}$ \\
\hline Lead & Tungsten, Tantalum & $\begin{array}{l}\text { Stainless Steel, } \\
\text { Nickel, Inconel, } \\
\text { Titanium, Niobium }\end{array}$ \\
\hline Silver & Tungsten, Tantalum & Rhenium \\
\hline
\end{tabular}

${ }^{\mathrm{a} S e n s i t i v e ~ t o ~ c l e a n i n g ; ~}{ }^{\mathrm{b}}$ with Austenitic SS

\section{Low Temperature Range}

The low temperature range is from 200 to $550 \mathrm{~K}$. Most heat pipe applications fall within this range. Commonly used fluids are ammonia, acetone, the Freon compounds, and water. Water, which is perhaps the most widely used working fluid, has good thermophysical properties such as large heat of vaporization and surface tension, and has the added benefit of being safe to use during handling.

\section{Intermediate Temperature Range}

The working fluids in the medium temperature range, 450 to $750 \mathrm{~K}$, are mercury and sulphur. Compounds such as Thermex or Dowtherm-A (diphenyl/diphenyl oxide eutectics) are also employed in this range. Mercury has extremely attractive properties inherent in a liquid metal such as its high thermal conductivity. However, problems with wetting the wick and wall present difficulties in using mercury in capillary heat pipes. The toxicity of mercury is also a significant problem. A review of intermediate temperature fluid life tests experiments was reported by Anderson et al. (2007).

\section{High Temperature Range}

Sodium, lithium, cesium, silver and a sodium-potassium compound (NaK) are often used in the high temperature range (750 K and above). The heat transport rates for liquid-metal heat pipes are generally much higher than those in the other temperature ranges because the surface tension coefficients, latent heats of vaporization, and thermal conductivities of liquid metals are very high.

Faghri (1995) presents thermophysical property data for most heat pipe working fluids and container materials along with polynomial temperature-property relations for the working fluids.

\section{CAPILLARY WICK DESIGNS AND STRUCTURES}

The wick structure within the heat pipe is present to return condensate to the evaporator section. While small pores are needed at the liquidvapor interface to develop high capillary pressures, large pores are preferred within the wick so that the movement of the liquid is not restricted too greatly. For this reason, many different types of wick structures have been developed in order to optimize the performance of the capillary heat pipe. The types of wick structures can be divided into two categories: homogeneous and composite wicks. Homogeneous wicks (Table 3) (Faghri, 1995) have the benefit of being relatively simple to design, manufacture and install. Composite wicks (Table 4) (Faghri, 1995), however, can significantly increase the capillary limit of the heat pipe, but have the drawback of high manufacturing costs. When selecting a wick structure for a particular application, one must keep in mind the benefits and drawbacks of each type of wick.

There are three properties of wicks that are important in heat pipe design:

Minimum capillary radius: This parameter should be small if a large capillary pressure difference is required, such as in terrestrial operation for a long heat pipe with the evaporator above the condenser, or in cases where a high heat transport capability is needed.

Permeability: Permeability is a measure of the wick resistance to axial liquid flow. This parameter should be large in order to have a small liquid pressure drop, and therefore, higher heat transport capability.

Effective thermal conductivity: A large value for this parameter gives a small temperature drop across the wick, which is a favorable condition in heat pipe design.

A high thermal conductivity and permeability, and a low minimum capillary radius are somewhat contradictory properties in most wick designs. For example, a homogeneous wick may have a small minimum capillary radius and a large effective thermal conductivity, but have a small permeability. Therefore, the designer must always make trade-offs between these competing factors to obtain an optimal wick design.

\section{Homogeneous Wicks}

Homogeneous wicks (Table 3) (Faghri, 1995) are constructed with one type of material or machining technique. The screen wick is seemingly the simplest and most common type of wick structure. It consists of a metal or cloth fabric which is wrapped around a mandrel and inserted into the heat pipe. After placement, the mandrel is removed, leaving the wick held by the tension of the wrapped screen, in the case of a metal fabric. For a cloth fabric, a spring may be inserted into the heat pipe to hold the wick against the inside of the pipe wall. The capillary pressure generated by a screen wick is determined by the size of the rectangular pores between the individual threads. The permeability is determined 
by the number of wraps and the looseness of the wraps, which create annular gaps through which the condensate can flow.

Table 3 Typical homogeneous wick designs

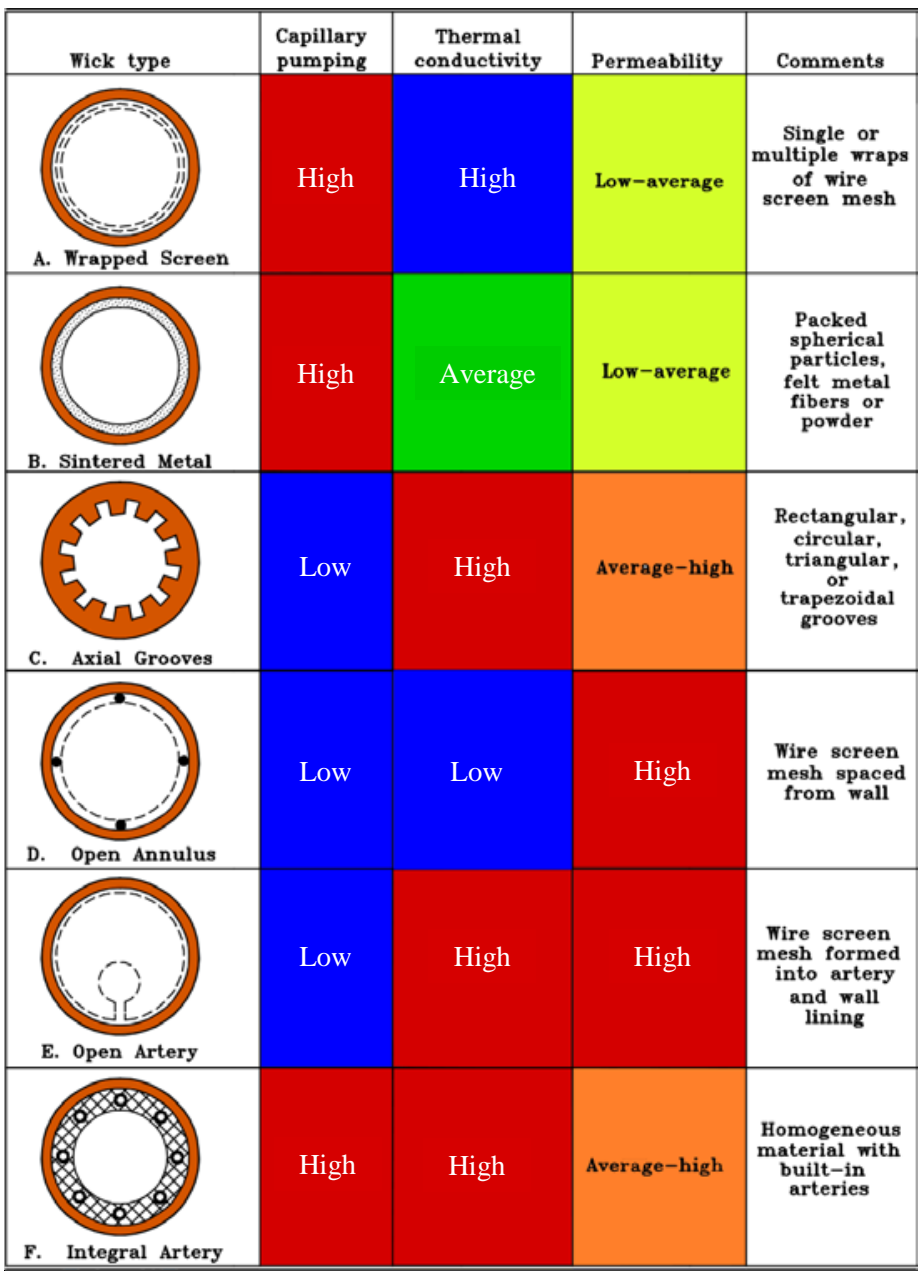

Sintered metal wicks are manufactured by packing tiny metal particles between the inner heat pipe wall and a mandrel in powder form. This assembly is then heated until the metal spheres are sintered to each other and to the inner wall of the heat pipe. Special materials are used for the mandrel so that it can be removed, leaving an open vapor space. This type of wick is obviously more difficult to manufacture compared to the simple screen wick. However, the capillary pressure developed by the sintered metal wick (and therefore capillary limit) is more easily predicted, as the annular gaps present in a screen wick present uncertainties in the permeability. Also, since a metal powder is sintered, the effective thermal conductivity is much higher than a comparable screen wick due to the poor thermal contact between the screen wraps.

Axial groove wicks are formed by the extrusion or broaching of grooves into the inner radius of the pipe. Several different types of grooves have been used and proposed, which have rectangular, triangular, trapezoidal, or nearly circular cross-sections. Trapezoidal grooves are currently the most common type. The performance of axial groove wicks is excellent, provided that the application does not call for a significant adverse elevation against gravity. Since the size of the grooves are large compared to those of a screen or sintered metal wick, the capillary pumping pressure is quite small. However, the permeability and the effective thermal conductivity are very high. Drawbacks to this type of wick are the difficulty in machining the grooves for long heat pipes, which might prove to be excessively expensive, and the liquid-vapor interaction at the opening of the groove at high vapor velocities. Other attractive features of axial groove wicks include the field-tested performance, reliability, and simplicity of design.

The open annulus wick is simply a single-wrap screen wick, held away from the inner pipe wall by stand-offs. This provides an unimpeded return flow path between the screen and the pipe, which greatly increases the permeability over the simple screen wick, while maintaining the high capillary pressure. However, the effective thermal conductivity of this wick is very low for most working fluids due to the low liquid thermal conductivity. Difficulties in priming during startup, and depriming during near-dryout operation are common in this type of wick. The idea of an open condensate return path is also present in the artery wick, but the problem of a low effective thermal conductivity, as is present in the open annulus wick, is significantly reduced.

The artery wick combines the two necessities of having a small pore radius for capillary pressure generation and having a large pore radius for high permeability. In the artery wick structure, the interior of the heat pipe is either covered by a screen wick or a sintered metal powder in the usual manner, but a hollow passage(s) running the length of the pipe is fashioned and is in communication with the rest of the wick structure. Condensate is collected within this passage(s) or artery and is pumped back to the evaporator section by the capillary forces generated at the liquid-vapor interface. Since the inner diameter of the artery is much larger than the effective pore radius of the wick, the liquid is able to easily traverse the length of the heat pipe with a minimum pressure drop. As with any design, there are difficulties associated with the artery wick. First, problems associated with the manufacturing of arteries must be addressed. The startup of artery wick heat pipes is also critical due to the inevitable presence of vapor bubbles within the artery, which effectively block liquid return. Methods of collapsing these bubbles are complicated and not always effective.

\section{Composite Wicks}

Composite wick structures (Table 4) (Faghri, 1995) employ the benefits of having small pores for generating high capillary pumping pressures and having large pores for increasing the permeability of the liquid return path. Again, the simplest type of composite wick is the screen wick, except that two screens with different pore sizes are used. Several wraps of a screen with a large pore size is used against the inner pipe wall for the liquid return path, and a single wrap of a screen with a much smaller pore size is placed adjacent to the vapor space to develop high capillary pressures. Similarly, axial grooves covered by a single wrap of a small-pore screen can solve many of the problems associated with the homogeneous axial groove wick. Since the screen effectively separates the liquid and vapor flows, the entrainment of the liquid into the vapor flow by the interfacial shear is nearly eliminated. Also, this composite wick can be used in adverse gravity fields because the screen generates the needed capillary pressures.

A slab wick in conjunction with circumferential grooves is often used for applications where vapor velocities are generally low. The slab wick, which is usually a felt or several layers of screen, is made in the shape of a bar with a rectangular cross section. The longest side of the cross section is the same as the inner diameter of the heat pipe. Circumferential grooves distribute the condensate around the entire circumference. Obviously, this type of wick is not appropriate for very long heat pipes due to the difficulty in machining circumferential grooves on the inside of the pipe. The tunnel or spiral artery also uses a felt or several layers of screen, but is fashioned in the shape of a tube, which is smaller than the inside diameter of the pipe. The artery is then located on the pipe axis by slab wick stand-offs, which provide condensate communication between the hollow artery and the circumferential grooves on the inside diameter of the pipe. In the monogroove heat pipe design, the vapor and liquid condensate flow in different channels separated by a narrow groove. As with other arterial type wick designs, circumferential grooves in the vapor channel help 
distribute the condensate. The double-walled artery consists of an inner tube with external grooves, which is perforated at the evaporator and condenser sections to allow vapor to escape into the interior. This inner tube is concentrically placed in an outer tube with a screen mesh wick at the inner wall. The double-walled artery wick design produces high capillary pressures, and since condensate returns to the evaporator by both a screen wick and arteries on the exterior of the inner pipe, total blockages of the liquid return are unlikely.

Table 4 Typical composite wick designs

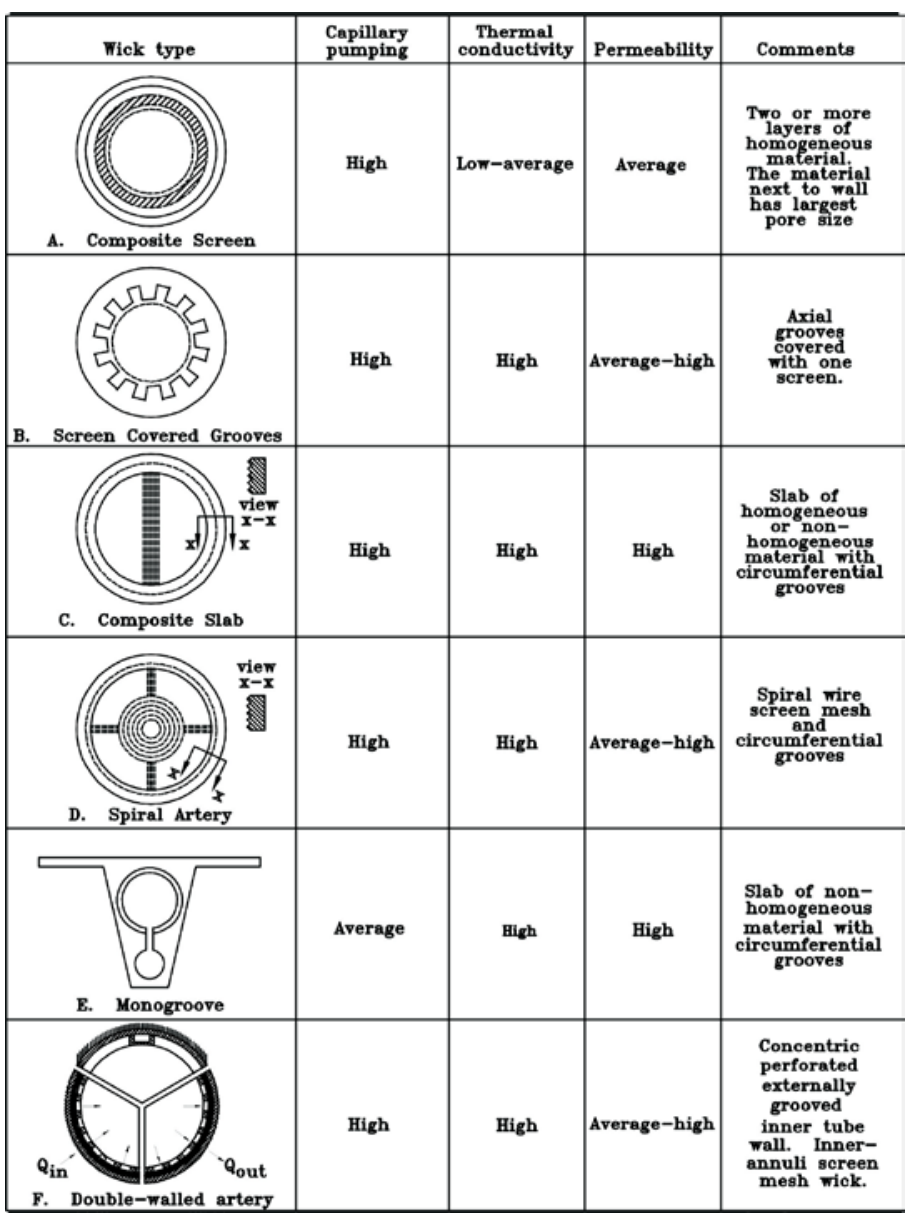

\section{HEAT TRANSFER LIMITATIONS}

There are various parameters that put limitations and constraints on the steady and transient operations of heat pipes (Faghri, 1995). In other words, the rate of heat transport through a heat pipe is subject to a number of operating limits. Physical phenomena that might limit heat transport in heat pipes are due to capillary, sonic, entrainment, boiling, frozen startup, continuum vapor, vapor pressure and condenser effects. The heat transfer limitation can be any of the above limitations depending on the size and shape of the pipe, working fluid, wick structure, and operating temperature. The lowest limit among the eight constraints defines the maximum heat transport limitation of a heat pipe at a given temperature. The physical phenomena for each limitation are briefly presented below. A detailed presentation of the criteria for the heat transfer limitations for heat pipes are provided in Faghri (1995).

\section{Capillary Limit}

The ability of a particular capillary structure to provide the circulation for a given working fluid is limited (Faghri and Thomas, 1989; Faghri, 1995). This limit is commonly called the capillary limitation or hydrodynamic limitation. The capillary limit is the most commonly encountered limitation in the operation of low-temperature heat pipes. It occurs when the pumping rate is not sufficient to provide enough liquid to the evaporator section. This is due to the fact that the sum of the liquid and vapor pressure drops exceed the maximum capillary pressure that the wick can sustain. The maximum capillary pressure for a given wick structure depends on the physical properties of the wick and working fluid. Any attempt to increase the heat transfer above the capillary limit will cause dryout in the evaporator section, where a sudden increase in wall temperature along the evaporator section takes place.

\section{Sonic Limit}

The evaporator and condenser sections of a heat pipe represent a vapor flow channel with mass addition and extraction due to the evaporation and condensation, respectively. The vapor velocity increases along the evaporator and reaches a maximum at the end of the evaporator section. The limitation of such a flow system is similar to that of a convergingdiverging nozzle with a constant mass flow rate, where the evaporator exit corresponds to the throat of the nozzle. Therefore, one expects that the vapor velocity at that point cannot exceed the local speed of sound. This choked flow condition is called the sonic limitation. The sonic limit usually occurs either during heat pipe startup or during steady state operation when the heat transfer coefficient at the condenser is high. The sonic limit is usually associated with liquid-metal heat pipes due to high vapor velocities and low densities. Unlike the capillary limit, when the sonic limit is exceeded, it does not represent a serious failure. The sonic limitation corresponds to a given evaporator end cap temperature. Increasing the evaporator end cap temperature will increase this limit to a new higher sonic limit. The rate of heat transfer will not increase by decreasing the condenser temperature under the choked condition. Therefore, when the sonic limit is reached, further increases in the heat transfer rate can be realized only when the evaporator temperature increases. Operation of heat pipes with a heat rate close to or at the sonic limit results in a significant axial temperature drop along the heat pipe.

\section{Boiling Limit}

If the radial heat flux in the evaporator section becomes too high, the liquid in the evaporator wick boils and the wall temperature becomes excessively high. The vapor bubbles that form in the wick prevent the liquid from wetting the pipe wall, which causes hot spots. If this boiling is severe, it dries out the wick in the evaporator, which is defined as the boiling limit. However, under a low or moderate radial heat flux, low intensity stable boiling is possible without causing dryout. It should be noted that the boiling limitation is a radial heat flux limitation as compared to an axial heat flux limitation for the other heat pipe limits. However, since they are related through the evaporator surface area, the maximum radial heat flux limitation also specifies the maximum axial heat transport. The boiling limit is often associated with heat pipes of non-metallic working fluids. For liquid-metal heat pipes, the boiling limit is rarely seen.

\section{Entrainment Limit}

A shear force exists at the liquid-vapor interface since the vapor and liquid move in opposite directions. At high relative velocities, droplets of liquid can be torn from the wick surface and entrained into the vapor flowing toward the condenser section. If the entrainment becomes too great, the evaporator will dry out. The heat transfer rate at which this occurs is called the entrainment limit. Entrainment can be detected by the sounds made by droplets striking the condenser end of the heat pipe. The entrainment limit is often associated with low or moderate temperature heat pipes with small diameters, or high temperature heat pipes when the heat input at the evaporator is high. 


\section{Vapor Pressure Limit}

At low operating temperatures, viscous forces may be dominant for the vapor moving flow down the heat pipe. For a long liquid-metal heat pipe, the vapor pressure at the condenser end may reduce to zero. The heat transport of the heat pipe may be limited under this condition. The vapor pressure limit (viscous limit) is encountered when a heat pipe operates at temperatures below its normal operating range, such as during startup from the frozen state. In this case, the vapor pressure is very small, with the condenser end cap pressure nearly zero.

\section{Frozen Startup Limit}

During the startup process from the frozen state, the active length of the heat pipe is less than the total length, and the distance the liquid has to travel in the wick is less than that required for steady state operations. Therefore, the capillary limit will usually not occur during the startup process if the heat input is not very high and is not applied too abruptly. However, for heat pipes with an initially frozen working fluid, if the melting temperature of the working fluid and the heat capacities of the heat pipe container and wick are high, and the latent heat of evaporation and cross-sectional area of the wick are small, a frozen startup limit may occur due to the freezing out of vapor from the evaporation zone to the adiabatic or condensation zone.

\section{Condenser Heat Transfer Limit}

In general, heat pipe condensers and the method of cooling the condenser should be designed such that the maximum heat rate capable of being transported by the heat pipe can be removed. However, in exceptional cases with high temperature heat pipes, appropriate condensers cannot be developed to remove the maximum heat capability of the heat pipe. Due to the presence of noncondensible gases, the effective length of the heat pipe is reduced during continuous operation. Therefore, the condenser is not used to its full capacity. In both cases, the heat transfer limitation can be due to the condenser limit.

\section{Vapor Continuum Limit}

For heat pipes with very low operating temperatures, especially when the dimension of the heat pipe is very small such as micro heat pipes, the vapor flow in the heat pipe may be in the free molecular or rarefied condition. The heat transport capability under this condition is limited, and is called the vapor continuum limit.

\section{Flooding Limit}

The flooding limit is the most common concern for long thermosyphons with large liquid fill ratios, large axial heat fluxes, and small radial heat fluxes (Faghri et al., 1989a). This limit occurs due to the instability of the liquid film generated by a high value of interfacial shear, which is a result of the large vapor velocities induced by high axial heat fluxes. The vapor shear hold-up prevents the condensate from returning to the evaporator and leads to a flooding condition in the condenser section. This causes a partial dryout of the evaporator, which results in wall temperature excursions or in limiting the operation of the system.

\section{HEAT PIPE START UP}

The procedures typically used in designing heat pipes are based on the fact that the heat pipe is in its normal operating state, i.e., nominal temperature at the steady state. However, the heat pipe must be started from the ambient temperature, which is either lower or higher than the operating temperature (Faghri, 1995). If the startup is too fast, the possibility of overheating the evaporator section can result in damage to the heat pipe.

Ideally, the heat pipe should first be started by increasing (or decreasing) the temperature of the entire pipe to its operating temperature. The heat input to the pipe is then slowly increased from zero to the operating input, maintaining a uniform temperature across the length of the pipe. This procedure is not usually feasible in practice. Normally, the heat input increases suddenly from zero to the operating input, without the benefit of increasing the temperature of the entire pipe. This may result in problems occurring in the startup period, which will be discussed here for three different common situations.

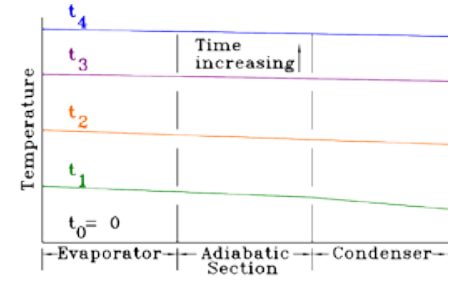

(a)

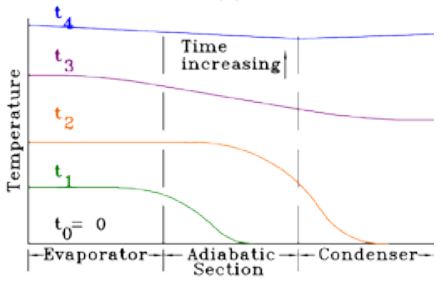

(b)

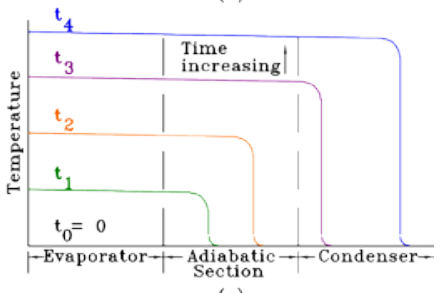

(c)

Fig. 22 Transient axial temperature profiles during heat pipe startup: (a) Uniform startup; (b) Frozen startup; (c) Gas-loaded heat pipe startup.

\section{Uniform Startup}

Figure 22(a) shows the startup of a heat pipe in which the axial temperature is nearly uniform throughout the startup period. This type of startup profile is normally seen in heat pipes in which the working fluid in the wick is in the liquid state, and the vapor is in the continuum state. An example is a copper-water heat pipe starting from ambient temperature to some higher operating temperature. As can be seen, no problems are encountered during the uniform startup.

\section{Frozen Startup}

Figure 22(b) presents the case of a heat pipe in which the working fluid within the wick structure is initially frozen, and the vapor space is essentially evacuated. This type of frontal startup is usually found in liquid-metal heat pipes, since liquid metals are in the solid state at room temperature. Frozen startup proceeds as follows: Heat is first conducted through the pipe wall and into the wick structure, increasing the temperature in the evaporator section only. After the working fluid in the evaporator wick is liquefied, evaporation begins to fill the vapor space with vapor. The vapor travels to the adiabatic section and condenses, releasing its latent heat and increasing the adiabatic section temperature. This front continues down the length of the pipe until it reaches the condenser end cap. At that time, the axial temperature distribution starts to become uniform, and the startup process is completed. The presence of large axial temperature gradients indicates that the sonic limit is occurring during frozen startup. In actuality, this is not a limit per se, since the heat pipe will not be damaged during this process. Another more important limit is the frozen startup limit, as previously discussed. The frozen startup limit occurs when more 
working fluid is evaporated than can be resupplied by the wick structure, due to the fact that the working fluid in the adiabatic and condenser sections is completely frozen. When this occurs, the evaporator section is depleted of liquid and overheats due to dryout.

\section{Gas-Loaded Heat Pipe Startup}

The noncondensible gas present in gas-loaded heat pipes gives the startup a frontal character. Figure 22(c) shows the case in which the working fluid in the wick is initially liquid in a gas-loaded heat pipe. Before the heat input is applied in the evaporator, the noncondensible gas is evenly distributed throughout the vapor space. When evaporation occurs, the working fluid vapor drives the gas to the condenser end of the heat pipe. Since the gas and the vapor are essentially separated, the effect of the gas is to block the condenser section from transferring heat to the heat sink. The presence of the gas can be seen in the axial temperature profile, which has an abrupt drop at the vapor-gas interface. More heat is then fed into the pipe, increasing the wall and vapor temperatures within the evaporator and adiabatic sections. This increases the vapor pressure, which compresses the gas in the condenser section. The vapor-gas front moves downstream into the condenser section, eventually unblocking part of the condenser, so that normal operation can take place.

\section{HEAT PIPE CHARACTERISTICS}

\section{High Effective Thermal Conductivity}

The heat pipe is a device of very high thermal conductance (Faghri, 1995). For example, a temperature difference of $900^{\circ} \mathrm{C}$ is needed to transfer $1 \mathrm{KW}$ heat across a 30-mm-diameter 1-m-long copper rod. A heat pipe of the same size can transfer the same amount of heat with a temperature difference of less than $10^{\circ} \mathrm{C}$. This indicates that the heat pipe can have a thermal conductivity 90 times higher than that of a copper bar of the same size. Numerous heat pipe designs have been developed for various applications with varied heat transport capabilities.
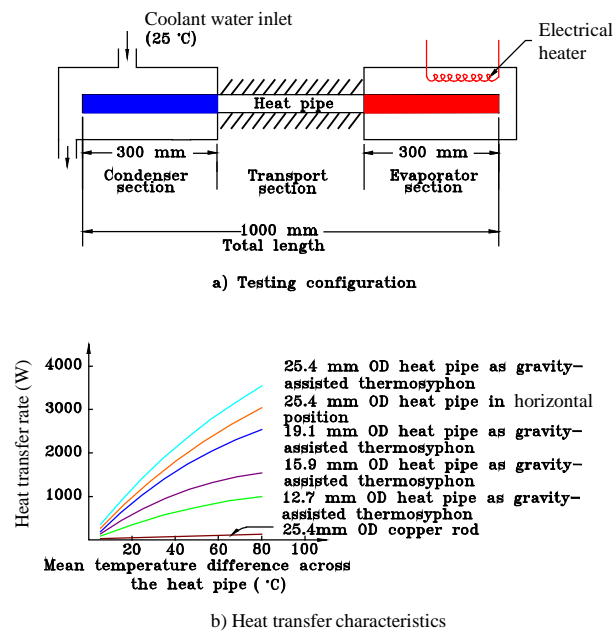

Fig. 23 Heat transfer characteristics of some typical commercial copper-water screen mesh heat pipes.

The heat transfer characteristics of a heat pipe can be measured using a conventional configuration as shown in Fig. 23(a). Figure 23(b) shows the heat transfer rate versus the mean temperature difference between the evaporator and condenser sections of commercially available copper-water heat pipes with a screen mesh wick and different diameters. Most of the tests were made in a vertical position (gravityassisted wicked heat pipe), where the driving force is due to both capillary pumping and gravity. A typical test for horizontal operation, as well as a comparison with a copper rod of $24.5 \mathrm{~mm} \mathrm{OD}$, are also shown in Fig. 23(b).

The thermal response of a conventional commercial screen mesh copper-water heat pipe with $6.35 \mathrm{~mm}$ OD and an inner diameter of 5.85 $\mathrm{mm}$ in comparison with a copper pipe of the same dimension is shown in Fig. 24. There are commercial companies all over the world (with more concentration in the Far East) who manufacture heat pipes of different shapes and sizes for various operating temperature ranges. A typical commercial off-the-shelf performance characteristic for several copper water heat pipes (Fujikura, Ltd) is presented in Fig. 25.

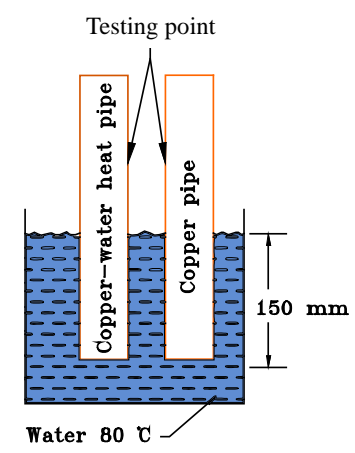

a) Testing configuration

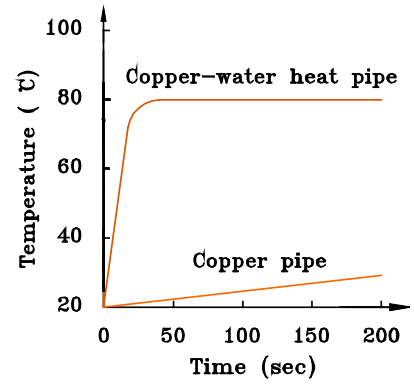

b) Transient response
Fig. 24 Transient response of a typical copper-water heat pipe compared to a copper pipe of the same dimensions.

Three of the important design parameters that are used to compare heat pipes and other two-phase thermal devices are the thermal resistance, the axial heat transport capacity (W-m) and the maximum radial heat flux at evaporator $\left(\mathrm{W} / \mathrm{cm}^{2}\right)$. Table 5 presents typical experimental operating values reported in literature for a number of heat pipes tested under various operating conditions. The operating temperature, wick design, wall material and dimensions of the heat pipes tested are listed in this table. Also, the axial heat transport rate $(\mathrm{W})$, axial heat transport capability $(\mathrm{W}-\mathrm{m})$ and the radial heat flux $\left(\mathrm{W} / \mathrm{cm}^{2}\right)$ are given. The radial heat flux or axial heat transport values reported may not necessarily be the limiting values.

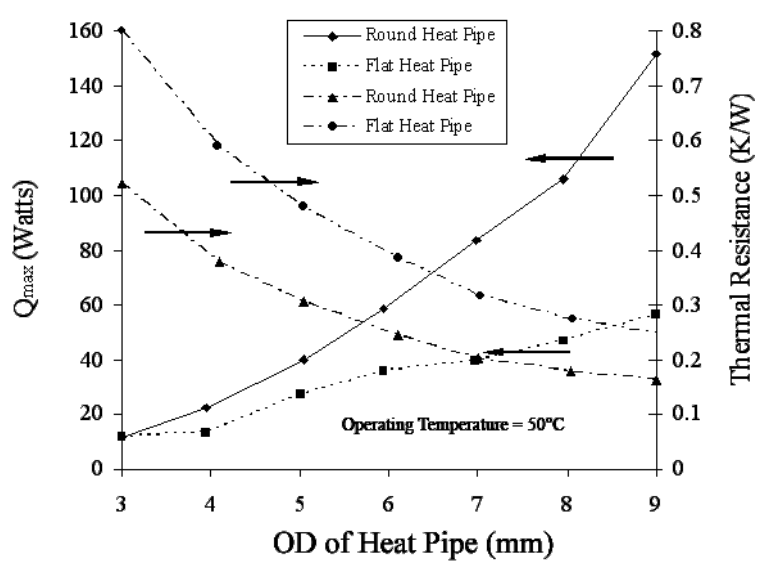

Fig. 25 Maximum heat transfer rate and thermal resistance of several commercially available copper-water heat pipes with fine fiber wicks for horizontal operation with $\mathrm{L}=300 \mathrm{~mm}, \mathrm{~L}_{\mathrm{e}}=50 \mathrm{~mm}$ and $\mathrm{L}_{\mathrm{c}}=250 \mathrm{~mm}$. 
Table 5 Some typical experimental heat pipe results

\begin{tabular}{|c|c|c|c|c|c|c|c|c|}
\hline $\begin{array}{l}\text { Working } \\
\text { Fluid }\end{array}$ & $\begin{array}{c}\text { Operating } \\
\text { Temperatu } \\
\text { re }\end{array}$ & Wick Design & $\begin{array}{c}\text { Wall } \\
\text { Material }\end{array}$ & Dimensions & $\begin{array}{l}\text { Axial Heat } \\
\text { Transport } \\
\text { (W) }\end{array}$ & $\begin{array}{c}\text { Axial Heat } \\
\text { Transport } \\
\text { Capability } \\
(\mathrm{W}-\mathrm{m})\end{array}$ & $\begin{array}{l}\text { Radial Heat } \\
\text { Flux }\left(\mathrm{W} / \mathrm{cm}^{2}\right)\end{array}$ & Reference \\
\hline Methane & $-140^{\circ} \mathrm{C}$ & $\begin{array}{l}\text { Circumferential } \\
\text { mesh wick and } \\
\text { arterial wick }\end{array}$ & Stainless steel & $\begin{array}{l}\mathrm{L}_{\mathrm{t}}=0.4 \mathrm{~m} \\
\mathrm{~L}_{\mathrm{e}}=3 \mathrm{~cm} \\
\mathrm{~L}_{\mathrm{c}}=11.5 \mathrm{~cm} \\
\mathrm{D}_{\mathrm{i}}=7 \mathrm{~mm}\end{array}$ & 12 & 3.93 & 1.82 & Rosler et al. (1987) \\
\hline Ammonia & $25^{\circ} \mathrm{C}$ & Monogroove & Aluminum & $\begin{array}{l}\mathrm{L}_{\mathrm{t}}=5.5 \mathrm{~m} \\
\mathrm{~L}_{\mathrm{e}}=0.91 \mathrm{~m} \\
\mathrm{~L}_{\mathrm{c}}=0.91 \mathrm{~m} \\
\mathrm{D}_{\mathrm{v}}=13.4 \mathrm{~mm} \\
\mathrm{D}_{\mathrm{l}}=6.32 \mathrm{~mm} \\
\text { slot width }=0.381 \\
\mathrm{~mm}\end{array}$ & 700 & 3200 & 7.26 & Alario et al. (1982) \\
\hline Water & $50^{\circ} \mathrm{C}$ & Axial grooves & Copper & $\begin{array}{l}\text { Outer pipe same as } \\
\text { above; Inner pipe: } \\
D_{o}=29.7 \mathrm{~mm} \\
D_{\mathrm{i}}=25.4 \mathrm{~mm} \\
\end{array}$ & 1300 & 940 & $\begin{array}{l}\text { Inner pipe: } 2.32 \\
\text { Outer pipe: } 1.47\end{array}$ & $\begin{array}{l}\text { Faghri and Thomas } \\
\text { (1989) (annular heat } \\
\text { pipe) }\end{array}$ \\
\hline Water & $50,70,80^{\circ} \mathrm{C}$ & \begin{tabular}{|l|}
3 wraps of a \\
copper wire screen \\
mesh with a wire \\
diameter of 0.11 \\
mm and 3937 \\
strands per meter \\
\end{tabular} & Copper & $\begin{array}{l}\mathrm{D}_{\mathrm{o}}=19.05 \mathrm{~mm} \\
\mathrm{D}_{\mathrm{i}}=15.75 \mathrm{~mm} \\
\mathrm{~L}_{\mathrm{t}}=355.6 \mathrm{~mm} \\
\mathrm{~L}_{\mathrm{e}}=101.6 \mathrm{~mm} \\
\mathrm{~L}_{\mathrm{c}}=152.4 \mathrm{~mm}\end{array}$ & $20-180$ & $4.6-41$ & $0.33-2.96$ & Kempers et al. (2008) \\
\hline Water & $60-95^{\circ} \mathrm{C}$ & $\begin{array}{l}\text { Micro capillary } \\
\text { grooves } \\
\text { (trapezoidal and } \\
\text { rectangular) }\end{array}$ & Copper & $\begin{array}{l}\mathrm{L}_{\mathrm{t}}=120.65 \mathrm{~mm} \\
\mathrm{~W}=13.41 \mathrm{~mm} \\
\mathrm{~L}_{\mathrm{e}}=15.6 \mathrm{~mm} \\
\mathrm{~L}_{\mathrm{c}}=34.4 \mathrm{~mm} \\
\mathrm{~L}_{\mathrm{a}}=70 \mathrm{~mm}\end{array}$ & $\begin{array}{l}130 \\
\text { (horizontal) } \\
170 \text { (vertical) }\end{array}$ & $\begin{array}{l}15.6 \\
20.4\end{array}$ & $\begin{array}{l}90 \text { (horizontal) } \\
150 \text { (vertical) }\end{array}$ & Hopkins et al. (1999) \\
\hline Water & $75^{\circ} \mathrm{C}$ & $\begin{array}{l}\text { Circumferential } \\
\text { copper screen (50 } \\
\text { mesh) }\end{array}$ & Copper & $\begin{array}{l}\mathrm{L}=1.0 \mathrm{~m} \\
\mathrm{~L}_{\mathrm{e}}=(4) @ 6.4 \mathrm{~cm} \\
\mathrm{~L}_{\mathrm{c}}=30 \mathrm{~cm} \\
\mathrm{D}_{\mathrm{v}}=25.4 \mathrm{~mm} \\
\mathrm{D}_{\mathrm{i}}=22 \mathrm{~mm}\end{array}$ & 392 & 283 & 1.92 & $\begin{array}{l}\text { Faghri and Buchko } \\
\text { (1991) (multiple } \\
\text { evaporators) }\end{array}$ \\
\hline Water & $100^{\circ} \mathrm{C}$ & Axial grooves & $\begin{array}{l}\text { Copper with } \\
\text { rectangular } \\
\text { cross section }\end{array}$ & $\begin{array}{l}\mathrm{L}_{\mathrm{t}}=120 \mathrm{~mm} \\
\mathrm{H}=2 \mathrm{~mm} \\
\mathrm{~W}=7 \mathrm{~mm} \\
\mathrm{~L}_{\mathrm{e}}=20 \mathrm{~mm} \\
\mathrm{~L}_{\mathrm{c}}=20 \mathrm{~mm}\end{array}$ & 70 & 8.4 & 35 & Plesch et al. (1991) \\
\hline Water & $100^{\circ} \mathrm{C}$ & $\begin{array}{l}\text { Copper wick, } 150 \\
\text { mesh }\end{array}$ & Copper & $\begin{array}{l}\mathrm{D}_{\mathrm{o}}=19.1 \mathrm{~mm} \\
\mathrm{D}_{\mathrm{i}}=17.3 \mathrm{~mm} \\
\mathrm{~L}_{\mathrm{t}}=610 \mathrm{~mm} \\
\mathrm{~L}_{\mathrm{e}}=393 \mathrm{~mm} \\
\mathrm{~L}_{\mathrm{c}}=170 \mathrm{~mm}\end{array}$ & 570 & 187 & 2.4 & $\begin{array}{l}\text { El-Genk and Huang } \\
\text { (1993) }\end{array}$ \\
\hline Water & & $\begin{array}{l}\text { Axial rectangular } \\
\text { grooves }\end{array}$ & Copper & $\mathrm{L}_{\mathrm{t}}=82 \mathrm{~mm}$ & 40 & & 20 & Cao et al. (1997) \\
\hline Water & $100^{\circ} \mathrm{C}$ & $\begin{array}{l}\text { Axial rectangular } \\
\text { grooves }\end{array}$ & Copper & $\begin{array}{l}\mathrm{L}_{\mathrm{t}}=120 \mathrm{~mm} \\
\mathrm{~W}=7 \mathrm{~mm} \\
\mathrm{H}=3 \mathrm{~mm}\end{array}$ & $\begin{array}{l}50 \\
\text { (horizontal) } \\
70 \text { (vertical) } \\
\end{array}$ & & $\begin{array}{l}25 \text { (horizontal) } \\
35 \text { (vertical) }\end{array}$ & Gao et al. (2000) \\
\hline Water & $160^{\circ} \mathrm{C}$ & Double-wall artery & Copper & $\begin{array}{l}\mathrm{L}_{\mathrm{t}}=1.2 \mathrm{~m} \\
\mathrm{~L}_{\mathrm{e}}=0.2 \mathrm{~m} \\
\mathrm{~L}_{\mathrm{c}}=0.2 \mathrm{~m} \\
\mathrm{D}_{\mathrm{v}}=13.4 \mathrm{~mm} \\
\mathrm{D}_{\mathrm{o}}=22.2 \mathrm{~mm}\end{array}$ & 900 & 900 & 6.45 & Faghri et al. (1984) \\
\hline $\begin{array}{l}\text { Therminol } \\
\text { VP-1 }\end{array}$ & $300-400^{\circ} \mathrm{C}$ & Thermosyphon & $\begin{array}{l}\text { 316-stainless } \\
\text { steel }\end{array}$ & $\begin{array}{l}\mathrm{D}_{\mathrm{o}}=15.8 \mathrm{~mm} \\
\mathrm{D}_{\mathrm{i}}=6 \mathrm{~mm} \\
\mathrm{~L}_{\mathrm{t}}=209 \mathrm{~mm} \\
\mathrm{~L}_{\mathrm{e}}=45 \mathrm{~mm} \\
\mathrm{~L}_{\mathrm{c}}=100 \mathrm{~mm}\end{array}$ & $35-70$ & $4.8-9.6$ & $1.57-3.13$ & $\begin{array}{l}\text { Jouhara and Robinson } \\
\text { (2009) }\end{array}$ \\
\hline $\begin{array}{l}\text { Sulfur- } \\
\text { Iodine 5\% } \\
\text { wt }\end{array}$ & $350^{\circ} \mathrm{C}$ & Thermosyphon & Mild steel & $\begin{array}{l}\mathrm{D}_{\mathrm{o}}=25 \mathrm{~mm} \\
\mathrm{D}_{\mathrm{i}}=20 \mathrm{~mm} \\
\mathrm{~L}_{\mathrm{t}}=1000 \mathrm{~mm} \\
\mathrm{~L}_{\mathrm{e}}=400 \mathrm{~mm} \\
\mathrm{~L}_{\mathrm{c}}=550 \mathrm{~mm}\end{array}$ & 390 & 204.8 & 1.24 & $\begin{array}{l}\text { Trovole and Raine } \\
\text { (1995) }\end{array}$ \\
\hline
\end{tabular}




\begin{tabular}{|c|c|c|c|c|c|c|c|c|}
\hline $\begin{array}{l}\text { Working } \\
\text { Fluid }\end{array}$ & $\begin{array}{c}\text { Operating } \\
\text { Temperatu } \\
\text { re }\end{array}$ & Wick Design & $\begin{array}{c}\text { Wall } \\
\text { Material }\end{array}$ & Dimensions & $\begin{array}{l}\text { Axial Heat } \\
\text { Transport } \\
\text { (W) }\end{array}$ & $\begin{array}{c}\text { Axial Heat } \\
\text { Transport } \\
\text { Capability } \\
(\mathrm{W}-\mathrm{m})\end{array}$ & $\begin{array}{l}\text { Radial Heat } \\
\text { Flux }\left(\mathrm{W} / \mathrm{cm}^{2}\right)\end{array}$ & Reference \\
\hline Sodium & $430-790^{\circ} \mathrm{C}$ & $\begin{array}{l}\text { Circumferential } \\
\text { stainless steel } \\
\text { screen (100 mesh) }\end{array}$ & Stainless steel & $\begin{array}{l}\mathrm{L}_{\mathrm{t}}=1.0 \mathrm{~m} \\
\mathrm{~L}_{\mathrm{e}}=(4) @ 5.3 \mathrm{~cm} \\
\mathrm{~L}_{\mathrm{c}}=29.2 \mathrm{~cm} \\
\mathrm{D}_{\mathrm{o}}=26.7 \mathrm{~mm} \\
\mathrm{D}_{\mathrm{i}}=21.5 \mathrm{~mm}\end{array}$ & 1309 & 979 & 6.64 & $\begin{array}{l}\text { Faghri et al. (1991a) } \\
\text { (multiple } \\
\text { evaporators) }\end{array}$ \\
\hline Sodium & $650^{\circ} \mathrm{C}$ & $\begin{array}{l}\text { Nickel sintered } \\
\text { powder metal } \\
\text { wick and an artery }\end{array}$ & Stainless steel & $\begin{array}{l}\mathrm{D}_{\mathrm{o}}=21.3 \mathrm{~mm} \\
\mathrm{D}_{\mathrm{i}}=- \\
\mathrm{L}_{\mathrm{t}}=460 \mathrm{~mm} \\
\mathrm{~L}_{\mathrm{e}}=100 \mathrm{~mm} \\
\mathrm{~L}_{\mathrm{c}}=160 \mathrm{~mm} \\
\mathrm{~L}_{\mathrm{c}, \text { inactive }}=100 \mathrm{~mm}\end{array}$ & 1400 & 322 & 21 & $\begin{array}{l}\text { Yamawaki et al. } \\
\text { (1998) }\end{array}$ \\
\hline Sodium & $800^{\circ} \mathrm{C}$ & Double-wall artery & Stainless steel & $\begin{array}{l}\mathrm{L}_{\mathrm{t}}=2.0 \mathrm{~m} \\
\mathrm{~L}_{\mathrm{e}}=25 \mathrm{~cm} \\
\mathrm{~L}_{\mathrm{c}}=91 \mathrm{~cm} \\
\mathrm{D}_{\mathrm{o}}=2.22 \mathrm{~cm}\end{array}$ & 758 & 1076 & 4.35 & Ponnappan (1989) \\
\hline Mercury & $630^{\circ} \mathrm{C}$ & Thermosyphon & $\begin{array}{l}\text { 316L stainless } \\
\text { steel }\end{array}$ & $\begin{array}{l}\mathrm{D}_{\mathrm{o}}=25.4 \mathrm{~mm} \\
\mathrm{D}_{\mathrm{i}}=21 \mathrm{~mm} \\
\mathrm{~L}_{\mathrm{t}}=1000 \mathrm{~mm} \\
\mathrm{~L}_{\mathrm{e}}=200 \mathrm{~mm} \\
\mathrm{~L}_{\mathrm{c}}=640 \mathrm{~mm}\end{array}$ & 1922 & 1115 & 12 & $\begin{array}{l}\text { Vieira da Cunha and } \\
\text { Mantelli (2009) }\end{array}$ \\
\hline $\begin{array}{l}\text { NaK (with } \\
\text { Argon as } \\
\text { NCG) }\end{array}$ & $700^{\circ} \mathrm{C}$ & 304 stainless wick & $\begin{array}{l}\text { 304L stainless } \\
\text { steel }\end{array}$ & $\begin{array}{l}\mathrm{D}_{\mathrm{o}}=19.1 \mathrm{~mm} \\
\mathrm{D}_{\mathrm{i}}=- \\
\mathrm{L}_{\mathrm{t}}=600 \mathrm{~mm} \\
\mathrm{~L}_{\mathrm{e}}=114 \mathrm{~mm} \\
\mathrm{~L}_{\mathrm{c}, 1}=73 \mathrm{~mm} \\
\mathrm{~L}_{\mathrm{c}, 2}=66 \mathrm{~mm} \\
\mathrm{~L}_{\mathrm{c}, \text { inactive }}=50 \mathrm{~mm}\end{array}$ & 250 & 57 & 3.65 & $\begin{array}{l}\text { Anderson and Tarau } \\
(2008)\end{array}$ \\
\hline Lithium & $\begin{array}{l}1227^{\circ} \mathrm{C} \\
(1500 \mathrm{~K})\end{array}$ & $\begin{array}{l}\text { Free-floating Mo- } \\
\text { 41wt.\%Re } 400- \\
\text { mesh screen wick } \\
\text { (0.41 mm thick) } \\
\text { A } 0.37 \mathrm{~mm} \\
\text { annular gap } \\
\text { separates the wick } \\
\text { from the wall }\end{array}$ & molybdenum & $\begin{array}{l}\mathrm{D}_{\mathrm{o}}=19.1 \mathrm{~mm} \\
\mathrm{D}_{\mathrm{i}}=16.06 \mathrm{~mm} \\
\mathrm{~L}_{\mathrm{t}}=1800 \mathrm{~mm} \\
\mathrm{~L}_{\mathrm{e}}=300 \mathrm{~mm} \\
\mathrm{~L}_{\mathrm{c}}=1470 \mathrm{~mm}\end{array}$ & 4000 & 3660 & 22.2 & $\begin{array}{l}\text { Tournier and El- } \\
\text { Genk (2003) }\end{array}$ \\
\hline
\end{tabular}

\section{Thermal Transformer}

The heat pipe can be effectively used as a thermal transformer to link energy sources and sinks having different heat fluxes. Energy can be added at a high heat flux rate to the heat pipe over a small surface area and removed over a larger surface area at a lower heat flux, or vice versa. Thermal flux transformation ratios as large as 15 to 1 can be achieved using heat pipes.

\section{Power Flattening}

A heat pipe that provides power flattening can be easily designed. A constant output heat flux at the condenser can be maintained for variations in the input heat flux in the evaporator section.

\section{Temperature Control}

By actively determining the conditions at the condenser (sink), a heat pipe can be designed to keep a nearly constant temperature at the evaporator even though the rate of heat input to evaporator varies. This is the basis for the variable conductance heat pipe which is discussed by Faghri (1995). The gas-loaded heat pipe, in which a noncondensible gas and a gas reservoir are constructed with a conventional heat pipe, is the simplest means to actively determine the conditions at the condenser.

\section{Freedom of Design}

Since the basic mechanisms of a heat pipe are the capillary pumping of a wick and the evaporation and condensation of a working fluid, heat pipe design is only restricted by the need to provide for these mechanisms. With this in mind, heat pipes can be designed so that they fit various shapes and configurations. These geometries range from simple cylindrical or flat heat pipes, to curved plate heat pipes for solar collectors and leading edge heat pipes.

\section{Maintenance-Free}

Since heat pipes are a closed systems and do not need any external electrical or mechanical drives, they can operate over long periods of time without maintenance.

\section{HEAT PIPE ANALYSIS AND SIMULATION}

\section{Background}

Numerical and analytical simulation of heat pipes has progressed significantly in the last several decades. The state of the art has been advanced in steady state, continuum transient, and frozen start up simulation for high-, intermediate-, and low-temperature heat pipes of conventional and nonconventional geometries.

In determining the heat capacity transmitted through a heat pipe or heat pipe performance characteristics, it is necessary to know the liquid and vapor pressure losses in the separate segments. The thermal fluid phenomena occurring within a heat pipe can be divided into four basic categories: (1) vapor flow in the core region, (2) liquid flow in the wick, (3) interaction between the liquid and vapor flows, and (4) heat conduction in the wall. Most of the detailed analytical and numerical research on heat pipes has been done on the vapor core region and wall 
heat conduction, since the liquid flow is difficult to describe with an exact theoretical model. Because of the presence of the wick structure, the analysis of categories (2) and (3) requires some empirical information that must be obtained from experimentation. Furthermore, the analyses of categories (2) and (3) are basically similar for heat pipes of various shapes. In contrast, the dynamics of vapor flow are related to the geometry and boundary specifications for nonconventional heat pipes.

The interaction between different regions can be best illustrated by following the real heat pipe operating condition, as shown by the flow chart in Fig. 26. Consider a heat pipe with an initial operating condition. If the heat load from the heat source to the heat pipe evaporator surface is increased at $\mathrm{t} \geq 0$ to a higher level, the temperature of the container wall is increased accordingly, and more heat is transferred from the container to the heat pipe wick structure. In this case, the heat pipe container wall is interacting with the heat pipe wick structure. Meanwhile, the state of the liquid-vapor interface may change due to the change in liquid pressure and temperature. The interface evaporation mass flux is also increased because more heat is transferred from the wick structure to the interface. A higher mass flux at the interface will increase the vapor velocity, and result in a change in the vapor working condition. In the above process, the liquid flow in the wick structure is interacting with vapor flow via the liquid-vapor interface. At the same time, more liquid mass may condense onto the liquid-vapor interface in the condenser section due to the higher mass flow rate from the evaporator section. This will subsequently change the interface state. The interaction between the vapor flow and the liquid-vapor interface in this case can be called feedback. These feedback interactions will also occur between the liquid-vapor interface and wick structure, and between the wick structure and the container.

In Fig. 26, regions can interact only with regions directly above or below. The container region, for example, cannot interact with the vapor region directly. It can only interact with the vapor region via the wick structure region and the liquid-vapor interface. This is due to the physical locations of the different regions, which prescribe the relation between different regions. In general, all of the regions in the flow chart should be solved as a conjugate problem. However, in the real application, approximations are often introduced due to the complex nature of the problem. Some regions in the flow chart may be neglected or combined with other regions. Regions can also be decoupled from other regions. For instance, if we neglect the liquid flow in the wick structure, and solve the region as a heat conduction problem, the region associated with the wick structure may be combined with the region associated with the heat conduction in the container. If we are only interested in the vapor flow in the heat pipe, we can neglect the three preceding regions, and directly go to the fourth region associated with vapor flow. In some applications, the liquid flow in the wick structure is of interest. Therefore, the wick region can be decoupled from other regions, and solved as a one region problem with appropriate assumptions.

For the convenience of analysis, the frozen start up process of a high-temperature heat pipe or frozen low-temperate heat pipe can be divided into several periods based on experimental evidence.

1. The working fluid in the wick is frozen at the ambient temperature. For a heat pipe without any noncondensible gas present in the vapor space, the vapor core is completely evacuated before start up.

2. Heat input is started in the evaporator section. Heat is conducted through the pipe wall and wick structure, and melting of the working fluid begins at the wall-wick interface. Because the liquid-solid interface has not reached the wick-vapor boundary, no evaporation takes place and the vapor space is still evacuated.

3. The working fluid is completely melted in the evaporator section only, and liquid is evaporated at the liquid-vapor interface. The vapor flow in the rarefied or free molecular condition due to the low vapor pressure. Some of the working fluid in the wick is still frozen in the adiabatic and condenser sections.

4. Continuum vapor flow is established in the evaporator section as the vapor pressure increases due to evaporation. In the remainder of the heat pipe, however, the vapor is still in the rarefied condition.

5. The working fluid is completely melted and continuum flow is established over the entire heat pipe length. The heat pipe temperature increases steadily until the steady state is reached.

6. The heat pipe is operating under steady state operation.

\begin{tabular}{|c|c|c|}
\hline Heat Source & & Heat Sink \\
\hline$\downarrow$ & & $\uparrow$ \\
\hline \multicolumn{3}{|c|}{ Heat Conduction in Heat Pipe Container } \\
\hline Variables & Phenomena & Governing Equations \\
\hline Temperature & Conjugate Effects & Heat Conductions \\
\hline Heat Input & Radiation or Convection B.C.'s & Stefan-Boltzmann Law \\
\hline Heat Output & Geometry Effects & Fourier Law \\
\hline \multicolumn{3}{|l|}{$\downarrow$} \\
\hline \multicolumn{3}{|c|}{ Liquid Flow and Heat Transfer in Wick Structure } \\
\hline Variables & Phenomena & Governing Equations \\
\hline Temperature & Phase Change & Continuity Equation \\
\hline Velocities & Porous Media Flow & Modified Navier-Stokes Equations \\
\hline Pressure Drop & Interfacial Shear Stress & Averaged Energy Equation \\
\hline Gravity & $\begin{array}{l}\text { Liquid Entrainment } \\
\text { Boiling Limitation }\end{array}$ & \\
\hline \multicolumn{3}{|l|}{ I } \\
\hline \multicolumn{3}{|c|}{ Liquid-Vapor Interface } \\
\hline Variables & Phenomena & Governing Equations \\
\hline Contact Angles & Capillary Pressure & Interfacial Mass Balance \\
\hline Interfacial Curvature & Disjoining Pressure & Interfacial Momentum Balance \\
\hline Interface Position & Evaporation & Interfacial Energy Balance \\
\hline Interfacial Mass Fluxes & Condensation & Clapeyron or Kelvin Equation \\
\hline & & $\uparrow$ \\
\hline \multicolumn{3}{|c|}{ Vapor Flow in Heat Pipe Core } \\
\hline Variables & Phenomena & Governing Equations \\
\hline Velocities & Compressibility Effects & Continuity Equation \\
\hline Pressure Drop & Continuum \& Rarefied Flows & Momentum Equations \\
\hline Density & Mass Diffusion & Energy Equation \\
\hline Temperature & Geometry Effects & Mass Diffusion Equation \\
\hline Concentration & Sonic Limitation & Equation of State \\
\hline
\end{tabular}

Fig. 26 Flow chart for heat pipe operation and interaction between different regions.

The parameters limiting heat transport in conventional heat pipes due to vapor flow are the capillary, sonic, and entrainment limitations. The sonic limitation is not greatly influenced by any aspect of the wick structure. Therefore, the choking phenomena should be of primary interest in the vapor flow analysis due to the fact that the vapor velocity becomes significant compared with the sonic velocity. Furthermore, vapor flow analyses are required to predict the capillary limitation. In each concentration, there are several levels of approximation, ranging from a simple one-dimensional vapor flow analysis to a complete threedimensional analysis, considering the conjugate nature of the wall and wick. Important modeling considerations include vapor compressibility, heat pipe geometry, and heat input distributions.

These methods cover various approximations and approaches, such as compressible vs. incompressible, analytical and closed-form solutions vs. numerical analyses, as well as one-dimensional, twodimensional, and three-dimensional modeling considerations in each region. Faghri (2012) reviewed the advances in analysis and simulation of the different types of heat pipes under various operating conditions, also presented in this section.

This section summarizes the developments in modeling and discusses important results for various types of heat pipes under various operating conditions in the following order (Faghri, 2012):

1 - Steady state (period 6 above)

2 - Transient (period 5 above)

3 - Frozen start up (periods 1 through 6 above)

4 - Axially grooved heat pipes

5 - Thermosyphons

6 - Rotating heat pipes

7 - Loop heat pipes 
8 - Capillary pump loop heat pipes

9 - Micro and miniature heat pipes

10 - Pulsating heat pipes

11 - Gas-loaded heat pipes

\section{Steady-State}

A steady state operational performance prediction is of significant value in the design of heat pipes. Faghri (1986) modeled the steady-state twodimensional incompressible vapor flow in an annular heat pipe. In this study, the boundary-layer approximations were used to reduce the fully elliptic conservation equations to the partially parabolic Navier-Stokes equations, which were solved using a fully implicit, marching finitedifference scheme.

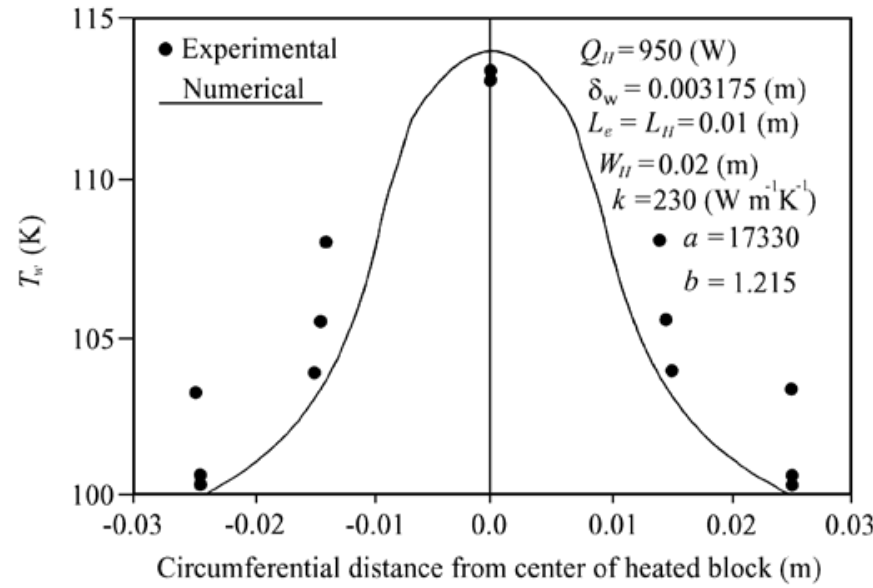

Fig. 27 Comparison of numerical results of Cao et al. (1989) with experimental data of Rosenfeld (1987).

This work was extended by Faghri and Parvani (1988) and Faghri (1989), where vapor compressibility was considered and the complete elliptic Navier-Stokes equations were solved. One- and twodimensional models were developed for the vapor flow in an annular heat pipe, and the assumptions used by Faghri (1986) were verified. A major contribution of this work is the derivation of analytic expressions for the axial pressure drop within the annular heat pipe. These relations can also be simplified to describe a conventional cylindrical heat pipe and be used directly in the design process of heat pipes.

Block-heated heat pipes are often used as heat transfer mechanisms for energy conservation systems and electronic cooling. The fundamental difference between these systems and conventional heat pipe systems is the nonuniform block heating at the evaporator, which influences the temperature distributions and vapor flow patterns throughout the heat pipe. Cao et al. (1989) proposed a simplified model of this process by defining two separate governing equations for the evaporator section: one for the pipe wall under the heated block and one for the remaining unheated pipe wall. In this method, a power-law relationship was used for the boiling heat flux. The block-heated simulation was performed for the heat pipe studied experimentally by Rosenfeld (1987), which used a narrow line heated on a lowtemperature heat pipe. The circumferential wall temperature profile predicted by Cao et al. (1989) is shown in Fig. 27, with good agreement with the experimental data. Cao et al. (1989) determined that the evaporative heat transfer coefficient has a strong influence on the wall temperature profile. This is because with a large evaporation coefficient, the majority of the input heat is removed through the phase change of the working fluid. With a lower evaporation coefficient, more heat is conducted circumferentially through the pipe wall, smoothing the temperature profile.

The importance of the effect of conjugate heat transfer within the heat pipe wall and wick was shown by Chen and Faghri (1990) with a model of the two-dimensional compressible vapor flow coupled to the two-dimensional conduction model in the wall and wick. This model solves the complete elliptic Navier-Stokes equations in the vapor with a finite control volume iterative technique. The simulation was performed for the high-temperature sodium/stainless-steel heat pipe studied in Ivanovskii et al. (1982) with the results shown in Fig. 28. They used three different methods: compressible elliptic, incompressible elliptic and compressible parabolic. Both the compressible elliptic and compressible parabolic solutions gave reasonable vapor temperature distributions, while the incompressible elliptic case shows the importance of including vapor compressibility.

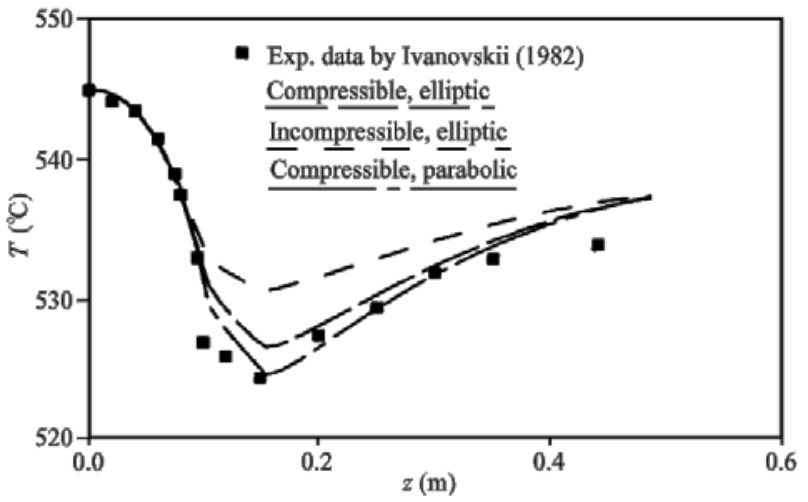

Fig. 28 The axial interface temperature profile along the sodium heat pipe with $\mathrm{Q}=560 \mathrm{~W}, \mathrm{R}_{\mathrm{v}}=0.007 \mathrm{~m}, \mathrm{~L}_{\mathrm{e}}=0.1 \mathrm{~m}, \mathrm{~L}_{\mathrm{a}}=0.05 \mathrm{~m}, \mathrm{k}_{\mathrm{l}}=66.2$ $\mathrm{W} / \mathrm{m}^{2}-\mathrm{K}, \mathrm{k}_{\mathrm{s}}=19.0 \mathrm{~W} / \mathrm{m}^{2}-\mathrm{K}, \delta_{\mathrm{l}}=0.0005 \mathrm{~m}, \delta_{\mathrm{w}}=0.001 \mathrm{~m}$. (Chen and Faghri, 1990)

This methodology was extended to model a low-temperature, multiple-evaporator heat pipe by Faghri and Buchko (1991). The heat pipe was simulated using a two-dimensional compressible formulation for the vapor flow, and a two-dimensional conduction model in the wall. However, Faghri and Buchko (1991) included the twodimensional effects of liquid flow in the wick using volume-averaged velocities in the porous media. The conservation equations were solved using an elliptic finite control volume iterative scheme with the results as shown in Fig. 29. The experimental data corresponded to a watercopper multiple-evaporator heat pipe. One case was performed with only evaporator 1 active and a heat input of $97 \mathrm{~W}$. Another had evaporators 1 and 2 active, with heat inputs of $99 \mathrm{~W}$ and $98 \mathrm{~W}$, respectively.
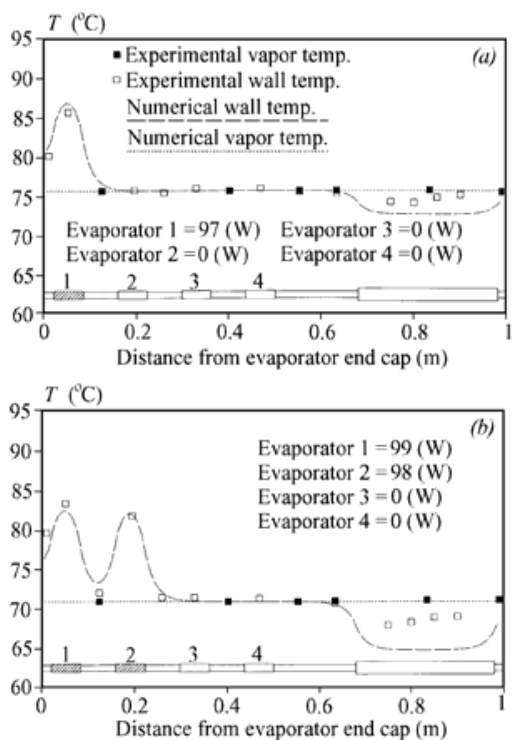

Fig. 29 Heat pipe wall and vapor temperature versus axial location for (a) single evaporator; (b) two evaporators (Faghri and Buchko, 1991). 
The block heating phenomena studied by Cao et al. (1989) was further investigated by Schmalhofer and Faghri (1993a; 1993b). The complete three-dimensional compressible Navier-Stokes equations were solved in the vapor, and the wall and wick were simulated with a threedimensional conduction model. The results of this simulation were compared with the experimental data of Schmalhofer and Faghri (1993a) for a water-copper heat pipe with good agreement (Schmalhofer and Faghri (1993b)).

An analytical and numerical study was carried out by Zhu and Vafai (1998b) for the steady incompressible vapor and liquid flow in flat plate heat pipes. The pseudo-three-dimensional analytical model employed the boundary layer approximation to describe the vapor flow conditions. The three-dimensional effects are discussed and the results show that a three-dimensional analysis is necessary if the vapor channel width-to-height ratio is less than 2.5 .

Lefevre and Lallemand (2006) developed an analytical solution for a 2D hydrodynamic model for both liquid and vapor coupled to 3D heat conduction for the wall to simulate the steady state operation of a flat miniature heat pipe. The proposed model is also capable to predict the maximum heat transfer capability for a miniature heat pipe with multiple heat sources.

A detailed, three-dimensional steady-state model was developed by Xiao and Faghri (2008) to analyze the thermal hydrodynamic behaviors of flat heat pipes and vapor chambers without empirical correlations. The model accounts for the heat conduction in the wall, fluid flow in the vapor chambers and porous wicks, and the coupled heat and mass transfer at the liquid-vapor interface. The flat heat pipes with and without vertical wick columns in the vapor channel (Fig. 30) were investigated in the model by Xiao and Faghri (2008).
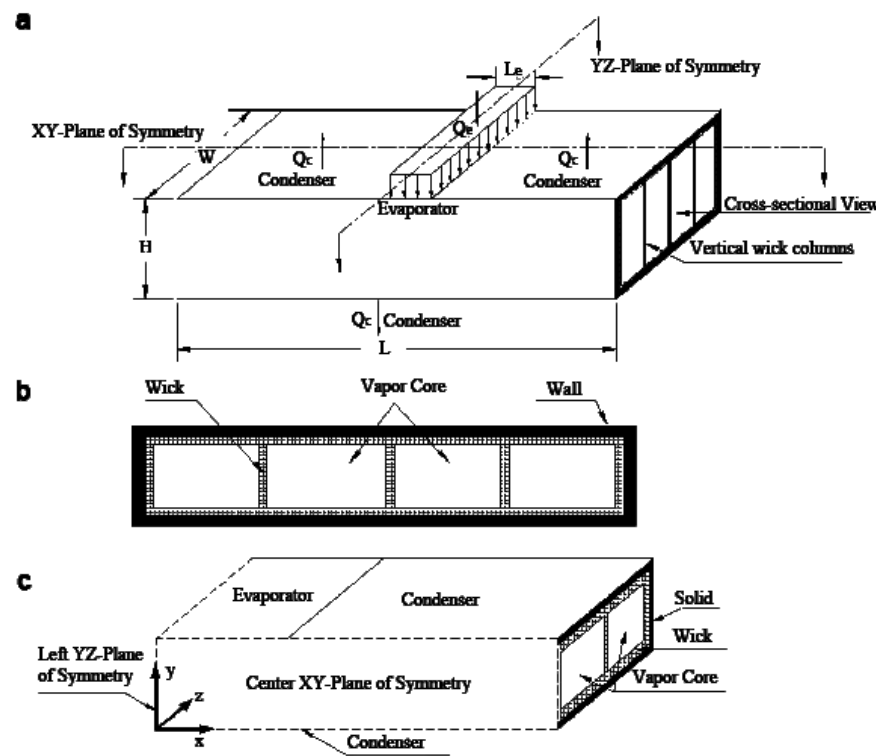

Fig. 30 Schematic diagram of the flat heat pipe: (a) geometry of the heat pipe; (b) cross-sectional view in YZ plane; and (c) computational domain (Xiao and Faghri, 2008).

Parametric effects, including the evaporative heat input and size on the thermal and hydrodynamic behavior in the heat pipes, were presented. The results showed that, the vertical wick columns in the vapor core can improve the thermal and hydrodynamic performance of the heat pipes, including thermal resistance, capillary limit, wall temperature, pressure drop, and fluid velocities due to the enhancement of the fluid/heat mechanism form the bottom condenser to the top evaporator. The results also predicted that higher evaporative heat input improves the thermal and hydrodynamic performance of the heat pipe, and shortening the size of heat pipe degrades the thermal performance of the heat pipe.
Figure 31 shows a comparison of the numerical results by Xiao and Faghri (2008) with the experimental data (Wang and Vafai, 2000) for the temperature distributions at the surface of the top and bottom walls of the flat heat pipe. The deviation in the condenser section in the top wall is mainly due to the variation of the convective heat transfer coefficient dependent of different surface temperature in the experiment, which is assumed to be constant in the numerical model.
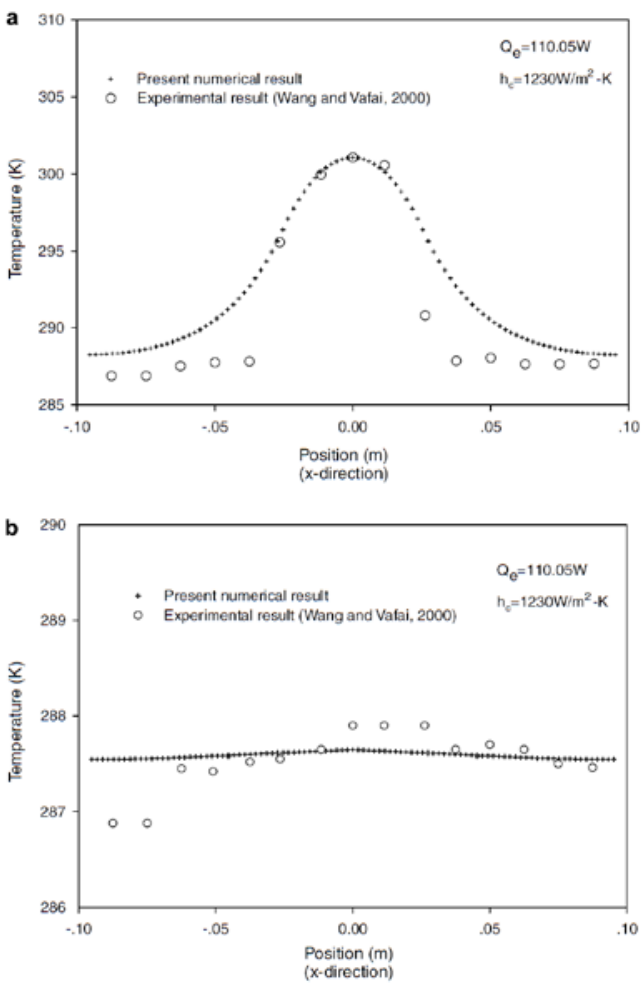

Fig. 31 Verification of numerical results for temperature distribution along a flat heat pipe with vertical wick columns at (a) the top wall; (b) the bottom wall at $\mathrm{Z}=\mathrm{W} / 2$ (Xiao and Faghri, 2008).

Aghvami and Faghri (2011) presented a steady-state analytical thermal-fluid model, including the wall and both liquid and vapor flows for flat heat pipes and vapor chambers with different heating and cooling configurations. The parametric investigations showed that the assumption of uniform evaporation and condensation in the axial direction is valid only if the wall thermal conductivity is small. Shabgard and Faghri (2011) extended the above model to cylindrical heat pipes with multiple evaporator sections. The two-dimensional heat conduction in the heat pipe's wall was coupled with the liquid flow in the wick and the vapor hydrodynamics. It was found that neglecting the axial heat conduction through the wall can result in overestimated pressure drops up to $10 \%$ depending on the heat pipe specifications.

\section{Transient}

A first-order transient model of the vapor flow in a heat pipe was proposed by Jang et al. (1991). This model simulated heat pipe operation with one-dimensional compressible vapor flow in a porous pipe, accounting for laminar and turbulent skin friction. The results of this model are compared with the experimental data of Bowman (1987) in Fig. 32, where the transient vapor pressure at three locations along the heat pipe is shown. As in a conventional heat pipe, pressure recovery occurs in the condenser section can be seen. A major advantage of this method is the ability to capture sharp pressure gradients, such as those that would occur in supersonic flow or across shock waves.

A comprehensive transient heat pipe analysis is presented by Cao and Faghri (1990). This two-dimensional model accounts for vapor 
compressibility and couples the vapor flow with heat conduction in the wall and wick. For high-temperature heat pipes, it was determined that the conduction model is sufficient to describe heat transfer in the wick. This methodology allows heat pipe simulation for pulsed heat inputs with either a convective or radiative boundary condition at the outer pipe wall of the condenser. The transient vapor temperature profile for a pulsed heat input of $\mathrm{Q}=623 \mathrm{~W}$ to $770 \mathrm{~W}$ with the convective boundary condition is shown in Fig. 33(a). The operating temperature of the heat pipe increases with time after the heat pulse. This is due to the coupling of the vapor to the wall, because the outer pipe wall temperature in the condenser must increase to reject the additional heat. The vapor temperature with the radiative boundary condition is shown in Fig. 33(b). Faghri et al. (1991b) adapted the numerical model of Cao and Faghri (1990) to a high-temperature heat pipe with multiple heat sources and sinks. Numerical results for continuum transient and steady-state operations with multiple heat sources were compared with the experimental results of Faghri et al. (1991a) and found to be in good agreement.

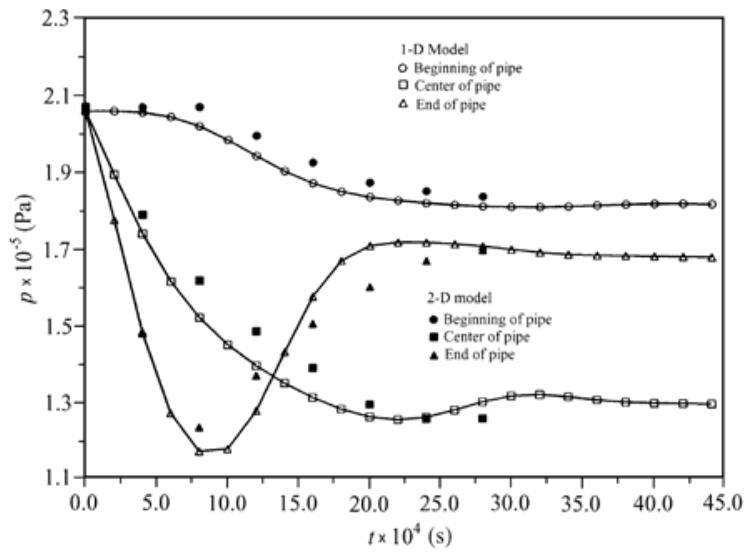

Fig. 32 Comparison of numerical results of Jang et al. (1991) with the experimental results of Bowman (1987) (Jang et al., 1991).

A transient model capable of simulating nonconventional geometries was proposed by Cao and Faghri (1991) and Cao and Faghri (1993a). This method solves the one-dimensional compressible vapor flow coupled to the two- or three-dimensional heat conduction in the wall and wick. The one-dimensional vapor flow is easier to solve than the two-dimensional formulation, but friction coefficient information is required for both laminar and turbulent flow regimes. For complex geometries, such as a wing leading edge or spacecraft nosecap, a multidimensional formulation is used in the wall and wick. Conduction in the wall and wick is coupled to the vapor flow through a conjugate heat transfer solution technique for the elliptic conservation equations in the vapor. In this analysis, the liquid flow in the wick was assumed to be decoupled from heat pipe operation to determine the capillary limit for nonconventional geometries. This simulation was used to investigate the use of heat pipes for cooling the leading edge of reentry vehicles and hypersonic aircraft. In this case, a line heat source was applied at the leading edge stagnation point of the wing to simulate aerodynamic heating. The results of this simulation are shown in Fig. 34 , where the extreme temperature gradient in the pipe wall at the leading edge can be seen. This is due to the severe heat flux $(\mathrm{q}=75 \mathrm{x}$ $106 \mathrm{~W} / \mathrm{m}^{2}$ ) at this point, which represents actual hypersonic heat loads.

A transient heat pipe model was developed by Zuo and Faghri (1997) using a transient two-dimensional wall and wick heat conduction and a quasi-steady-state one-dimensional vapor flow. The assumption of quasi-steady-state vapor was based on the fact that the vapor dynamics have a much smaller timescale than the wall conduction based on dimensional analysis. The transient twodimensional wall heat conduction was solved by a boundary element method (BEM). A control volume finite difference method (FDM) was employed to solve the vapor flow continuity and momentum equations.
Two iterative "estimate-correction" processes and a new pressurecorrection method were incorporated in the vapor solution procedure. Significant reduction of the computation time was obtained by using this hybrid FDM/BEM. Comparisons with previous experimental and numerical results validated the assumption of a quasi-steady-state vapor and the solution methods.

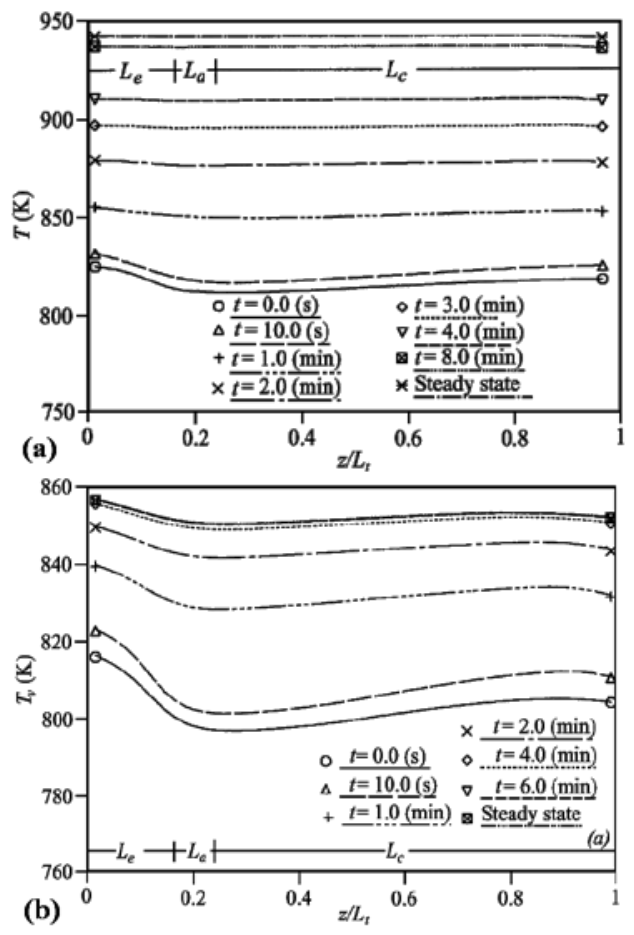

Fig. 33 Centerline vapor temperature for transient response to heat input pulse: (a) convective boundary condition; (b) radiative boundary condition (Cao and Faghri, 1990).

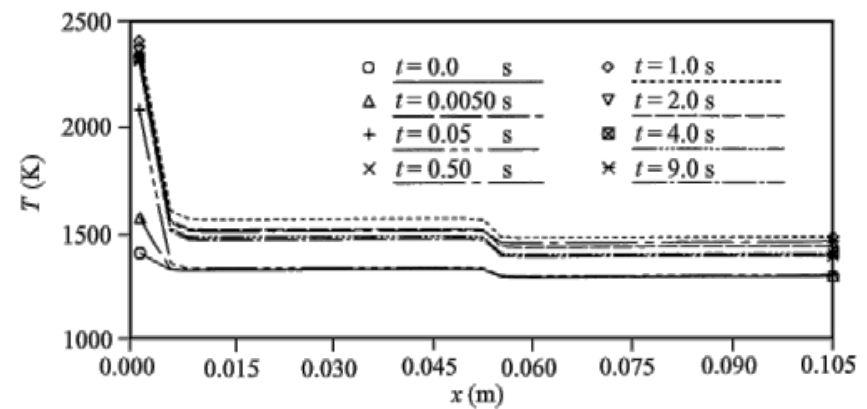

Fig. 34 Leading edge heat pipe outer wall temperature distribution (Cao and Faghri, 1993a).

An accurate, but simple lumped model using the "network" model was developed for transient heat pipe analysis by Zuo and Faghri (1998). The heat pipe consists of a number of components with different thermal resistances and dynamic responses in the network model. Governing equations of the transient heat pipe behavior were significantly simplified to a set of first-order, linear, ordinary differential equations. Figure 35 compares the transient network model with experimental results. For this specific case, the computational time required by the network model is about 1 minute on a standard desktop PC compared to several hours of CPU needed for a full twodimensional numerical model. Zhu and Vafai (1998a) developed an analytical solution for quasi-steady and incompressible vapor flow with transient one-dimensional heat conduction in the wall and wick for an asymmetrical flat plate heat pipe. 


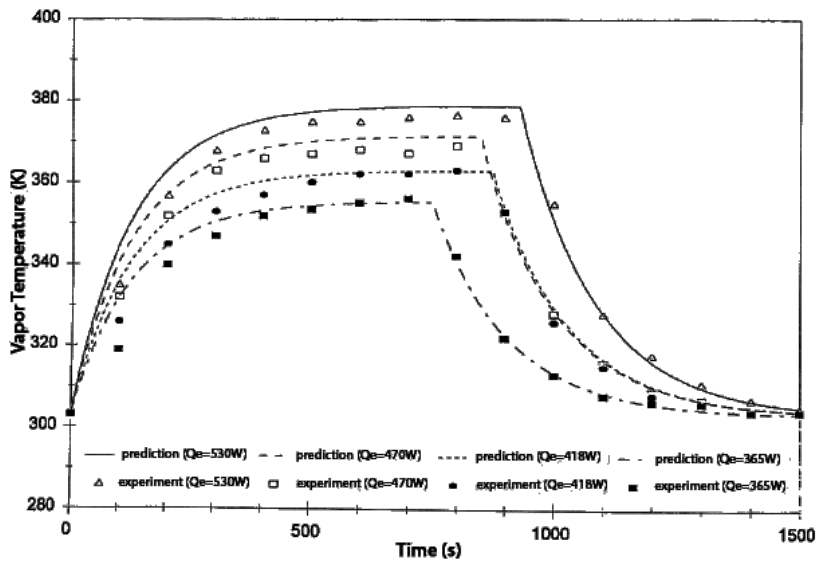

Fig. 35 Comparisons of predicted and measured transient vapor temperatures (Zuo and Faghri, 1998).

A more detailed two-dimensional transient numerical analysis of flat and cylindrical screen wick heat pipes was performed with no empirical correlations by Rice and Faghri (2007), while including the flow in the wick. Single and multiple heat sources were used as well as constant, convective, and radiative heat sinks. The numerical model by Rice and Faghri (2007) does not fix the internal pressure references by a point, but allows it to rise and fall based on the physics of the problem. Accordingly, the capillary pressure needed in the wick to drive the flow was obtained for various heating configurations and powers. These capillary pressures, in conjunction with an analysis that predicts the maximum capillary pressure for a given heating load, were used to determine the dry-out limitations of a heat pipe.

Special considerations need to be accounted for when considering the interface between the wick and the vapor region because the vapor interacts with the liquid in the wick's pores and the solid wick itself. Figure 36 is a schematic of the vapor/wick interfacial region.

Transient models with couplings between the various layers (wall, wick, and vapor) have successfully predicted the performance of heat pipes under all operating conditions for porous wick structures by neglecting the curvature effect at the liquid vapor interface. As heat pipe size or wick thickness decreases in size in the micro ranges, mainly for high thermal conductivity wicks, details of transport at the liquid vapor interface may become important in determining the capillary limit. Several efforts (Tournier and El-Genk (1994), Rice and Faghri (2007), and Ranjan et al. (2011)) have been made to include the effect of varying the radius of the curvature of the liquid meniscus formed in the wick pores for a screen mesh wick in the full numerical simulation of heat pipes for predicting the capillary limit.

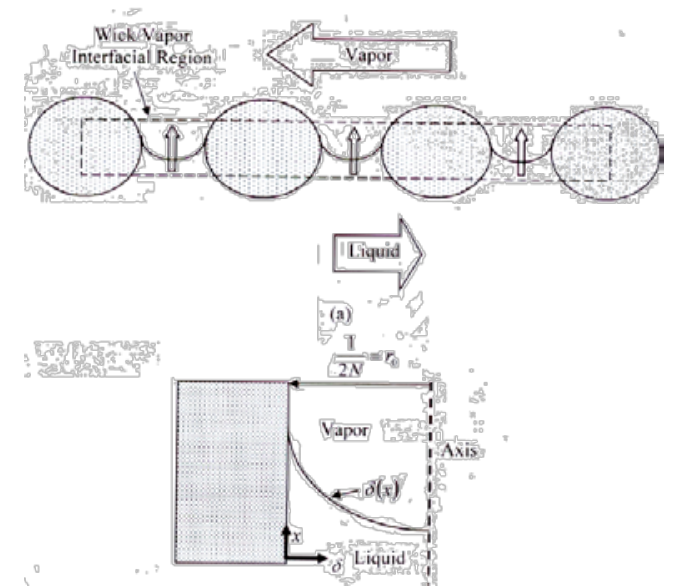

Fig. 36 Schematic of (a) a wick/liquid/vapor interfacial region and (b) an idealized single pore (Rice and Faghri, 2007).

\section{Frozen Start Up}

In some applications, heat pipes are required to transfer energy with the working fluid initially in the solid phase. As heat transfer progresses, the frozen working fluid melts, and the heat pipe undergoes a transition to normal operation. To fully understand frozen start up, significant efforts have been made toward numerical simulation of this process.

Early frozen start up research classified the frozen start up process into six periods, as discussed earlier (Jang et al., 1990). These stages describe the condition of the working fluid as solid, mushy, or liquid, and the condition of the vapor flow as free molecular, partially continuum, continuum transient, and continuum steady. In the mathematical formulation by Jang et al. (1990), the heat transfer through the free molecular vapor flow was neglected and the frozen start up was solved in the wick and wall for the first two stages.

During the early start up period, the vapor density in the heat pipe vapor space is extremely low and partly loses its continuum characteristics. This condition is referred to as rarefied vapor flow. During the early stage of start up, when the melting interface has reached the wick-vapor interface, the liquid-vapor interface cannot be considered to be adiabatic. Otherwise, there would be no molecular vapor accumulation in the vapor space and the vapor would never reach the continuum flow state. The rarefied vapor flow was simulated by a self-diffusion model (Cao and Faghri, 1993b), where self-diffusion refers to the interdiffusion of particles of the same species due to the density gradient. This method has the advantage of modeling the heat transfer through the rarefied vapor flow as coupled to the phase change of the working fluid in the wick. However, this model is only valid for the early stages of frozen start up.

A complete numerical simulation of frozen start up was completed by Cao and Faghri (1993c) by combining the rarefied self-diffusion model of Cao and Faghri (1993b) with the continuum transient model of Cao and Faghri (1990). The model completely described frozen start up, including the effects of conjugate heat transfer within the wall. Heat transfer and fluid flow in the wick coupled to the vapor flow were simulated. This methodology was applied to simulate the multipleevaporator high-temperature sodium/stainless-steel heat pipe studied by Faghri et al. (1991a) shown in Fig. 37(a) and the single evaporator sodium heat pipe of Ponnappan (1990) as shown in Fig. 37(b). The comparison with the experimental data is excellent, and the location and progression of the hot front is closely simulated as a function of time.

As mentioned previously, it may not always be possible to initiate frozen start up of a heat pipe. To address this difficulty, Cao and Faghri (1992) derived a closed-form analytical expression to describe heat pipe operation from frozen start up to continuum steady state. Also, a criterion was derived for the frozen start up limitation. The analytical model was derived under the assumption that the temperature profile at any time can be represented by three linear temperature approximations: one each in the hot and cold section of the heat pipe and one across the hot-cold front. The results of the model are shown in Fig. 38(a) when compared with the experimental frozen start up profiles of Faghri et al. (1991a), and in Fig. 38(b) when compared with the data of Ponnappan (1990).

It was determined that the frozen start up of a high-temperature heat pipe depends on several factors, such as the difference between the melting temperature of the working fluid and the ambient temperature, the liquid density of the working fluid, the porosity of the wick, and the physical dimensions of the heat pipe. These parameters were combined into a nondimensional parameter, which is a measure of the frozen start up ability of the heat pipe. This frozen start up limit (FSL) was validated using different experimental cases. Determination of the frozen start up limitation is one of the most significant contributions to frozen start up heat pipe analysis in recent years. The limit provides a fundamental design tool when considering heat pipe operation from a frozen state (Cao and Faghri, 1992). 

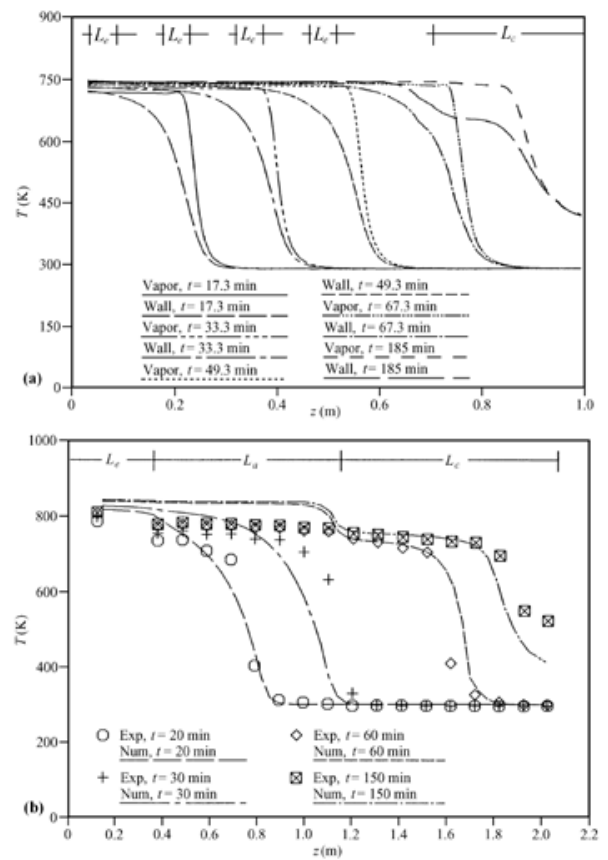

Fig. 37 Wall temperature prediction for frozen start up by Cao and Faghri (1993c) compared with the experimental data of (a) Faghri et al. (1991a); (b) Ponnappan (1990) (Cao and Faghri, 1993c).
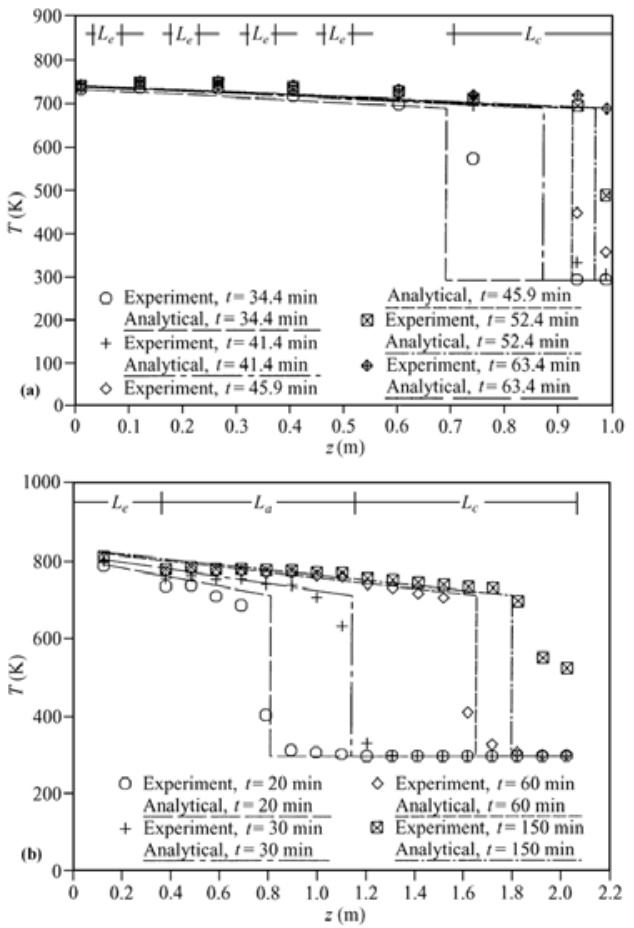

Fig. 38 Analytical wall temperature prediction for frozen start up by Cao and Faghri (1992) compared with experimental data of a (a) Faghri et al. (1991a); (b) Ponnappan (1990) (Cao and Faghri, 1992).

The aforementioned 2D models were quite successful and accurately predicted the frozen startup of low and high temperature heat pipes under various operating conditions by including both 2D free molecular and continuum vapor core regimes and freezing and melting phenomena by assuming flat liquid-vapor interface. Other frozen startup simulation efforts (Hall et al. (1994) and Tournier and El-Genk (1996)) were made by assuming 1-D vapor flow regimes, while accounting for the local interfacial radius of the curvature of the liquid meniscus.

\section{Axially Grooved Heat Pipes}

In the modeling of axially-grooved heat pipes (AGHP), the fluid circulation should be considered along with the heat and mass transfer processes during evaporation and condensation. Khrustalev and Faghri (1995a) have developed a mathematical model for low-temperature axially grooved heat pipes. The Khrustalev and Faghri (1995b) model accounts for the heat transfer in the microfilm region, which is of significant importance. Khrustalev and Faghri (1995a) modeled the heat transfer through the liquid film and the fin between the grooves (Fig. 39) in both the evaporator and condenser with respect to the disjoining pressure, interfacial thermal resistance and surface roughness, which was not accounted for by previous investigators. In this model, heat transfer processes in the heat pipe container and working fluid were considered to be one-dimensional in the radial direction, thereby neglecting the axial heat conduction. It was also assumed that no puddle flow occurred in the AGHP, no part of the condenser was blocked by the liquid working fluid, the liquid was distributed uniformly between the grooves, and the fluid flow along the axis was related to the capillary potential gradient, as described by the main radius of curvature of the liquid in a groove.

The numerical model is an iterative mathematical procedure which involved the following problems:

1. Heat transfer in the evaporating film on a rough surface.

2. Heat transfer in the condensate film on the fin top surface.

3. Heat conduction in a metallic fin and liquid meniscus.

4. Fluid circulation in the AGHP.

The first three problems have been presented in detail in by Khrustalev and Faghri (1995b). These three interconnected problems are included in the mathematical procedure along with the fluid circulation equations presented by Khrustalev and Faghri (1995a).
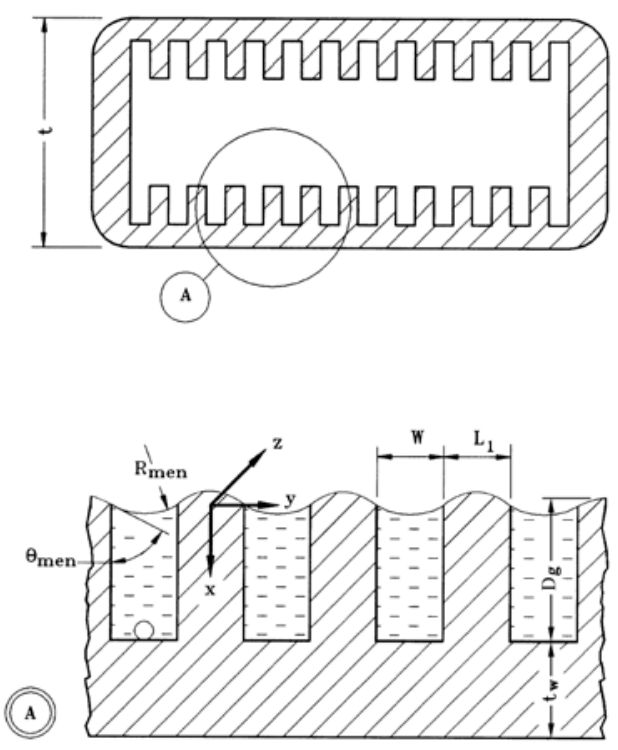

(b)

Fig. 39 Flat axially-grooved heat pipe cross-sections.

Khrustalev and Faghri (1995a) compared their numerical results with the experimental data by Schlitt et al. (1974), who studied an AGHP with the following geometry: $\mathrm{Lt}_{\mathrm{t}}=0.914 \mathrm{~m}, \mathrm{~L}_{\mathrm{c}}=0.152 \mathrm{~m}, 0.15 \leq$ $\mathrm{Le} \leq 0.343 \mathrm{~m}, \mathrm{~W}=0.610 \mathrm{~mm}, \mathrm{D}_{\mathrm{g}}=1.02 \mathrm{~mm}, \mathrm{~L}=0.430 \mathrm{~mm}, \mathrm{R}_{\mathrm{v}}=4.43$ $\mathrm{mm}, \mathrm{R}_{\mathrm{o}}=7.95 \mathrm{~mm}, \gamma=0, \mathrm{~N}=27$, and $\mathrm{t}_{\mathrm{t}}=0$. The working fluids were ammonia and ethane, and the container material thermal conductivity was assumed to be $\mathrm{k}_{\mathrm{w}}=170 \mathrm{~W} /(\mathrm{m}-\mathrm{K})$. The longitudinal distribution of the meniscus contact angle, which is influenced by the inclination angle 
and the fluid pressure variation $(\Delta p)$, is shown in Fig. 40(a) for ammonia $\left(\mathrm{L}_{\mathrm{e}}=0.343 \mathrm{~m}, \mathrm{~T}_{\mathrm{V}}=250 \mathrm{~K}\right)$. For positive values of the inclination angle $\varphi$ (when the condenser end is elevated) the points of minimum and maximum liquid surface curvature (the so-called "dry" and "wet" points) were shifted from the ends of the heat pipe towards the adiabatic section. As a result, the meniscus contact angle distributions in the heat loaded sections were even more uniform than those in the horizontal case. Note that the meniscus angles in the condenser differ very slightly from the maximum value, and their values in the evaporator can be almost the same as that in the condenser for positive $\varphi$. The corresponding longitudinal distributions of the local heat transfer coefficients in the evaporator and condenser and also wall and vapor temperature variations are shown in Figs. 40(b) and 40(c). The local heat transfer coefficient in the middle of the condenser was about two times larger than that at the entrance or end cap, which resulted in the external wall temperature variation shown in Fig. 40(c). In the evaporator section, the variation of the local heat transfer coefficient was weaker (for heat loads which are not close to the maximum), so the wall temperature profile was very smooth. The temperature drop along the vapor flow was less than $0.01 \mathrm{~K}$.
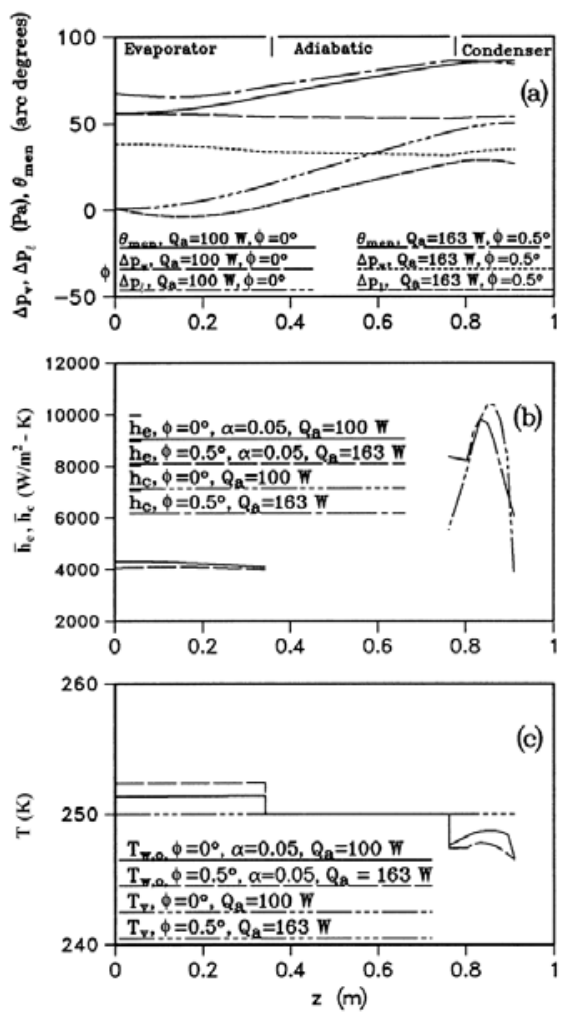

Fig. 40 Performance characteristics of the ammonia-Al heat pipe $\left(\mathrm{T}_{\mathrm{v}}=\right.$ $250 \mathrm{~K})$ : (a) Meniscus contact angle and fluid pressure; (b) Local heat transfer coefficients; (c) Wall and vapor temperatures (Khrustalev and Faghri, 1995a).

Advances in modeling of enhanced flat miniature heat pipes with capillary grooves were reviewed by Faghri and Khrustalev (1997). Lefèvre et al., (2010) extended the model by approximating the temperature along the heat pipe using different thermal resistances in their nodal model. The axial heat conduction cannot be neglected when the heat pipe wall is thick and/or the operating temperature is in the intermediate or high range. Do et al. (2008) extended the model by Khrustalev and Faghri (1995a; 1995b) to include the axial heat conduction along the heat pipe wall. The wall temperature profile and maximum heat transport rate obtained from the model developed by Do et al. (2008) are compared in Figure 41 with the experimental data of
Hopkins et al. (1999) for a flat miniature heat pipe with a micro rectangular axial grooved wick structure.
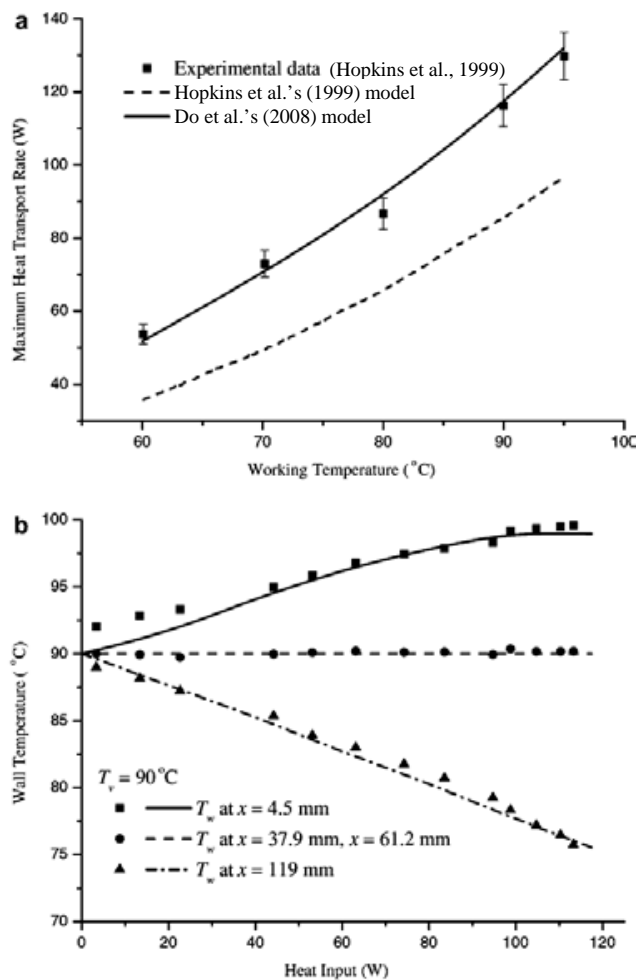

Fig. 41 Comparison of the model predictions with experimental data ((symbols) experimental data from Hopkins et al. (1999) and (lines) numerical simulation results from the Do et al. (2008) model): (a) maximum heat transport rate, and (b) wall temperature. (Adopted from Do et al. (2008))

\section{Thermosyphons}

When applying the Nusselt theory to a closed, two-phase thermosyphon, a variable vapor condensation rate must be considered. This approach was taken by Spendel (1984), who modeled a conventional thermosyphon condenser section with a two-dimensional incompressible formulation in the vapor space and an application of the Nusselt theory for the falling liquid film. With this model, Spendel (1984) performed a limited parametric study on the importance of including the interfacial shear stress and vapor pressure drop in determining the falling film thickness and the resulting Nusselt number for the thermosyphon. Based on these effects, the local Nusselt number in the condenser of a thermosyphon can vary as much as $60 \%$ from the approximate formulation derived by Nusselt.

An examination of conventional and concentric annular thermosyphons was performed by Faghri et al. (1989a), by which an improved flooding limit formulation was determined. Furthermore, in this study, the effects of the empirically obtained interfacial shear stress of the counterflowing vapor on the falling liquid film were considered in the condenser section alone.

Harley and Faghri (1994b) coupled a general quasi-steady Nusselttype solution of the falling film with the complete two-dimensional vapor solution to simulate the transient two-dimensional behavior of thermosyphons with variable properties. This model is significantly different from the previous models in that it simulates the entire thermosyphon, rather than only the condenser section. A twodimensional transient formulation for the vapor is coupled with unsteady heat conduction in the pipe wall. Furthermore, the quasisteady falling condensate film in the condenser, adiabatic, and evaporator sections are simulated by accounting for the variable vapor condensation rate, interfacial shear stress, and vapor pressure drop. The 
numerical results of Harley and Faghri (1994b) were compared with the experimental data of Mingwei et al. (1991).

The transient axial variations of the outer wall and centerline vapor temperatures are shown in Fig. 42(b), where the agreement with the steady-state experimental data of Mingwei et al. (1991) is quite good. The transient centerline axial vapor velocities for this low-temperature case are small and the axial pressure drop is negligible. The low axial vapor velocity is due in part to both the relatively high vapor density and latent heat of water and the low heat flux input to the evaporator. Obviously, compressibility is not a factor for the low-temperature thermosyphon because the maximum Mach number is much less than 0.3. The negligible axial pressure variation is typical of lowtemperature two-phase heat transfer devices due to the low vapor velocities.
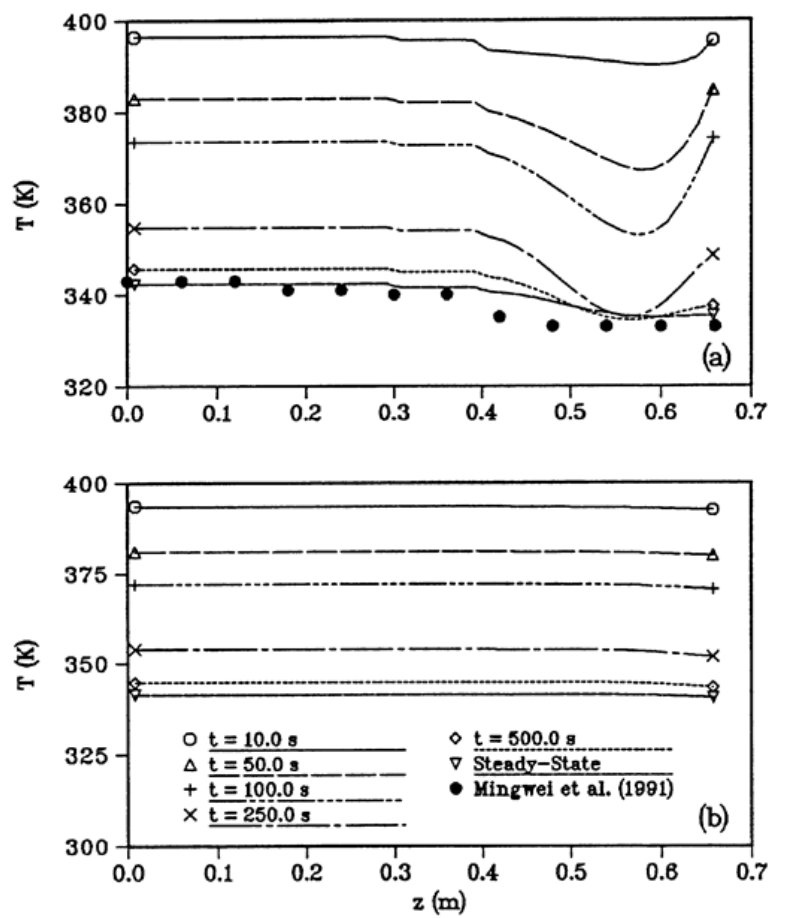

Fig. 42 Transient temperature profiles for the low-temperature thermosyphon experimentally studied by Mingwei et al. (1991): (a) transient outer wall temperature profiles; (b) transient centerline vapor temperature profiles (Harley and Faghri, 1994b).

The condensation process is affected by the presence of a small amount of noncondensible gas in a thermosyphon. During normal operation, the noncondensible gas is swept to the condenser by the vapor, which partially blocks the condenser section. This blockage reduces the area available for the heat transfer. Gas-loaded thermosyphons were studied by Hijikata et al. (1984), where a steady two-dimensional model that neglected heat conduction through the wall and falling liquid film was developed. However, since only the condenser section of the thermosyphon was modeled, a complex system of boundary conditions with several different empirical parameters was required. The behavior of the noncondensible gas was described by a modified two-dimensional steady-state species equation.

A more complete model of the condenser section of a gas-loaded thermosyphon was developed by Kobayashi and Matsumoto (1987). This two-dimensional steady-state model accounts for diffusion across the vapor-gas interface but neglects the falling film and axial heat conduction through the pipe wall.

Peterson and Tien (1989) extended the steady-state model of Hijikata et al. (1984) by accounting for the effect of heat conduction in the pipe wall. Due to the integral simplification of the governing equations, however, this model can only be used in cases where heat conduction in the wall is either dominant or negligible. Furthermore, this formulation only models the condenser section where all properties were assumed to be constant.

Harley and Faghri (1994a) coupled a general quasi-steady Nusselttype solution of the falling film with the complete two-dimensional vapor-gas formulation to simulate the transient two-dimensional behavior of gas-loaded thermosyphons with variable properties. This formulation is significantly different from the previous models in that it simulates the entire thermosyphon rather than only the condenser section, using a two-dimensional transient formulation for the vapor and gas that is coupled to unsteady heat conduction in the pipe wall. Furthermore, this formulation models the quasi-steady falling condensate film in the condenser, adiabatic, and evaporator sections that accounts for the variable condensation rate, interfacial shear stress, and vapor pressure drop.

Zuo and Gunnerson (1995) presented a numerical model of inclined thermosyphon performance. Liquid-vapor interfacial shear stress and the effects of working fluid inventory at various inclination angles were included in the model. They analyzed limiting mechanisms of the dryout and flooding and demonstrated that the model is capable of predicting the performance of an inclined thermosyphon. A onedimensional steady-state mathematical model describing natural circulation two-phase flow in a thermosyphon with a tube separator was developed by Lin and Faghri (1997b). Void fraction distributions along the thermosyphon were obtained under various operating conditions. Liquid fill ratios for steady flow were suggested. Lin and Faghri (1998b) numerically studied the hydrodynamic stability of natural circulation two-phase flow in a high performance thermosyphon with tube separator. The simulation results showed that the operating temperature, the heat rate and thermosyphon inclination angle have significant influence on the flow instability.

El-Genk and Saber (1999) developed a one-dimensional, steadystate model to determine the operation envelopes of closed, two-phase thermosyphons in terms of dimensions, type, vapor temperature of working fluid, and power throughput. The thermosyphon operationenvelope was an enclosure with three critical boundaries, related to dryout, boiling, and flooding limits. The calculations showed that an increase in the thermosyphon diameter, evaporator length, or vapor temperature expanded the operation-envelope, while an increase in the length of either the condenser or the adiabatic section only slightly changed the envelope's upper and lower boundaries. Pan (2001) presented a condensation model for a two-phase, closed thermosyphon by considering the interfacial shear stress due to the mass transfer and interfacial velocity. The relative velocity ratio and the momentum transfer factor greatly affect the condensation heat transfer in the thermosyphon. A sub-flooding limit was proposed to capture the interaction between the condensation and evaporation in the thermosyphon.

Jiao et al. (2008) developed a model to investigate the effect of the filling ratio on the distribution of the liquid film and liquid pool. The total heat transfer rate of the liquid pool, including natural convection and nucleate boiling, was calculated by combining their effective areas and heat transfer coefficients. The correlation for effective area was obtained based on experimental results. The range for the filling ratio was proposed for the steady and effective operation of the thermosyphon based on analysis and comparison. The effects of heat input, operating pressure, and geometries of the thermosyphon on the range of the filling ratio were also discussed. Jiao et al. (2012) further developed the model presented by Jiao et al. (2008) to investigate the effect of the filling ratio on dryout, flooding and boiling limits. The experiments were conducted using nitrogen as working fluid and the experimental results were compared with the calculations. The maximum filling ratio was introduced, beyond which the heat transfer performance could be declined due to the accumulation of the liquid in 
condenser end. The sensitivity of the operation range to the operating pressure and geometries were also analyzed.

\section{Rotating Heat Pipes}

The rotating heat pipe concept was first proposed by Gray (1969), who showed that such a rotating heat pipe can transfer significantly more heat than a similar stationary heat pipe.

Faghri et al. (1993) performed a rotating heat pipe vapor flow analysis by using a two-dimensional axisymmetric formulation to determine the influence of the rotation rate on the vapor pressure drop and interfacial shear stresses. They found that pressure drop and shear stress correlations for conventional heat pipes do not apply in rotating heat pipes as the vapor flow profiles are significantly different from the patterns seen in stationary heat pipes. However, that model did not consider heat transfer in the pipe wall or the counterflowing liquid film. Harley and Faghri (1995) developed a detailed transient numerical simulation of rotating heat pipes, including the thin liquid condensable film, vapor flow, and heat conduction in the pipe wall.

The complete rotating heat pipe simulation was done by Harley and Faghri (1995) for the heat pipe experimentally studied by Daniels and Al-Juimaily (1975) for a heat input of $\mathrm{Q}=800 \mathrm{~W}$ and a rotational rate of $\omega=600 \mathrm{rpm}$. The dimensions of this heat pipe were $\mathrm{L}_{\mathrm{t}}=0.325 \mathrm{~m}, \mathrm{~L}_{\mathrm{e}}$ $=0.05 \mathrm{~m}, \mathrm{~L}_{\mathrm{a}}=0.123 \mathrm{~m}, \mathrm{~L}_{\mathrm{c}}=0.152 \mathrm{~m}, \mathrm{R}_{\mathrm{v}}=0.02125 \mathrm{~m}, \mathrm{R}_{\mathrm{o}}=0.02650$ $\mathrm{m}$, and $\alpha=2 \mathrm{deg}$. The heat pipe wall was copper and the working fluid was Freon-113. A true comparison with actual data was impossible due to the assumption for the outer heat transfer coefficient. An approximate heat transfer coefficient $\left(600 \mathrm{~W} / \mathrm{m}^{2}-\mathrm{K}\right)$ was determined from an examination of the wall temperature profile given by Daniels and Al-Juimaily (1975). Because both the wall temperature and total heat input were given, the assumption of an ambient temperature is needed to obtain the external convective heat transfer coefficient.

The axial variation of the outer wall temperature is shown in Fig. 43(a). This assumed heat transfer coefficient resulted in the isothermal operation of the rotating heat pipe, which can be seen in Fig. 43(b), where the centerline vapor temperature is nearly constant along the length of the rotating heat pipe. Daniels and Al-Jumaily (1975) determined the vapor temperature with two pressure transducers located on the centerline at the two end caps, where the vapor was assumed to be saturated. As can be seen in Fig. 43(b), the assumption of a saturated vapor is valid because the vapor velocity is low enough to neglect compressibility effects.

Lin and Faghri (1997a) investigated the flow behavior and the related heat transfer characteristics of stratified flow in axially rotating heat pipes with cylindrical and stepped wall configurations using theoretical and semi-empirical models. The predicted results and experimental data showed a good agreement. Lin and Faghri (1997c) presented a mathematical model of the hydrodynamic performance of a rotating miniature heat pipe (RMHP) with a grooved inner wall surface. Influences of operating temperature, rotational speed, and liquid-vapor interfacial shear stress on the maximum performance and optimum liquid fill amount were discussed. Pressure drops of the axial liquid flow and vapor flow were demonstrated.

The region of hysteretic annular flow in rotating stepped wall heat pipes was experimentally determined by Lin and Faghri (1998a). A model for predicting the condensation heat transfer coefficient was also proposed and the theoretical results were compared with experimental data. Lin and Faghri (1999) developed a theoretical model that describes the evaporating film flow in a rotating miniature heat pipe with an axial triangular grooved internal surface. The theory of thin liquid film vaporization heat transfer was used to predict the evaporation heat transfer in the micro region. The effects of disjoining pressure, surface tension, and centrifugal force on the flow are discussed. It was concluded that the influence of rotational speed on the evaporation heat transfer in the micro region can be neglected. Therefore, the heat transfer analysis in the micro region at zero rotational speed can be applied to the case of rotational operation. Cao
(2010) developed numerical and analytical analysis for miniature high temperature rotating heat pipes for applications in gas turbine cooling.
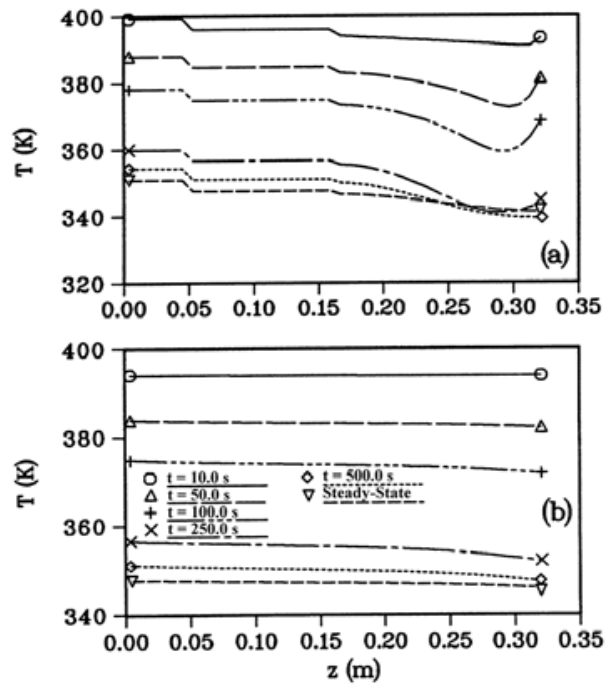

Fig. 43 Numerical simulation of the low-temperature rotating heat pipe: (a) transient outer pipe wall temperatures; (b) transient centerline vapor temperatures (Harley and Faghri, 1995).

All of the aforementioned analyses focused on a pure vapor flow with no noncondensible gases in the rotating heat pipe core. Harley and Faghri (2000) accounted for the noncondensible gas, the vapor pressure drop, the thin liquid film, the interfacial shear stress, and the heat conduction in the pipe wall of a rotating heat pipe without the need for specifying condenser inlet conditions. The problem is solved as a conjugate coupled heat transfer problem. A parametric study was also presented to determine the influence of rotational speed, heat input and output, and the mass of noncondensible gas on a rotating heat pipe.

\section{Loop Heat Pipes}

Various numerical and analytical models have been developed in order to understand the fundamental mechanisms of thermal and hydrodynamic couplings between LHP components, as well as to quantitatively predict the LHP operational characteristics. Most of the models are based on energy and pressure balances written for each component of the LHP. Some examples of steady-state LHP modeling studies are Maydanik et al. (1994), Kaya and Hoang (1999), Hoang and Kaya (1999), Kaya and Ku (1999), Muraoka et al. (2001), Kaya and Ku (2003), Hamdan (2003), Chuang (2003), Furukawa (2006), Kaya and Goldak (2006), and Launay et al. (2007c; 2008). Transient LHP modeling efforts include Cullimore and Bauman (2000), Hoang and Ku (2003), Launay et al. (2007a; 2007b), Kaya et al. (2008), Chernysheva and Maydanik (2008), and Khrustalev (2010).

LHP transient modeling of two-phase systems with capillary evaporators using a Thermal Desktop was pioneered by Cullimore and Bauman (2000) and extended by Khrustalev (2010) to upgraded loop heat pipe systems with complex radiators, multiple components, and varying environmental conditions. Launay et al. (2008) proposed separate closed-form solutions for two distinct LHP operating modes: the variable conductance mode (VCM), and the fixed conductance mode (FCM). These modes are exhibited on an experimentally observed LHP operating curve, depicting the operating temperature (usually represented by the compensation chamber temperature or evaporator temperature) versus the heat input. These models are also linked to the distribution of the condenser heat transfer area: one part is used for condensation, and the other is for liquid subcooling.

In terms of the closed-form solutions, the LHP operating temperature can be easily calculated as a function of the heat input. In Figs. 44 and 45, predictions by full numerical simulation and simplified 
closed-form solutions, are compared with experimental measurements for two LHP designs (Chuang, 2003; Boo and Chung, 2004) using acetone and ammonia as the working fluids, respectively. It appears that the relative difference between the full numerical simulation and closed-form solutions peaks at the transition between the VCM and FCM; however, the maximum difference is less than $15 \%$. The general agreement of the modeling predictions with the experimental data validates both the model and closed-form solutions as useful tools for possible LHP designs. A recent review of the fundamentals, operation, and design of loop heat pipes was given by Ambirajan et al. (2012).

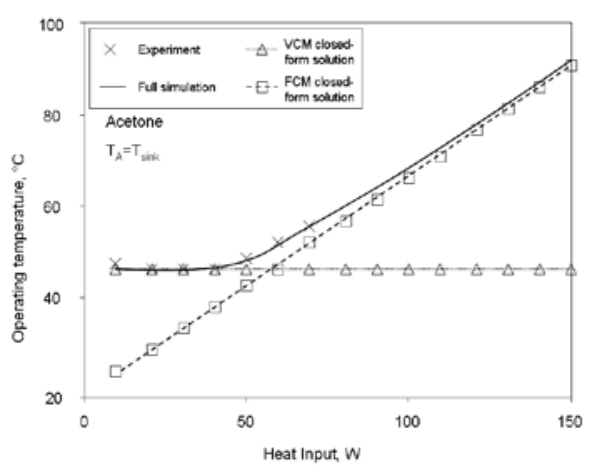

Fig. 44 Comparison of LHP modeling predictions (Launay et al., 2008) with experimental results (Boo and Chung, 2004) for acetone as the working fluid (Launay et al., 2008).

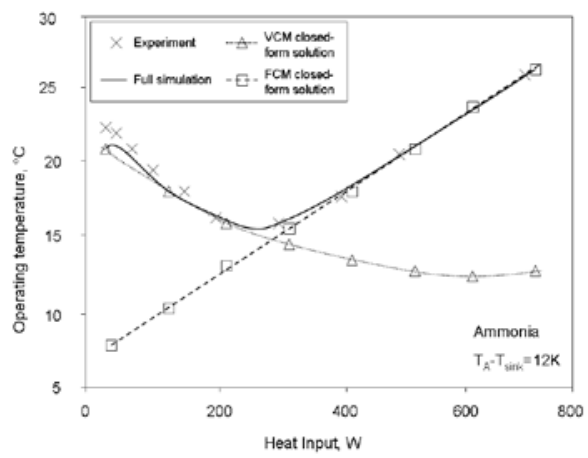

Fig. 45 Comparison of LHP modeling predictions (Launay et al., 2008) with experimental results (Chuang, 2003) for ammonia as the working fluid (Launay et al., 2008).

\section{Capillary Pumped Loop Heat Pipes}

There are three approaches related to the analysis of CPLs. The first approach is to examine the heat transfer without including the fluid flow analysis in the wick or vapor regions of the evaporator (Kiper et al., 1990). Since an analytical approach was used for solving the energy equation instead of a numerical approach, approximations were made in the solution procedure. It should be noted that the fluid flow problem is of significant importance in the evaporator and no meaningful conclusions can be made without a combined fluid flow and heat transfer analysis. This approach also included a lumped analysis of the evaporator and subcooler, in which an exponential temperature profile was assumed in the analysis. A second approach included a detailed and accurate analysis of the evaporator component for steady and transient performance, based on solving the complete differential forms of the momentum and energy equations (Cao and Faghri, 1994b; 1994c). This methodology is the most appropriate technique for analyzing the CPL system. The third approach is related to an overall system simulation using existing semi-empirical correlations under $1 \mathrm{~g}$ conditions to calculate the pressure drop and heat transfer coefficients in different parts of the CPL (Kroliczek et al., 1984; Ku et al., 1986a; 1986b; 1987a; 1987b; Chalmers et al., 1988; Ku et al., 1988; Benner et al., 1989; Schweickart and Buchko, 1991; Ku, 1993). Some analytical studies concerning the complex transient phenomena of startup have been conducted (Cullimore, 1991).

\section{Micro Heat Pipes}

Khrustalev and Faghri (1994) developed a detailed mathematical model which allows the examination of the heat and mass transfer processes in a micro heat pipe (MHP). The model gave the distribution of the liquid in a micro heat pipe and its thermal characteristics as a function of the liquid charge and the applied heat load. The liquid flow in the triangular-shaped corners of a micro heat pipe with a polygonal cross section is considered by accounting for the variation of the curvature of the free liquid surface and the interfacial shear stresses due to liquidvapor interaction. The predicted results are compared to existing experimental data. The importance of the liquid fill, minimum wetting contact angle, and the shear stresses at the liquid-vapor interface in predicting the maximum heat transfer capacity and thermal resistance of the micro heat pipe is demonstrated.
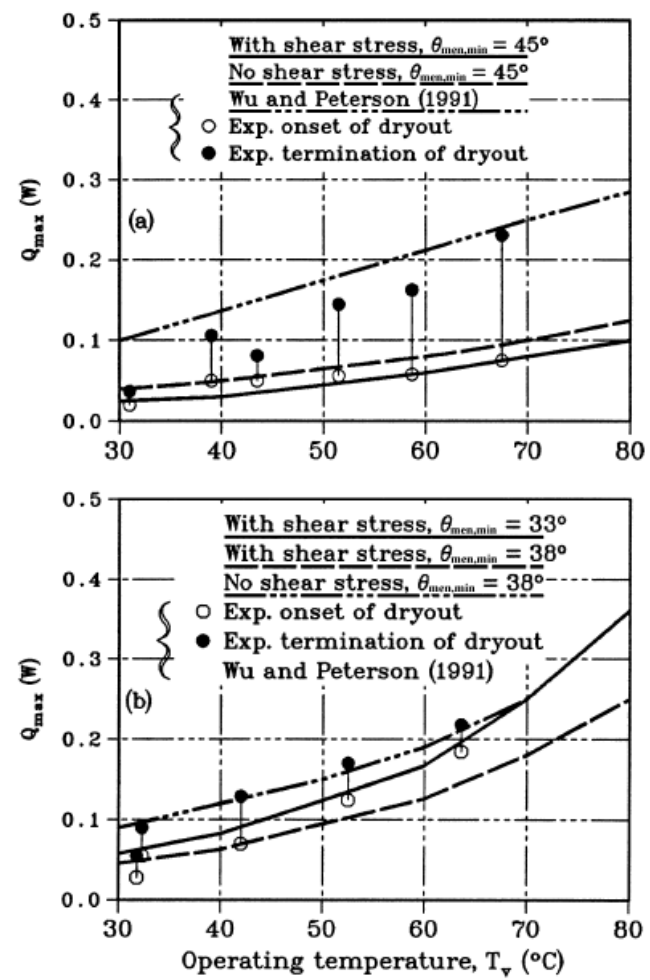

Fig. 46 Maximum heat transfer versus operating temperature: (a) Copper-water MHP; (b) Silver-water MHP (Khrustalev and Faghri, 1994).

The comparison of the numerical results (Khrustalev and Faghri, 1994) and the experimental data reported by Wu and Peterson (1991) for the maximum heat transfer capacity are shown in Fig. 46 for micro heat pipes with copper and silver casings. While the data for the minimum contact angles are contradictory and can be influenced by many physical factors, the numerical results are presented for $\theta_{\text {men,min }}=$ $33^{\circ}, 38^{\circ}$ and $45^{\circ}$. The experimental results of the onset of dryout and the present numerical prediction show a good agreement. Neglecting the shear stress at the free surface of the liquid due to liquid-vapor frictional interaction ("no shear stress" in Fig. 46) can lead to an overestimation of the maximum heat transfer capacity. The shear stress at the free liquid surface influences the liquid distribution along the heat pipe, which can result in an increase of the liquid locking of the condenser end, compared to the case of neglecting this shear stress.

Sartre et al. (2000) and Suman and Kumar (2005) extended Khrustalev and Faghri's model (1994) to include heat conduction in the 
wall to simulate micro heat pipes of polygonal shapes. Wang and Peterson (2002) and Launay et al. (2004b) have improved Khrustalev and Faghri's model (1994) to simulate arrays of micro heat pipes made of several alluminim wires bounded between two aluminum sheets.

\section{Pulsating Heat Pipes}

Since slug flow is the primary flow pattern in PHPs, most existing efforts on modeling have focused on slug flow. Miyazaki and Akachi (1996) proposed a simple analytical model of self-exciting oscillation based on an oscillating feature observed during experimentation. The reciprocal excitation of pressure oscillation due to changes in the heat transfer rate caused by the oscillation of the void fraction was investigated. Oscillation of the void fraction was out of phase with the pressure oscillation by $-\pi / 2$. This model indicates that an optimal charge ratio exists for a particular PHP. If the charge ratio is too high, the PHP will experience a gradual pressure increase followed by a sudden drop. Insufficient charging will cause chaotic pressure fluctuation. However, proper charging will generate a symmetrical pressure wave.

Miyazaki and Akachi (1998) derived the wave equation of pressure oscillation in the PHP based on the self-excited oscillation, in which the reciprocal excitation between the pressure oscillation and void fraction was accounted for. Miyazaki and Arikawa (1999) investigated the oscillatory flow in the PHP and then measured the wave velocity, which fairly agreed with the predictions of Miyazaki and Akachi's model (1998). Hosoda et al. (1999) reported a simplified numerical model of a PHP, in which temperature and pressure were calculated by solving the momentum and energy equations for twodimensional, two-phase flow. However, the thin liquid film that surrounds a vapor plug on the tube wall and the friction between the tube and the working fluid were neglected. Experimental results were used as initial conditions for the model. The numerical results for pressure in the PHP were higher than the experimental results; however, the model showed that the propagation of vapor plugs induced fluid flow in the capillary tubes.

Zuo et al. (Zuo et al., 1999; 2001) attempted to model the PHP by comparing it to an equivalent single spring-mass-damper system, with the parameters of the system affected by heat transfer. Zuo et al. (2001) showed that the spring stiffness increases with increasing time, and therefore, the amplitude of oscillation must decrease with increasing time; this is in contradiction with steady oscillations observed in PHP operation. Wong et al. (1999) modeled an open-loop PHP by considering it as a multiple spring-mass-damper system with the flow modeled under adiabatic conditions for the entire PHP. A sudden pressure pulse was applied to simulate local heat input into a vapor plug.

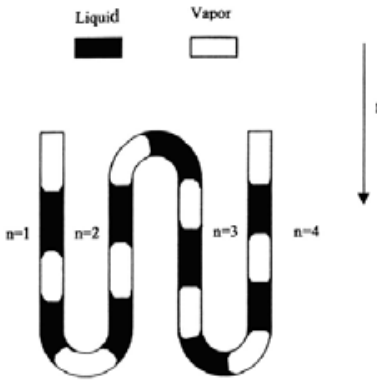

(a)

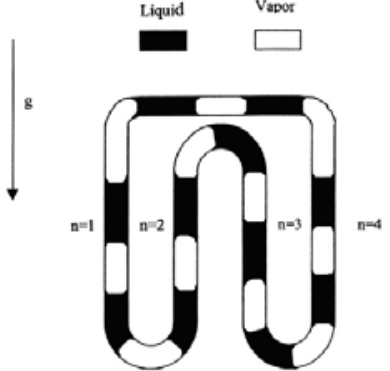

(b)
Fig. 47 Pulsating heat pipes: (a) Open-loop, (b) Closed-loop (Shafii et al., 2001).

Shafii et al. (2001) developed a theoretical model to simulate the behavior of liquid slugs and vapor plugs in both closed- and open-loop PHPs with two turns (see Fig. 47). The model solved for the pressure, temperature, plug position and heat transfer rates. The most significant conclusion was that the majority of the heat transfer (95\%) is due to sensible heat; not due to the latent heat of vaporization. Latent heat served only to drive the oscillating flow. Sakulchangsatjatai et al. (2004) applied Shafii et al.'s model (2001) to model closed-end and closed-loop PHPs as an oscillating two-phase heat and mass transfer in a straight pipe, while neglecting the thin liquid film between the vapor plug and the pipe wall.

Zhang et al. (2002) analytically investigated oscillatory flow in a U-shaped miniature channel-a building block of PHPs. A significant difference between this model and other mathematical models is the nondimensionalizing of the governing equations. Flow in the tube was described by two dimensionless parameters, the non-dimensional temperature difference and the evaporation and condensation heat transfer coefficients. It was found that both the initial displacement of the liquid slug and gravity had no effect on the amplitude and angular frequency of the oscillation. In addition, the amplitude and frequency of oscillation were increased by increasing the dimensionless temperature difference. The amplitude and frequency of oscillation were correlated to the heat transfer coefficients and temperature difference.

Zhang and Faghri (2003) investigated oscillatory flow in a closed-end pulsating heat pipe with an arbitrary number of turns (see Fig. 48). The results showed that for a PHP with few turns (less than 6), the amplitude and frequency of oscillation were independent of the number of turns. The motion of the vapor plugs was identical for odd numbered plugs once a steady state had been reached. Even numbered plugs also exhibited identical motion. Odd and even numbered plugs had the same amplitude, but were out of phase by a factor of $\pi$. As the number of turns increased above 6 , the odd and even numbered plugs no longer showed identical oscillation. Each plug lagged slightly behind the next. Each plug remained out of phase by $\pi$, however. (see Fig. 49).

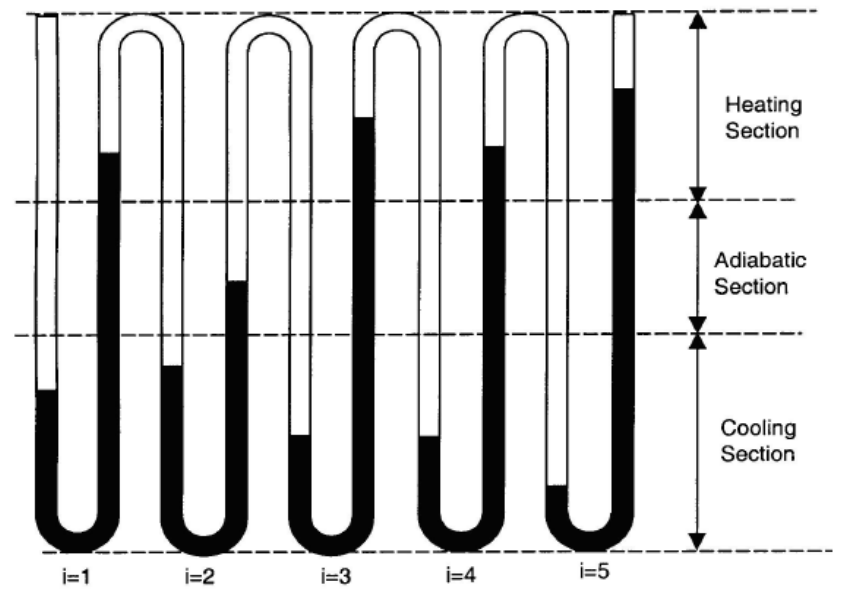

Fig. 48 Open-loop PHP with arbitrary turns (N=5) (Zhang and Faghri, 2003).

Dobson and Harms (1999) investigated a PHP with two open ends. The open ends were parallel and pointed in the same direction. These ends were submerged in water, while the evaporator section was coiled and attached to a float so that it remained out of the water. The evaporator was heated and the oscillatory fluid motion produced a net thrust. A numerical solution of the energy equation and the equation of motion for a vapor plug was presented to predict the plug's temperature, position and velocity. Oscillatory motion in the PHP generated a net average thrust of $0.0027 \mathrm{~N}$. Heat transfer due to sensible heat was not taken into account. Dobson (2004; 2005) proposed the use of open-ended PHP in conjunction with two check valves to pump water; however, the maximum attainable mass flow rates are on the order of $\mathrm{mg} / \mathrm{s}$, which is hardly enough to irrigate fields. An improved model for liquid slug oscillation that considered pressure difference, friction, gravity, and surface tension was also presented. 


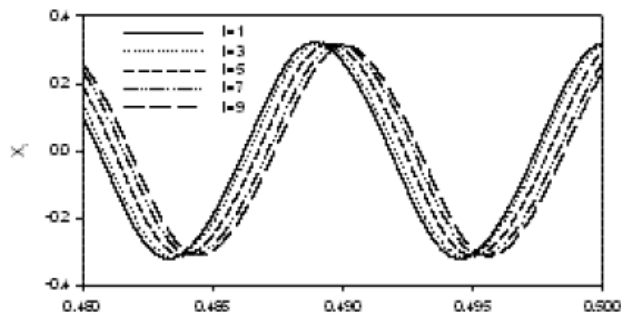

(a) Odd number liquid shos

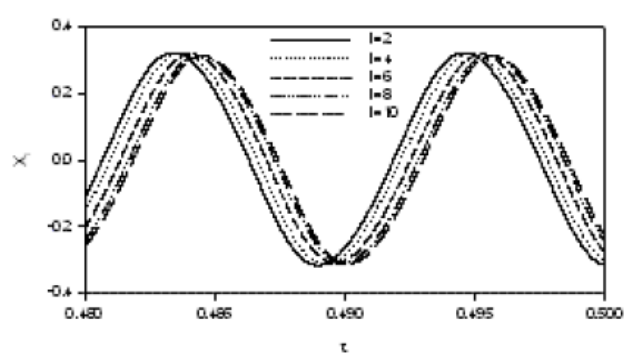

(b) Even number liquid shg;

Fig. 49 Displacement of liquid slugs ( $\mathrm{N}=10)$ (Zhang et al., 2002).

Zhang and Faghri (2002) proposed models for heat transfer in the evaporator and condenser sections of a PHP with one open end by analyzing thin film evaporation and condensation. Heat transfer in the evaporator is the sum of evaporative heat transfer in the thin liquid film and at the meniscus. Heat transfer in the condenser is similarly calculated, and sensible heat transfer to the liquid slug is also considered. It is found that the overall heat transfer is dominated by the exchange of sensible heat, not by the exchange of latent heat. Shafii et al. (2002) further developed their earlier numerical model (Shafii et al., 2001) by including an analysis of the evaporation and condensation heat transfer in the thin liquid film separating the liquid and vapor plugs. Both open- and closed-loop PHPs were considered, and each displayed similar results. As shown in Fig. 50, the total heat transfer is due mainly to the exchange of sensible heat ( 95\%). Total heat transfer slightly increases as the surface tension of the working fluid increases. The total heat transfer significantly decreases with decreased heating section wall temperature. Increasing the diameter of the tube results in a higher total heat transfer.
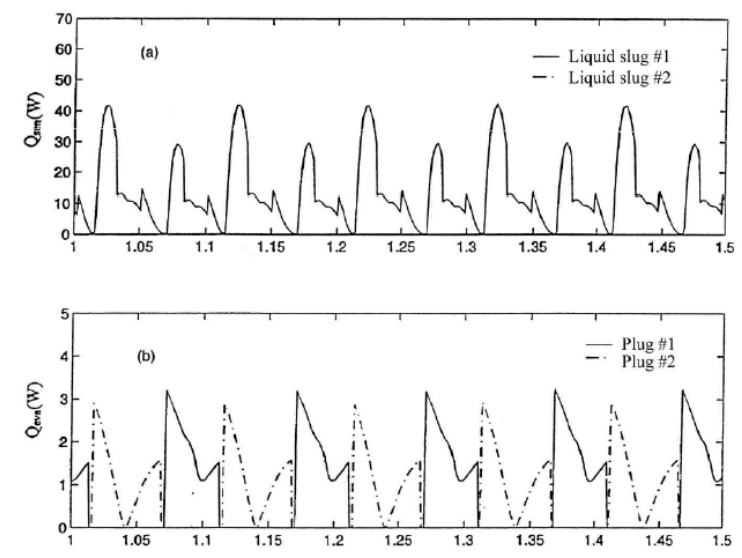

Fig. 50 Heat transfer rate: (a) sensible heat; (b) evaporative heat (Shafii et al., 2002).

Liang and Ma (2004) presented a mathematical model describing the oscillation characteristics of slug flow in a capillary tube. In addition to the modeling of oscillating motion, numerical results indicated that the isentropic bulk modulus generates stronger oscillations than the isothermal bulk modulus. While it demonstrated that the capillary pipe diameter, bubble size, length and the number of unit cells determine the oscillation, the capillary force, gravitational force, and initial pressure distribution of the working fluid significantly affects the frequency and amplitude of oscillating motion in the capillary tube. Ma et al. (2002; 2006) analytically described the oscillating motion by performing force balances of the thermally driven, capillary, frictional, and elastic restoring forces on a liquid slug. Pressure differences between the evaporator and the condenser were related to the temperature difference between the evaporator and the condenser by the Clapeyron-Clausius equation. The temperature difference between the evaporator and the condenser of the PHP was utilized as a driving force of the oscillating motion. Ma et al. (2006) concluded that oscillating motion depends on the charge ratio, total characteristic length, diameter, temperature difference between the evaporation and condenser sections, and the working fluid and operating temperature. When compared to experimental results, the mathematical model under-predicted the temperature difference between the evaporator and condenser when compared to experimental results (Ma et al., 2002).

Holley and Faghri (2005) presented a numerical model for a PHP with a sintered copper capillary wick and with flow channels that have different diameters. The effects of the varying channel diameters, inclination angles, and the number of parallel channels were presented. When a channel was of a smaller diameter, it induced circulation of the fluid, which in turn increased the heat load capability of the PHP. The modeled PHP performed better in bottom heat mode (smaller temperature differential) than in top heat mode. Varying the mean Nusselt number had little effect on the PHP performance. As the number of parallel channels increased, its heat load capability increased, and the PHPs sensitivity to gravity decreased.

Khandekar et al. (2002) used an Artificial Neural Network (ANN) to predict the PHP performance. The ANN was of the fully connected feed forward configuration, and was trained using 52 sets of experimental data from a closed-loop PHP. The ANN was fed the heat input and fill ratio of each data set and then calculated the effective thermal resistance of the PHP. The ANN model predicted the thermal performance for this type of PHP but neglected many parameters that affect PHP performance, including tube diameter, number of parallel channels, length of the PHP, inclination angle, and properties of the working fluid. If the ANN had more input nodes with which to consider these parameters, it would be a more effective model. Even then it would require considerably well-organized experimental data for the ANN to be effective.

Khandekar and Gupta (2007) modeled heat transfer in a radiator plate with an embedded PHP using a commercial package FLUENT. However, oscillatory flow and heat transfer of the PHP were not modeled in this investigation. The contribution of the PHP on the heat transfer in the radiator plate was considered using an effective thermal conductivity obtained from the experiment. Zhang and Faghri (2008) made a detailed review of pulsating heat pipe analysis. Khandekar et al. (2010) presented the experimental and theoretical methodologies to predict hydrodynamic characteristics in unidirectional two-phase Taylor bubble flows and recommended directions for further research on modeling of pulsating heat pipes.

\section{Gas-Loaded Heat Pipes}

Noncondensible gas-buffered heat pipes (NCHPs) offer isothermal operation for varying heat loads by changing the overall thermal resistance of the heat pipe. As the heat load increases, the vapor temperature and total pressure increase in the heat pipe. This increase in total pressure compresses the noncondensible gas in the condenser, thereby increasing the surface area available for heat transfer. This maintains a constant heat flux and temperature. NCHP operation can 
also be examined through the partial vapor pressure. As the heat input increases, the total pressure increases. However, because the total pressure is comprised of both the partial vapor and partial gas pressures, the increase in total pressure is accounted for by an increase in the partial gas pressure, maintaining a constant vapor pressure, and thus a constant vapor temperature.

Noncondensible gas-buffered heat pipes have been modeled previously with several different levels of approximation. The classic flat-front analytical model of Marcus and Fleishman (1970) neglected all diffusion across the vapor-gas interface. Later studies modeled onedimensional steady diffusion (Edwards and Marcus, 1972) and onedimensional transient diffusion (Shukla, 1981). Rohani and Tien (1973) studied the steady-state two-dimensional diffusion process in a noncondensible gas-buffered heat pipe. The importance of modeling radial diffusion in a NCHP was demonstrated where the noncondensible gas tends to accumulate at the liquid-vapor interface, which retards vapor condensation. However, Rohani and Tien (1973) neglected the effect of conjugate heat transfer through the wall as well as transient effects. The importance of the transient response of a NCHP was shown by Shukla (1981), as transient thermal overshoots were discovered. This study, however, did not include the effects of radial heat conduction in the wall or wick or the radial diffusion effects of the noncondensible gas.

Harley and Faghri (1994c) studied the two-dimensional, transient NCHP operation, including the effects of conjugate heat transfer through the wall, and is modeled through a solution of the general differential conservation equations. This procedure was used to simulate the high-temperature heat pipe experimentally studied both with and without noncondensible gases. The major advantage over previous models was that this model treats the noncondensible gas as a separate entity that is described by mass transport phenomena. Additionally, the energy transport through the wall is coupled to the transient operation of the heat pipe through the use of a conjugate solution technique. The complete behavior of the heat pipe, along with the location and two-dimensional shape of the noncondensible gas front, are modeled from the initial continuum-flow, liquid-state start up to steady-state conditions. The proposed model by Harley and Faghri (1994c) predicted the existing experimental data for the operation of high-temperature heat pipes with and without noncondensible gases. The gas-loaded heat pipe experimentally studied by Ponnappan (1989) was simulated (Case 2), with results shown in Figs. 51 and 52. This case has a higher radiative emissivity than Case 1 , which results in a decrease in the thermal resistance at the outer condenser surface. In the experiment performed by Ponnappan (1989), the emissivity was increased when the noncondensible gas was added, so that a nearconstant operationg temperature (compared with Case 1) could be maintained. In Fig. 51, the wall and vapor temperatures decreased significantly in the condenser section due to the presence of the noncondensible gas. The gas density increased in the condenser during transient operation, as shown in Fig. 52(a). The steady-state wall temperature is in good agreement with the data by Ponnappan (1989).

A transient lumped heat pipe formulation for conventional heat pipes is presented, and the lumped analytical solutions for different boundary conditions at the evaporator and condenser are given by Faghri and Harley (1994). For high temperature heat pipes with a radiative boundary condition at the condenser, a nonlinear ordinary differential equation is solved. In an attempt to reduce computational demands, a transient lumped conductive model was developed for noncondensible gas-loaded heat pipes. The lumped flat-front transient model was extended by accounting for axial heat conduction across the sharp vapor-gas interface. The analytical solutions for conventional and gas-loaded heat pipes were compared with the corresponding numerical results of the full two-dimensional conservation equations and experimental data, showing a good agreement.
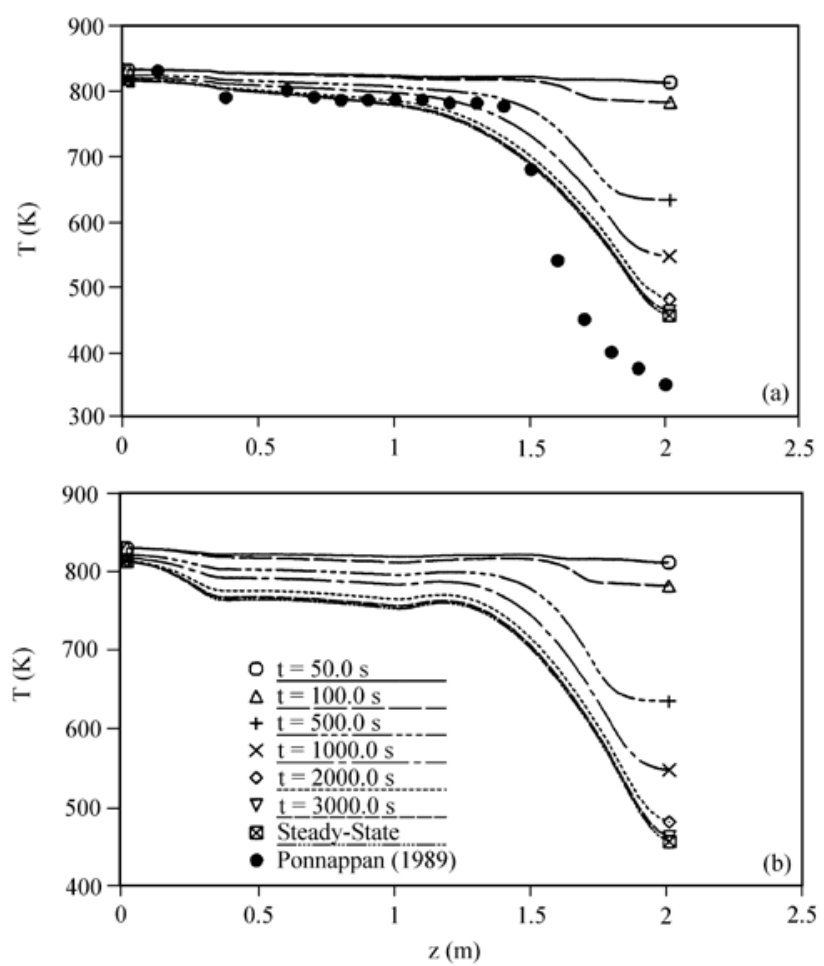

Fig. 51 Temperature profiles for the gas-loaded heat pipe with $\mathrm{Q}_{\text {in }}=$ 258 W (Case 2): (a) transient wall temperature profile; (b) transient centerline temperature profile (Harley and Faghri, 1994c).
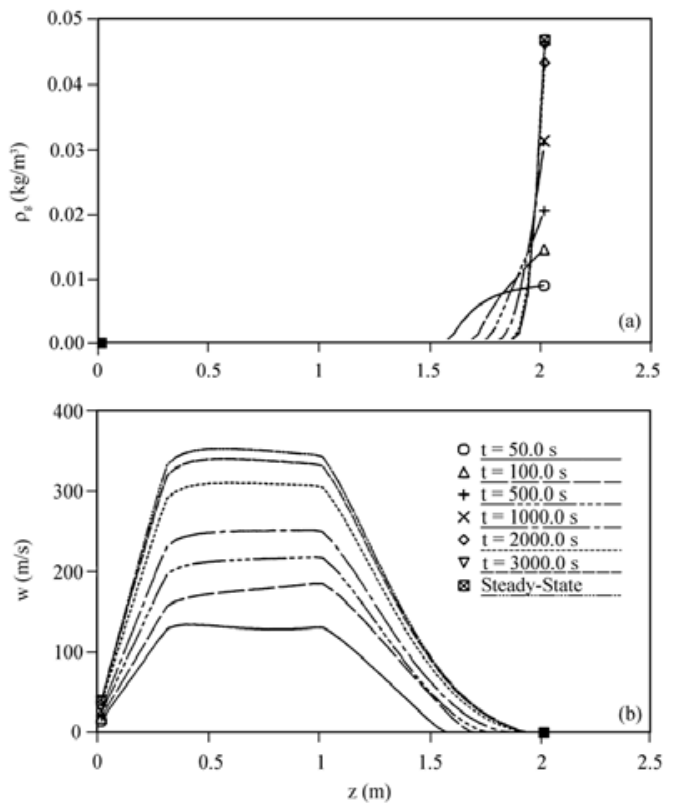

Fig. 52 Vapor-gas dynamics for the gas-loaded heat pipe with $\mathrm{Q}_{\text {in }}=$ 451 W (Case 2): (a) transient centerline gas density profile; (b) transient centerline axial velocity profiles (Harley and Faghri, 1994c).

\section{HEAT PIPE APPLICATIONS}

Heat pipes have been applied in many ways since their introduction in 1964 (Vasiliev, 2005; Mochizuki et al., 2011). Depending on their intended use, heat pipes can operate over a temperature range from 4.0 to $3000 \mathrm{~K}$. In all cases, their applications can be divided into three main 
categories: separation of heat source and sink, temperature equalization, and temperature control. Due to their extremely high thermal conductivity, heat pipes can efficiently transport heat from a concentrated source to a remotely mounted sink. This property can enable dense packing of electronics, for example, without undue regard for heat sink space requirements. Another benefit of the high thermal conductivity is the ability to provide an accurate method of temperature equalization. For example, a heat pipe mounted between two opposing faces of an orbiting platform will enable both faces to maintain constant with equal temperatures, thus minimizing thermal stresses. The temperature control is a result of the capability of heat pipes to transport large quantities of heat very rapidly. This feature enables a source of varying flux to be kept at a constant temperature as long as the heat flux extremes are within the operating range of the heat pipe.

\section{Electronic and Electrical Equipment Cooling}

Miniaturization of electronic components is accompanied by increased demands on heat dissipation systems due to the increased density of the components. For example, the digital computer has evolved from a massive system that filled an entire room to a unit which can be stored in a small briefcase. However, the overheating problems associated with the dense packing of heat-generating integrated circuit chips used in the computer (CPU and GPU Cooling) have escalated dramatically. Since the reliability of these and other types of electronic components is sensitive to their operating temperature, steps have been taken to improve heat dissipation by using heat pipes. Other applications to electronic cooling have included rectifiers, thyristors, transistors, traveling wave collectors, audio and RF amplifiers and high density semiconductor packages.

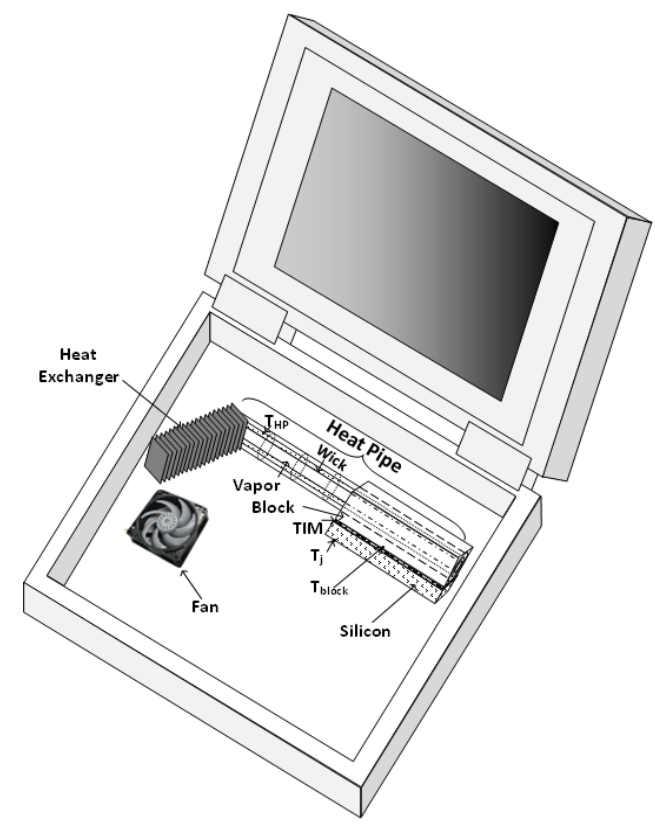

Fig. 53 Remote heat exchanger using a heat pipe embedded in a block for a laptop computer.

After the introduction of the Pentium processor in 1993, the processor performance and power consumption trend has significantly increased annually. In the year 2000, the heat flux was approximately 10-15 $\mathrm{W} / \mathrm{cm}^{2}$, eventually reaching $120-150 \mathrm{~W} / \mathrm{cm}^{2}$ in 2010 . The average power consumption for laptop/notebook computers is currently between 25-50 W, while desktops and servers consume between 80 and $150 \mathrm{~W}$. Regardless of components, power level, or type of computer/processor, as electronics are packed into smaller volumes, it is important to optimize the thermal management components with higher cooling rates.
Presently, almost all laptop/notebook computers use a heat pipe remote heat exchanger (RHE), where a heat pipe is used to transfer heat from the processor to the heat exchanger. Heat pipes have been an important part of laptop/notebook computer cooling systems and will remain so for the foreseeable future. Figure 53 shows a simplified typical layout of a heat pipe remote heat exchanger for laptop/notebook computers, using the heat pipe embedded inside a metal block (CPU case) over the silicon (die). For simplicity, a single heat sink is shown in Fig. 53 to illustrate the concept of thermal resistance optimization for personal computers.

The overall thermal resistance of this system is presented by the following equation:

$$
Q=\text { Heat dissipation }(W)=\frac{T_{j}-T_{\infty}-T_{s y s}}{R_{j-\infty}}
$$

where

$\mathrm{R}_{\mathrm{j}-\infty}=\mathrm{R}_{\mathrm{Si}}+\mathrm{R}_{\mathrm{TIM}}+\mathrm{R}_{\mathrm{e}}+\mathrm{R}_{\mathrm{c}}+\mathrm{R}_{\mathrm{a}}+\mathrm{R}_{\mathrm{HT}-\infty}$

$\mathrm{T}_{\mathrm{j}}=$ Junction temperature $\left[{ }^{\circ} \mathrm{C}\right]$

$\mathrm{T}_{\infty}=$ Ambient temperature $\left[{ }^{\circ} \mathrm{C}\right]$

$\mathrm{T}_{\text {sys }}=$ Impact of other energy sources in the system $\left[{ }^{\circ} \mathrm{C}\right]$

$\mathrm{R}_{\mathrm{j}-\infty}=$ Thermal resistance of the CPU die to ambient $\left[{ }^{\circ} \mathrm{C} / \mathrm{W}\right]$

$\mathrm{R}_{\mathrm{Si}}=$ Thermal resistance of silicon (microprocessor package) $\left[{ }^{\circ} \mathrm{C} / \mathrm{W}\right]$

$\mathrm{R}_{\mathrm{TIM}}=$ Thermal resistance through thermal interface material (TIM) $\left[{ }^{\circ} \mathrm{C} / \mathrm{W}\right]$

$R_{e}, R_{c}, R_{a}=$ The thermal resistances for the evaporator, condenser, and adiabatic section of the heat pipe, respectively.

$\mathrm{R}_{\mathrm{HT}-\infty}=$ Thermal resistance of heat exchanger to ambient $\left[{ }^{\circ} \mathrm{C} / \mathrm{W}\right]$

The thermal resistances of both the evaporator and condenser sections of the heat pipe are much higher than the adiabatic sections. Figure 54 (Machiroutu et al., 2006) shows a simple pie chart with fractional distributions of various thermal resistances for a heat pipe remote heat exchanger technology for laptop computers. Machiroutu et al. (2006) also showed that the overall thermal resistances presented in Fig. 54 can be reduced by $17 \%$ by reducing the thermal resistances of the evaporator and condenser sections.

Mochizuki et al. (2007) presented the various typical CPU thermal resistances versus heat dissipation (Fig. 55) by assuming a junction temperature of $100^{\circ} \mathrm{C}$, outside ambient temperature of $35^{\circ} \mathrm{C}$, and a system temperature rise of $10^{\circ} \mathrm{C}$. Mochizuki et al. (2006) presented a number of potential future cooling technologies for higher power cooling chips, including vapor chambers and loop heat pipes (LHPs) for desktop computers and servers. Figure 56 (Mochizuki et al., 2006) fins are soldered directly to the vapor chamber and proposed to replace the solid copper metal interface heat spreaders (IHS) with a two-phase micro-channel vapor chamber. Wu et al. (2011) proposed a cold energy storage system using wickless thermosyphons for cooling large scale data centers $(8800 \mathrm{~kW})$.

Annular heat pipes are proposed for use in the fusing units of copy machines by some copy machine manufacturers as heat drums for fast thermal response and uniform fusing (Jalilvand et al., 2006). The proposed annular heat pipe is composed of two unequal diameters, where the evaporation and condensation is separated in the radial direction so that the heat is transferred in the radial direction.

While miniaturization is not a significant factor in large-scale electrical equipment, the application of heat pipes to this area is important due to the increase in efficiency when the components operate at lower temperatures (Oslejsek and Polasek, 1976; Giessler et al., 1987; Momose et al., 1987; Alonso and Perez, 1990).

Electric motors have been designed which incorporate heat pipes around the periphery of the rotor for cooling during operation. Another design replaced the solid motor shaft with an on-axis rotating heat pipe with an internal taper for cooling. These designs removed heat from the interior of the electric motor so that the bearings operated at a lower temperature, which increased efficiency. Also, since the resistance of 
the electric windings decreases with temperature, less power was required to maintain a particular load. Similarly, circuit breakers and electric transformers designed with heat pipe cooling benefit from the decrease in internal temperature.

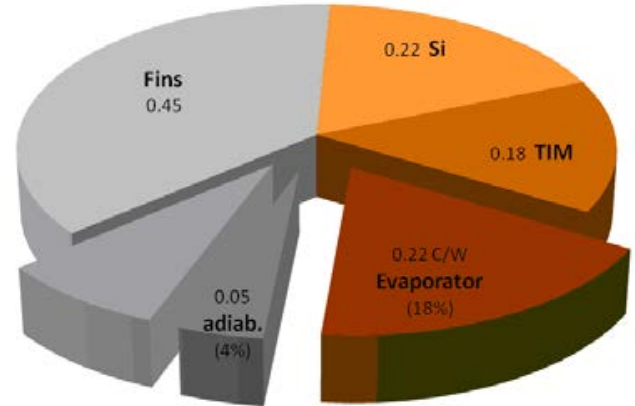

Fig. 54 Pie chart showing component thermal resistances of a heat pipe remote heat exchanger for a laptop PC (Machiroutu et al., 2006).

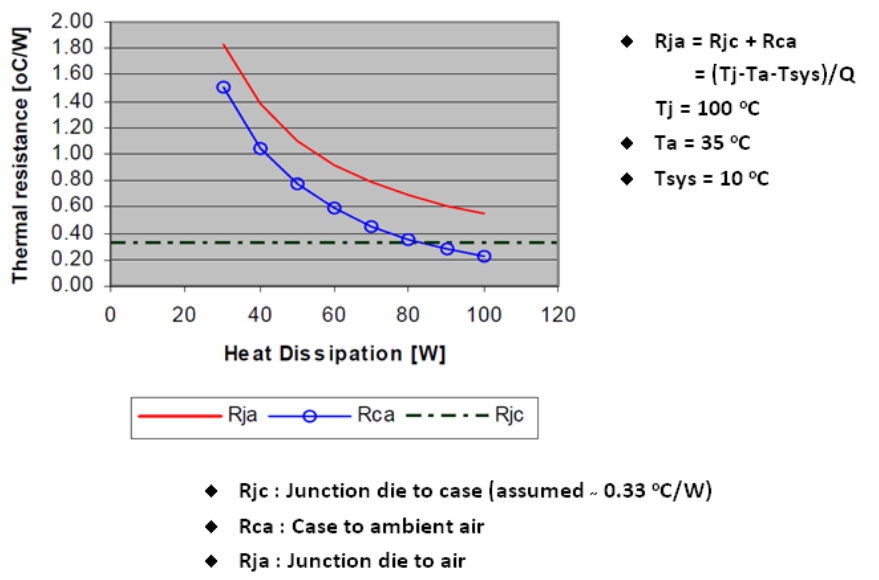

Fig. 55 Various typical CPU thermal resistances versus heat dissipation (Mochizuki et al., 2007).

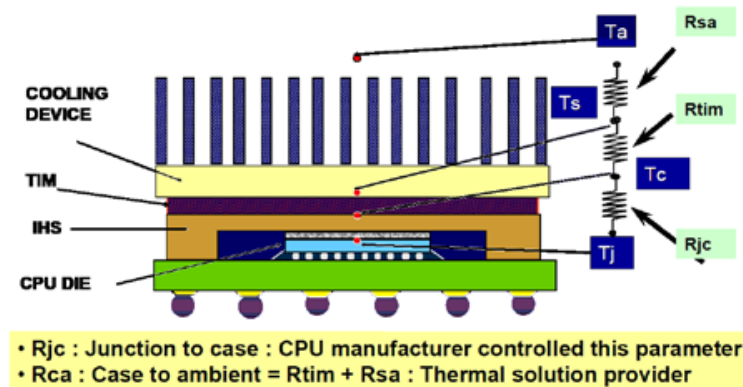

Fig. 56 Thermal solution integration for desktop and servers (Mochizuki et al., 2006).

Underground power transmission cables that are placed close to hot water or steam pipes are sometimes subjected to limitations in the maximum permissible current due to thermal interference. Therefore, it is advantageous to place maintenance-free cooling systems using heat pipes at these locations. Several heat pipes are placed at the hot spot along the direction of the cable, which are bent so that the condenser sections are above ground or in the soil away from the heated section (Iwata et al., 1984). The two methods of removing heat, either by natural convection to the atmosphere or by conduction to the soil, provide sufficient cooling so that higher current loads are capable of being provided to the user.

\section{Energy Systems}

With home heating costs increasing, more attention has been focused on the use of heat pipes to collect solar energy (Bienert, 1973; Roberts, 1978). A relatively simple design incorporates a bank of inclined thermosyphons exposed to the south side of a residence. Solar energy is absorbed and transported into the living space, where it is convected to the interior air or stored in a water tank for later use. During the night, the thermosyphons essentially act as thermal diodes, since the only way heat can be transferred from the interior to the outside is by axial conduction through the pipe walls. A similar design can be used for desalinating sea water using solar energy. In this application, however, a heat pipe would be positioned at the focal point of a trough-shaped parabolic reflector in order to generate the high temperatures and heat fluxes necessary for desalination.

Singh et al. (2011) presented the design and characteristics of various energy conservation systems and renewable energy systems utilizing heat pipes as the thermal control mechanism. A wide range of energy systems including data center cooling, agricultural products cold storage, bakery waste heat recovery and automotive dashboard cooling were discussed. It was argued that zero emission and economical advantages can be achieved by using thermosyphon and capillary pumped loop.

Concentrating photovoltaic (PV) systems use low-cost optical systems such as the Fresnel lens, a mini-reflecting mirror that can concentrate solar intensity from 200 to 1000 suns. The concentrated solar energy delivered from the solar cell is from 20 to $100 \mathrm{~W} / \mathrm{cm}^{2}$. Part of the energy is directly converted to electricity, while the remainder is removed as waste heat. Heat pipe cooling systems (Fig. 57) were developed to passively remove the high heat flux at the PV cell and reject it to the ambient by natural convection (Akbarzadeh and Wadowski, 1996; Gi and Maezawa, 2006; Anderson et al., 2008).

Heat transfer devices and methodologies for novel thermal energy storage systems (TES) for various applications including concentrating solar power (CSP) generation systems using latent heat phase change materials (PCMs) are in great demand in the energy field. However, latent heat thermal energy storage PCMs, despite their great potential, suffer from low thermal conductivity. Faghri (1990; 1991) invented two methods (Figs. 58 and 59) to significantly increase the thermal conductivity of PCMs by embedding micro or conventional heat pipes in the PCM for applications in thermal energy storage systems and heat exchangers.

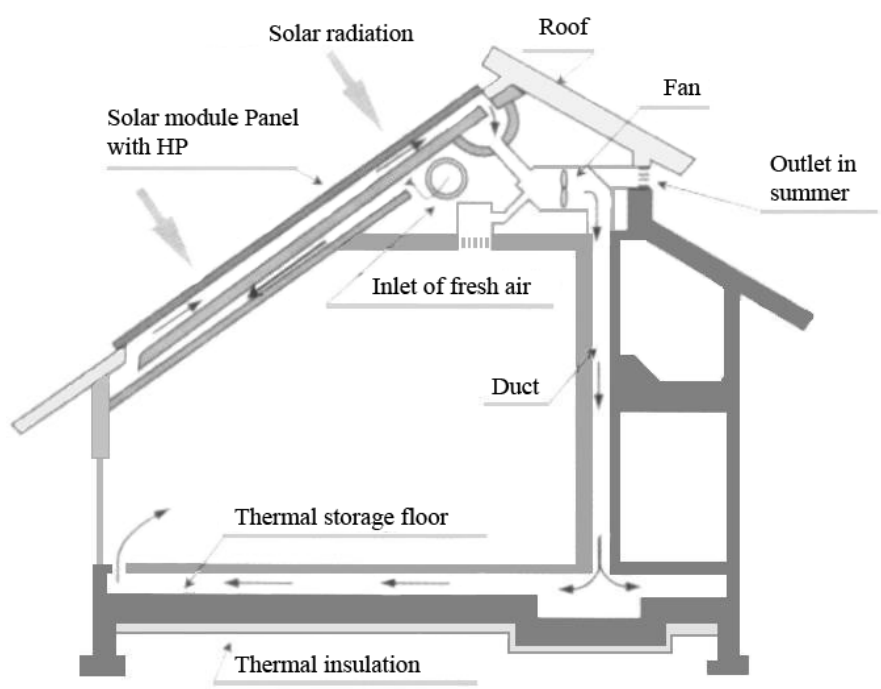

Fig. 57 Solar house which has an energy collection mechanism (Gi and Maezawa, 2006). 


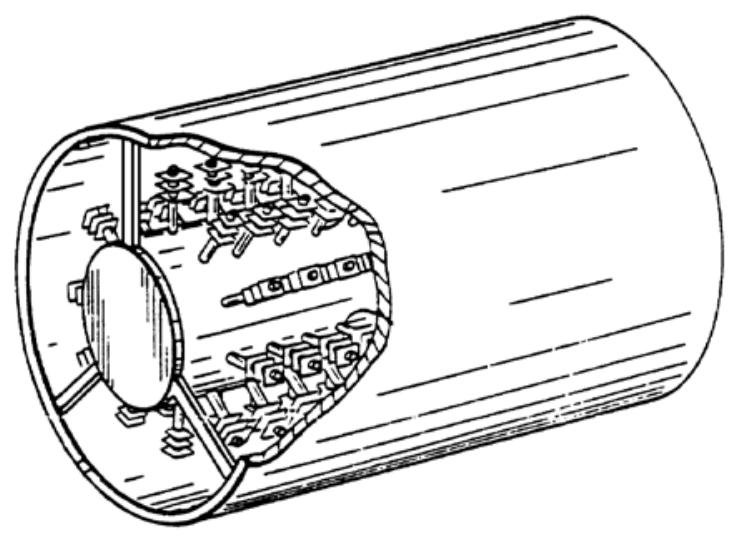

Fig. 58 Thermal energy storage system (Faghri, 1990).

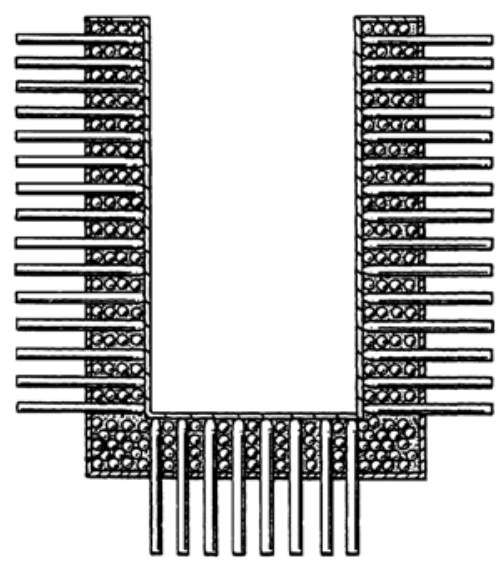

Fig. 59 Micro heat pipe exchanger (Faghri, 1991).

The effect of heat pipes to improve the performance of latent heat thermal energy storage systems has been investigated experimentally and theoretically (Shabgard et al., 2010; Robak et al., 2011; Nithyanandam and Pitchumani, 2012). The experimental results of Robak et al. (2011) showed $60 \%$ and more than $100 \%$ increase in the heat transfer rates during melting and solidification, respectively, compared to the fin-assisted storage systems as well as non-fin, nonheat pipe configurations. Shabgard et al. (2010) developed a thermal network modeling approach for computationally-efficient simulation of such heat pipe-assisted latent heat thermal energy storage systems. The modeling results also showed substantial heat transfer enhancements during charging and discharging of latent heat thermal energy storage systems equipped with heat pipes. The developed thermal network model was later extended to simulate a large scale heat pipe-assisted cascaded latent heat thermal energy storage system for CSP applications (2012).

Fuel Cells are versatile energy conversion devices with numerous potential applications: large electrical plants, stationary electricity generation, vehicle propulsion and small portable power (Faghri and Guo, 2005; 2008). In recent years, proton exchange membrane fuel cells (PEMFCs), direct methanol fuel cells (DMFCs), solid oxide fuel cells (SOFCs) and molten carbonate fuel cells (MCFCs) have become the major types of fuel cell technologies that draw the most attention for commercialization. Heat pipe technology is beneficial for fuel cell development in two main ways: using heat pipes in fuel cells as thermal management components and using the heat pipe concept in the fuel cell systems to achieve passive high-effective fluids-thermal management. Most fuel cell systems produce electrical energy at high efficiencies that may range from $40 \%$ to $60 \%$ based on the lower heating value (LHV) of the fuel. For example, a fuel cell operating at
$1.0 \mathrm{~kW}$ and $50 \%$ efficiency generates $1.0 \mathrm{~kW}$ of waste heat. This heat may be dissipated by convection, conduction, radiation or phase change. The heat generated in a fuel cell stack may be dumped to the atmosphere, but often, it is used in other system components that require heat. In some cases, the heat is used to run a thermodynamic cycle for additional power generation. Heat pipes can be utilized in fuel cell systems for thermal management purposes which allow for effective use of the fuel cell byproduct, heat, leading to a substantial increase in heat transfer and overall system efficiency (Faghri and Guo, 2005; 2008).

The matter of heat generation in fuel cell stacks presents challenges for thermal management. Stacks operating at $40 \%$ to $60 \%$ efficiency generate heat at the same rate to more than twice the rate of electric generation. Due to changes in mass concentration, temperature gradients, and in some cases, phase change throughout the stack, the heat generation is not uniform. This non-uniform heat generation further increases thermal gradients in the stack. Increasing the mobility of the heat is a challenge that, if met, leads to three main benefits: (1) The risk of stack failure due to overheating is reduced, (2) The stack operates more closely to its design temperature, resulting in better power density and efficiency, and (3) The heat can be reused, perhaps for reactant preheating, prevaporization, combined cycle operation, or cogeneration. For example, the heat pipe embedded with a bipolar plate (Faghri and Guo, 2008) is an innovative approach that would increase heat transfer in fuel cell stacks while requiring significantly smaller thermal gradients and much smaller volumes and weights than alternative methods. As conceptualized in Fig. 60, a bipolar plate is fabricated with holes, into which micro heat pipes are inserted and bonded. The micro heat pipes that are shown in Fig. 60 are embedded in an axial and transverse direction.

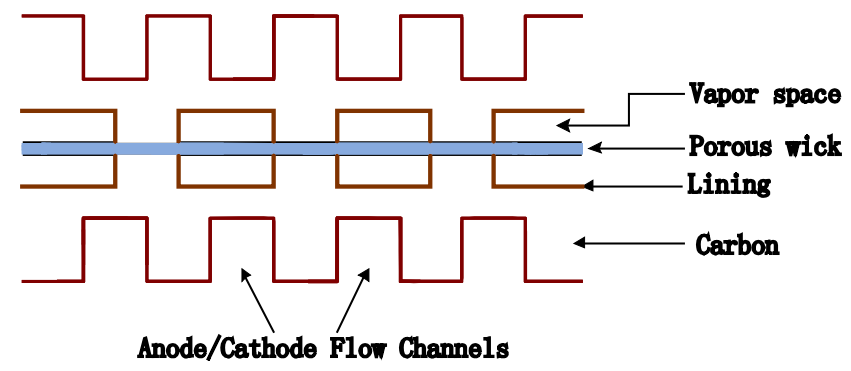

Fig. 60 Bipolar plate integrated heat pipe (Faghri and Guo, 2008).

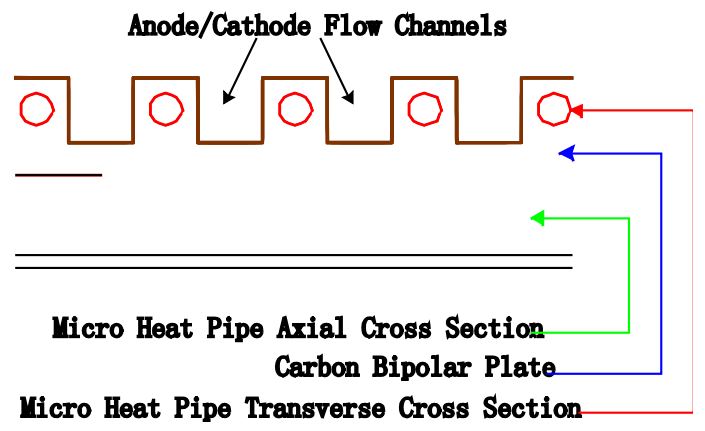

Fig. 61 Micro heat pipe embedded bipolar plate (Faghri and Guo, 2008).

Another method for thermal control in the fuel cell stack is presented with the integrated bipolar plate flat heat pipe (Faghri and Guo, 2008). For example, as conceptualized in Fig. 61, a carbon bipolar plate contains a flat heat pipe. A challenge for developing this component is sealing the heat pipe. Due to the permeability of the carbon, two halves of the bipolar plates are coated with a liner--silver activated brazing alloy (ABA). Also in the enclosure is a porous wick 
of metal foam, felt, or porous carbon. The two halves are then sealed together, perhaps with brazing in an inert gas. The structure of the interior is designed to allow good electrical conductivity, thermal conductivity to the wick, and structural support, while the working fluid is typically at a pressure different than the surroundings.

Passive DMFC technology uses various capillary approaches to manage methanol and water without the need for a complex microfluidic subsystem (Fig. 62) (Guo and Faghri, 2006a; 2006b; Faghri and Guo, 2005; 2009). At the core of this new technology is a unique passive system that uses the heat pipe concept for fuel delivery. Furthermore, the fuel cell is designed for both passive water management and effective carbon dioxide removal. The passive components that are critical to the fuel cell design are the fuel delivery, and air-breathing and water recirculation systems. The passive fuel delivery system stores pure methanol, which can be mixed with water in situ without the use of a pumping system, and can be passively supplied to the fuel cell anode at an optimal concentration. Since water is needed in the anode for the methanol reaction to occur, the water created in the cathode can be passively supplied to the anode. This water recirculation, in conjunction with passive methanol fuel delivery, can dramatically extend the operation time of the fuel cell per refueling. The passive mass transfer concept (wick structure) developed in heat pipe technology is an effective approach for mass transfer management in various fuel cell technologies. The proposed DMFC technologies developed were operated passively, without moving parts, which resulted in a highly reliable system. Due to their significantly longer charging life, passive miniature DMFC system are seriously being considered for replacing the battery for applications such as cell phones, digital cameras and laptops.

Current dish/Stirling systems use directly illuminated receiver design in which the concentrated solar radiation is absorbed by tubular receiver which also serve as the heater tubes of the Stirling engine. Replacing the directly illuminated receiver design with spherical heat pipe receivers improves the performance by about 20\% (Andraka et al., 1996). Two primary reasons contribute to this improvement; (a) in the heat pipe receiver the temperature difference between the output gas temperature and the receiver peak temperature is much less than the directly illuminated receiver due to nearly isothermal operation of the heat pipe. This allows higher operating temperatures resulting in higher conversion efficiencies, and (b) in heat pipe receiver heat is transferred to the Stirling engine by condensation on the entire surface of the heater tubes, whereas in directly illuminated receivers only one side of the tubes is irradiated. Hence the "dead volume" of the engine is decreased and higher compression ratios can be achieved which result in greater system efficiency (Andraka et al., 2012).

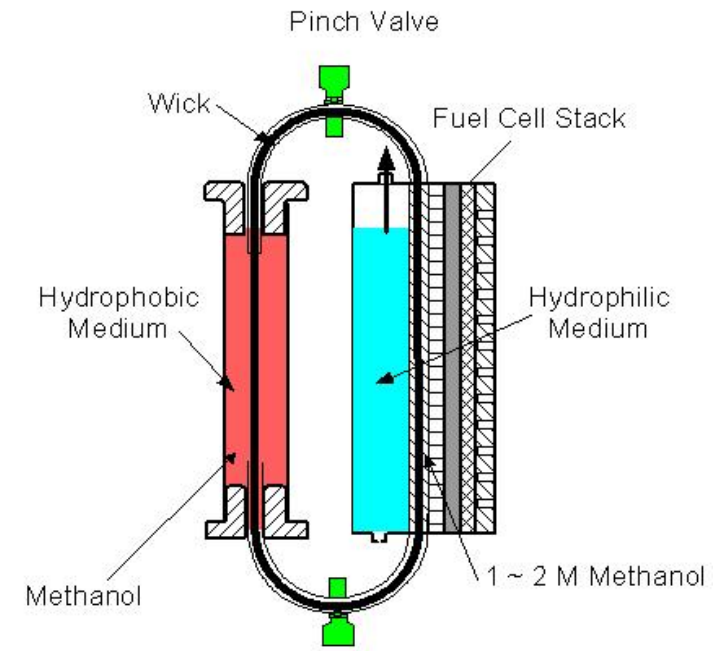

Fig. 62 Passive direction methanol fuel cell using heat pipe concept (Faghri and Guo, 2008).

\section{Aerospace and Avionics}

Heat pipes are very attractive components in the area of spacecraft cooling and temperature stabilization due to their low weight penalty, zero maintenance, and reliability. Structural isothermalization is an important problem with respect to orbiting astronomy experiments due to the possible warpage from solar heating. During orbit, an observatory is fixed on a single point such as a star. Therefore, one side of the spacecraft will be subjected to intense solar radiation, while the other is exposed to deep space. Heat pipes have been used to transport the heat from the side irradiated by the sun to the cold side in order to equalize the temperature of the structure. Heat pipes are also being used to dissipate heat generated by electronic components in satellites.

Early experiments of heat pipes for aerospace applications were conducted in sounding rockets which provided six to eight minutes of 0 -g conditions. In 1974, ten separate heat pipe experiments were flown in the International Heat Pipe Experiment (McIntosh et al., 1976). Also in 1974, heat pipe experiments were conducted aboard the Applications Technology Satellite-6 (Kirkpatrick and Brennan, 1976), in which an ammonia heat pipe with a spiral artery wick was used as a thermal diode. With the use of the space shuttle, flight testing of prototype heat pipe designs continued at a much larger scale. In 1983, on the eighth space shuttle flight, a 6-ft. monogroove heat pipe with Freon 21 as the working fluid was flight tested as a heat pipe radiator (Rankin, 1984). The Space Station Heat Pipe Advanced Radiator Element, which consisted of a $50-\mathrm{ft}$. long high capacity monogroove heat pipe encased in a radiator panel, was flown on the space shuttle in 1989 (Brown et al., 1990), and during a 1991 shuttle flight, two heat pipe radiator panels were separately flight tested (Brown et al., 1991). Heat pipe thermal buses were proposed which facilitate a connection between heat-generating components and external radiators (Morgownik and Savage, 1987; Amidieu et al., 1987; Peck and Fleischman, 1987). The components may be designed with a clamping device which can be directly attached to the heat pipe thermal bus at various points in the spacecraft. In 1992, two different axially grooved oxygen heat pipes were tested in a Hitchhiker Canister experiment that was flown aboard the Shuttle Discovery (STS-53) by NASA and the Air Force to determine startup behavior and transport capabilities in micro gravity (Brennan et al., 1993).

An advanced capillary structure which combined re-entrant and a large number of micro grooves for the heat pipe evaporator was investigated in microgravity conditions during the 2005 FOTON-M2 mission of the European space agency (Schulze et al., 2007). Swanson (2007) presented the NASA thermal technical challenges \& opportunities for the new age of space exploration with emphasis on heat pipes and two phase thermal loops.

A heat pipe laser mirror has been fabricated in order to test the feasibility of this technology compared to water-cooled or uncooled mirrors for high power lasers (Barthelemy et al., 1978). Presently, uncooled mirrors are limited to only a few seconds of use prior to distortion from thermal overheating. Water-cooled mirrors have longer service times, but are subjected to high internal pressures causing distortion, which must be removed by polishing under pressure. A copper-water heat pipe mirror was constructed, which was not affected by the problems associated with conventional mirrors due to the heat pipe action. The experiments conducted used a $10 \mathrm{~kW}$ carbon dioxide laser, and it was found that heat pipes can be used with success if the heat pipe is sufficiently preheated.

Thermal diodes have been proposed for use in cooling lowtemperature sensors, such as an infrared detector in low subsolar earth orbits (Williams, 1978). This type of heat pipe was proposed due to its characteristic of being able to cool the instrument during normal operation, but effectively insulating it when exposed to an external heat flux. One type of thermal diode uses a liquid reservoir at the evaporator end of the heat pipe, which does not communicate with the wick structure. During normal operation, the reservoir is empty. If the condenser is subjected to an external heat flux, however, the working 
fluid condenses in the reservoir, causing the wick to dry out. This results in the heat pipe becoming an insulator, because heat can only be conducted axially through the thin pipe wall. Heat pipes have also been qualified and/or used for thermal control applications in avionic systems including aircrafts with more electric architectures.

Radioisotope Stirling systems are proposed to replace the radioisotope thermoelectric generating systems as a long-lasting electricity generation solution in space missions due to their higher efficiency (Thieme and Schreiber, 2003). In the current radioisotope Stirling systems if the Stilrling engine stops, the heat removal from the system would be ceased and the insulation will be spoiled to prevent damage to the clad fuel, but the mission will also be ended. Alkalimetal variable conductance heat pipes are proposed and tested to allow multiple stops and restarts of the Stirling engine (Tarau and Anderson, 2010). In the proposed design, the evaporator of the heat pipe is connected to the heat generation module. During the normal operation, the heat is transferred from the heat generation unit to the heater head of the Stirling engine by evaporation and condensation of the sodium working fluid. When the Stirling engine stops, the temperature and pressure of the heat pipe working fluid increases. The higher pressure inside the heat pipe compresses the non-condensable gas and opens up a radiator through which the heat is dissipated and the system temperature stabilizes. Once the Stirling engine restarts, the temperature and pressure drop and the radiator is covered by the non-condensable gas to prevent unwanted heat rejection.

\section{Heat Exchangers and Heat Pumps}

Increases in the cost of energy have promoted the use of heat pipe technology in industrial applications. Due to their high heat transfer capabilities with no external power requirements, heat pipes are being used in heat exchangers for various applications. In the power industry, heat pipe heat exchangers are used as primary air heaters on new and retrofit boilers. The major advantages of heat pipe heat exchangers compared to conventional heat exchangers are that they are nearly isothermal and can be built with better seals to reduce leakage. Heat pipe air heaters should also be cheaper than conventional tubular heat exchangers, as they are smaller and can be shipped in a small number of modules. Heat pipe heat exchangers can serve as compact waste heat recovery systems which require no power, a low pressure drop and are easy to install on existing lines. Heat pipe heat exchangers can be categorized into gas-gas, gas-liquid, and liquid-liquid type heat units. Among these three, gas-gas heat pipe heat exchangers have the widest application in industry. A gas-gas heat pipe exchanger consists of a group of externally finned heat pipes which reclaim waste heat (Hassan and Accensi, 1973; Holmes and Field, 1986). These units eliminate cross-contamination due to the solid wall between the hot and cold gas streams. Also, the heat pipe design is totally reversible (heat can be transferred in either direction). Gas-gas energy recovery units typically fall into three categories: heat recovery in air-conditioning systems (low temperatures), recovery of excess process heat for space heating (moderate temperature), and recovery of waste heat from high temperature exhaust streams for reuse in the process (preheating of combustion air, for example). The units for these applications vary in size and construction depending on the specific application, but many commercial models are now available that implement this heat pipe design.

Gas-liquid heat pipe exchangers are less commonly available than gas-gas models due to the fact that the present design of waste heat boilers is very efficient. In the past, exhaust heat from boilers was simply dispersed to the atmosphere. Figure 63 shows schematics for waste heat recovery with liquid-gas and gas-gas heat exchangers. Faghri (1993a) invented an innovative design for a centrifugal heat pipe vapor absorption heat pump (Fig. 64). The heat pipes in this heat pump system are disk-shaped, with one face partially or completely being the evaporator and the opposite face partially or completely being the condenser (Faghri, 1994). The wick is designed such that the centrifugal force aids in the delivery of the condensate to the evaporator. This design will significantly improve the heat and mass transfer characteristics of the rotating components of the vaporabsorption heat pump by increasing the heat pumping capacity that can be packaged in a given value. This results in a more efficient and compact vapor-absorption heat pump system.

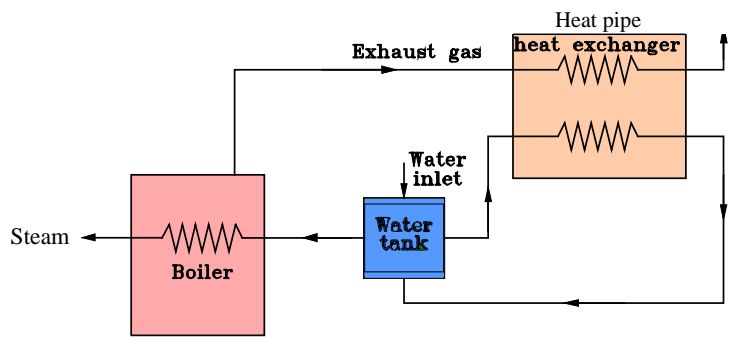

a) Liquid-gas heat pipe heat exchanger

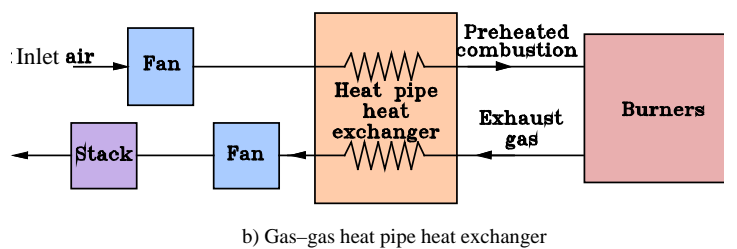

Fig. 63 Waste heat recovery using heat pipe heat exchangers.

\section{Gas Turbine Engines and the Automotive Industry}

The temperature limitation is one of the most crucial limiting factors related to the efficiency of a gas turbine aircraft engine or power gas turbine. An increased turbine inlet temperature decreases both the specific fuel and air consumption, while increasing efficiency. This desire for a high turbine inlet temperature, however, is often in conflict with materials available to withstand the high temperature. As a result, innovative cooling systems for hot-gas-path components are required. Among the hot-gas-path components, the first-stage rotor blade and nozzle guide vane require the most challenging cooling consideration. In addition to improving energy utilization efficiency, effective cooling could also drastically improve the reliability of high-speed rotating components. It has been observed that the creep life of turbine blades is reduced by half with every 10 to $15^{\circ} \mathrm{C}$ rise in metal temperature. Therefore, the temperature of the turbine blade must be kept within certain tolerable limits.

The primary cooling technology in use today for turbine blades and nozzle guide vanes (NGVs) is the film cooling technology. Since 1995, a number of efforts have been initiated to utilize the concepts of miniature, radially rotating, high-temperature heat pipes, for gas turbine blades and disk cooling. This also includes a series of experimental and numerical studies (Cao, 1996; 1997; 2010; Zuo et al., 1998). High temperature heat pipe cooling is a promising cooling technology for gas turbine hot components, such as first stage rotor blades, nozzle guide vanes, and rotor disks. This has the potential to significantly reduce the temperature of these hot components, allowing for a much higher gas turbine inlet temperature, while also reducing the consumption of highpressure compressor air.

A Stirling engine heated by sodium heat pipes has been constructed and tested (Alleau et al., 1984; 1987; Meijer and Khalili, 1990). This engine operates at highest efficiency when the thermal energy is supplied to it at a very constant temperature and high heat fluxes. Helium is heated to increase its pressure, which is used to drive pistons 
and a crankshaft for the generation of power from thermal energy. The sodium heat pipes deliver heat from a molten salt heat storage system to the gaseous helium which is used to drive the engine. The coupling of a Stirling cycle engine with sodium heat pipes can also be used in the direct conversion of solar energy.
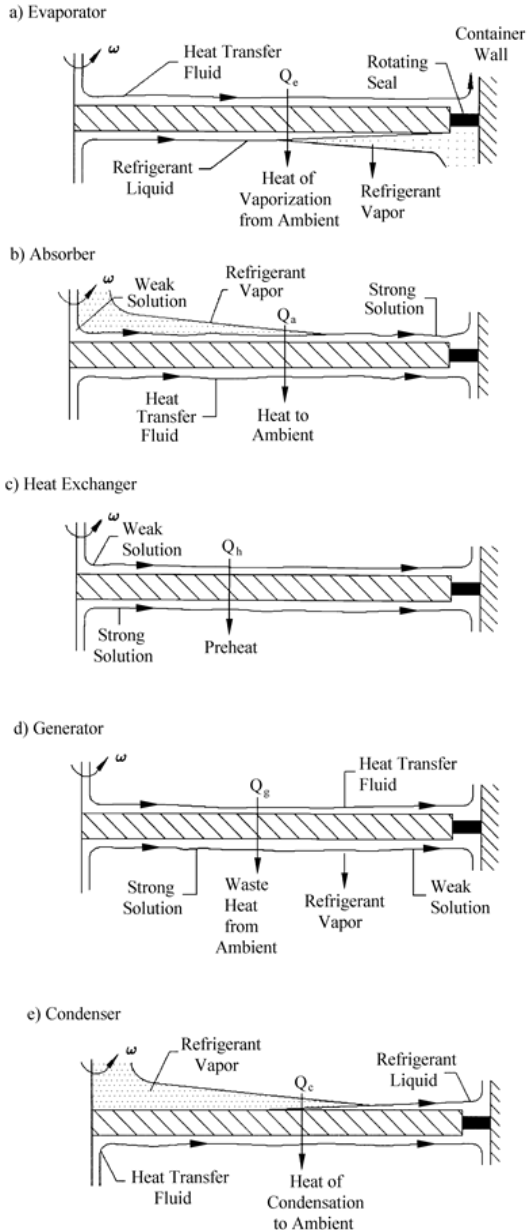

Fig. 64 Schematic of centrifugal heat pipe heat pump vapor-absorption cycle (Faghri, 1993a).

Nguyen et al. (1992) proposed a thermosyphon Rankine engine for power generation using solar and other available waste heat energy sources. The basis of the engine (Fig. 65) is the modification of a heat pipe to incorporate a turbine and thereby, making the system into a Rankine cycle engine to convert thermal energy to electrical energy.

Another potential application of heat pipes has been toward the cooling of vehicle brake systems (Maezawa et al., 1981). Normally, the brake pads and rotors of a conventional automobile brake system suffer greatly from the effects of elevated temperatures. Thermal cycling induces stresses and causes increased amounts of corrosion, which shorten the working lives of the rotors.

High temperatures at the rotor-pad interfaces cause embrittlement of the brake pad material, which also reduces the service life. Rotating and stationary heat pipes have been proposed to cool both the rotor and brake pads, which would result in lower, more uniform temperatures. The use of this development could also increase the service life of brake pads so that 'lifetime' pads, lasting the entire life of the automobile, may become a reality. Vibration/shock-tolerant capillary two-phase loops are developed to meet the cooling requirements of the high performance electronics of future military vehicles which undergo intense shocks during operation (Tang and Park, 2008). The shock tolerant feature is achieved by utilizing an in-situ sintered wick which also reduces the manufacturing costs.

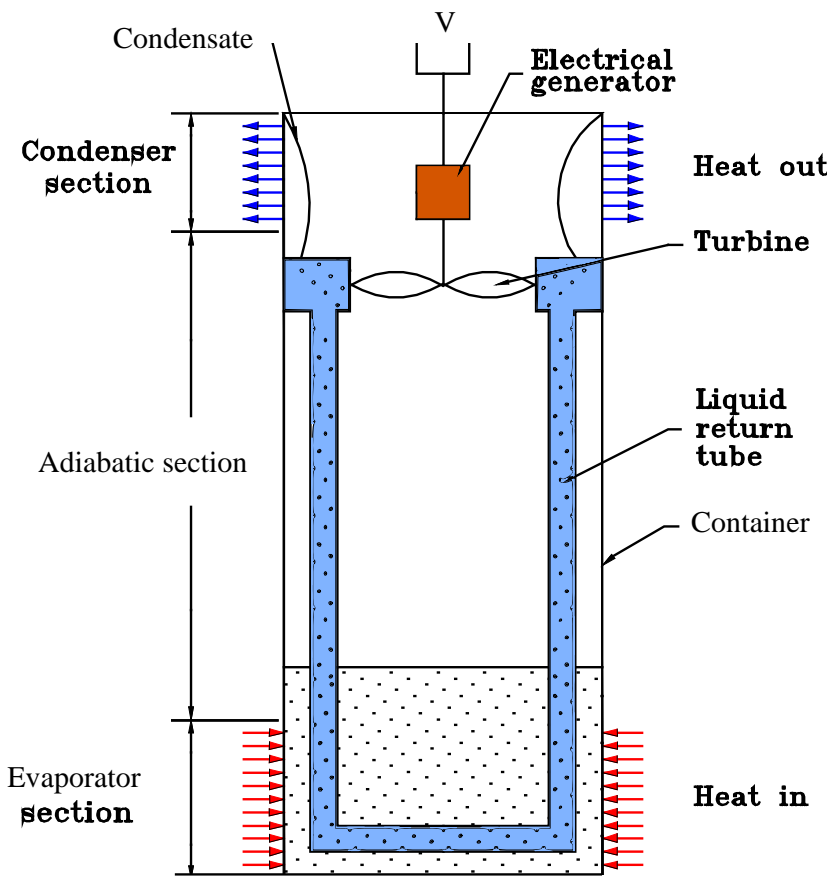

Fig. 65 Experimental thermosyphon Rankine engine (Nguyen et al., 1992).

\section{Production Tools}

An important application of heat pipes is in the field of die casting and injection molding (Winship, 1974; Reay, 1977). The most obvious use of heat pipes in this field is the removal of heat during the solidification process; however, heat pipes are also useful in minimizing thermal shock in the dies. Die casting involves introducing a material in molten form into a closed die. The material is cooled until it solidifies, the part is removed, and the process repeated. An important consideration is the time required for the material to cool into solid form, so most dies are water cooled. It is often difficult to cool inaccessible parts of the die, however, so heat pipes are used to cool these sections. These heat pipes can also be used to preheat the die to assure the continuous flow of molten material due to the reversible nature of heat pipes.

\section{Medicine and Human Body Temperature Control}

Another application is of heat pipes is related to human physiology. A surgical probe incorporating a cryogenic heat pipe is being used to destroy tumors in the human body (Basiulis, 1976). This type of surgery, where the tissue is frozen instead rather than irradiated, is beneficial because the surrounding tissue sustains practically no damage. Also, the surgery results in very little bleeding or pain. The cryoprobe is a hand-held device with a reservoir of liquid nitrogen and a 12-inch heat pipe extension, which is maintained at approximately 77 K for about one-half hour. Fletcher and Peterson (1997) invented a catheter using micro heat pipes that provide precise temperature control for treating diseased tissue.

Another application related to human physiology concerns the control of body temperature (Faghri et al., 1989b; Faghri, 1993b). In regions or occupations where humans are exposed to extreme temperatures, such as workers in polar regions or foundry workers, adverse health effects from these environments are evident. Frostbite on the extremities in cold regions and heat exhaustion in warm climates are very serious problems which must be handled with extreme care. These problems can be avoided with the use of gloves, socks, and suits in which heat 
pipes are placed in order to transfer heat either to or from parts of the body (Fig. 66). In cold climates, heat pipes could bring heat from the torso to the extremities such as the fingers, toes, and ears to prevent frostbite. Figure 67 shows a conceptual design for cold weather handwear with heat pipes, where body heat is transferred from the forearm to the fingers. In very hot environments, such as those experienced by fire fighters, a cold suit employing heat pipes could be developed which would be lighter and less bulky than the suits presently worn. This type of suit would also be beneficial in the respect that the wearer would be kept cooler, resulting in more time available for extracting people from a burning building, for instance.

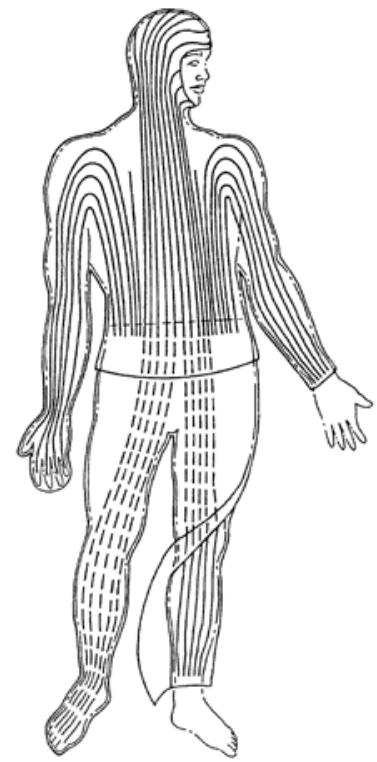

Fig. 66 Temperature regulation system for the human body using heat pipes (Faghri, 1993b).

Similar garments or blankets using heat pipes (Faghri, 1993b) could also be applied to medical patients whose own body temperature regulation system is impaired or not functioning. Patients with spinal cord injuries or people with Multiple Sclerosis often become overheated during hot weather because of the inability of the nervous system to control their body temperature. A heat pipe suit equipped with an external heat exchanger could significantly improve the quality of life of these patients by allowing them to be more exposed to the elements. Likewise, patients who are bedridden often become overly warm or cold. In some cases, a blanket with a single-phase fluid loop is placed on the patient for heating or cooling. Since this type of blanket is quite heavy due to the fluid loop, a heat pipe blanket has been proposed, which would decrease the weight and improve the heat transfer and temperature uniformity.
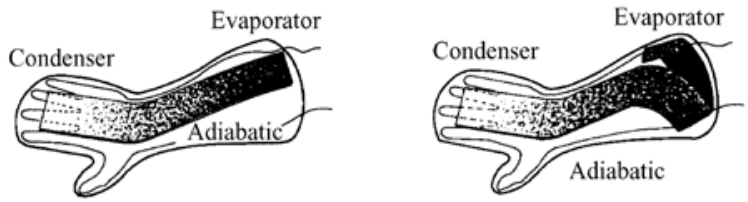

Mitten designs with heat pipe

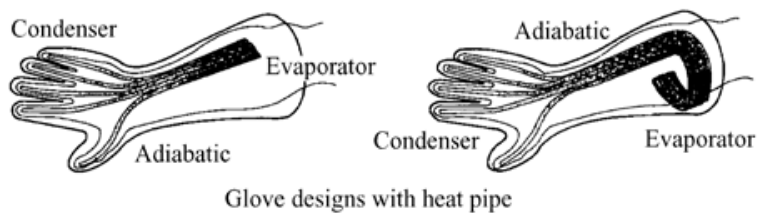

Fig. 67 Models of cold weather handware with heat pipes (Faghri et al., 1989b).
It has been found experimentally that when the temperature of the cauterizing forceps used in surgical operations increase above $80^{\circ} \mathrm{C}$, the tissue under operation tends to stick to the forceps. Small-diameter heat pipes are employed to precisely control the forceps temperature by removing heat from the forceps tip as well as the tissue (Bilski and Broadbent, 2010). The heat generated during cauterization evaporates the working fluid of the heat pipe. The vapor moves towards the cold section of the heat pipe where it dissipates its thermal energy content and condenses. Capillary action then returns the condensed liquid to the forceps tip. This technology represents the smallest known massproduced heat pipe assembly (with a diameter of $2.34 \mathrm{~mm}$ ) and makes it possible to passively control the temperature of forceps tips with diameters ranging from 0.5 to $4 \mathrm{~mm}$.

\section{Ovens and Furnaces}

One of the first applications of heat pipes (actually, two-phase closed thermosyphons) was in baking ovens (Anonymous, 1867). Normal flame-heated baking ovens warmed the firebrick in the firebox, which then conducted the heat to the baking chamber so that the baked food was not contaminated by the combustion products. With the advent of the heat pipe, heat was transferred to the baking chamber by the evaporation and condensation of the working fluid within the array of tubes. This arrangement was not only more efficient, saving up to 25 percent of the fuel normally needed, but also resulted in a more uniform oven temperature. A similar concept is the gas-fired restaurant griddle, which is a flat plate heat pipe separating the gas fire from the cooking surface (Basiulis, 1976). This provides a surface with an extremely uniform temperature, even with heavy food loading. It also has the benefit of a fast warm-up time from a cold start, and the efficiency is comparable to the above-mentioned baking oven. Other food processing equipment has been designed using heat pipe technology such as braisers, kettles, saucepans, and deep fat fryers (Lamp, 1978). High temperature furnaces have been developed for heat-treating, sintering, and other applications (Finlay et al., 1976; Brost et al., 1990). These furnaces are actually annular heat pipes with liquid-metal working fluids. The isothermal behavior of the interior of the annular heat pipe makes it ideal for use as a furnace. The temperature gradient across the length is very small, which is always a significant problem with conventional furnaces. Due to the operation of the heat pipe, only a small portion of the outer surface of the annular heat pipe needs to be heated. Upon insertion of a cold charge, the area in contact with the cold charge becomes the condenser. Annular heat pipe furnaces are also being used in the calibration of temperature measurement devices (Chengsheng et al., 1984; Bassani et al., 1990). Thermocouples, RTD's and thermistors have been calibrated using a variable conductance heat pipe furnace; the temperature of which was measured with a traceable platinum RTD. Optical pyrometers, which measure surface temperature from the emitted radiation, have also been calibrated with heat pipe blackbody sources.

\section{Permafrost Stabilization}

Permafrost stabilization is an important matter in designing the foundations of buildings or other structures in arctic regions. During the summer months, heat is conducted into the permafrost, which tends to melt the water trapped in the soil. Normally, this thawing would allow the foundation to sink or shift, thereby damaging the building. To avoid this problem, engineers responsible for the Trans-Alaskan pipeline placed heat pipes around the pilings of the pipeline supports (Fig. 68) (Waters, 1976). The heat from the soil adjacent to the pilings was dissipated to the ambient by the heat pipes, which maintained a permafrost bulb around the pilings throughout the year.

Mashiko et al. (1989) developed an artificial permafrost storage facility in Hokkaido, Japan (Fig. 69), where the evaporator of the heat pipe is buried underground and the condenser is exposed to the ambient. The heat pipe transfers the ground heat to the ambient in winter which freezes the soil. When the temperature rises in the spring, 
the heat is not transmitted from the ambient to the ground (thermal diode), so the frozen soil is kept throughout the year. The main feature of this system is that no power is required, and the temperature is kept constant for a long period of time.

\section{Manufacturing}

High temperature heat pipes have been proposed for use in the manufacturing of glass bottles (Brost et al., 1973). The glass bottle forming procedure starts by periodically dipping a steel piston into a steel form filled with molten glass. This forms a hollow glass tube, which is later blown into its final shape. The initial glass temperature is around $1100^{\circ} \mathrm{C}$ and the surface temperature of the piston needs to be kept around $600^{\circ} \mathrm{C}$. At higher piston temperatures, the glass will stick to the piston, and at lower temperatures, the glass viscosity increases, causing insufficient deformation during the forming process. Insufficient deformation is the cause of thin-walled bottles which contribute to the waste rate. A stainless-steel/potassium heat pipe was proposed and tested, and it was found that the heat pipe could be kept nearly isothermal. This resulted in a higher dipping frequency and a reduced amount of glass bottle waste.

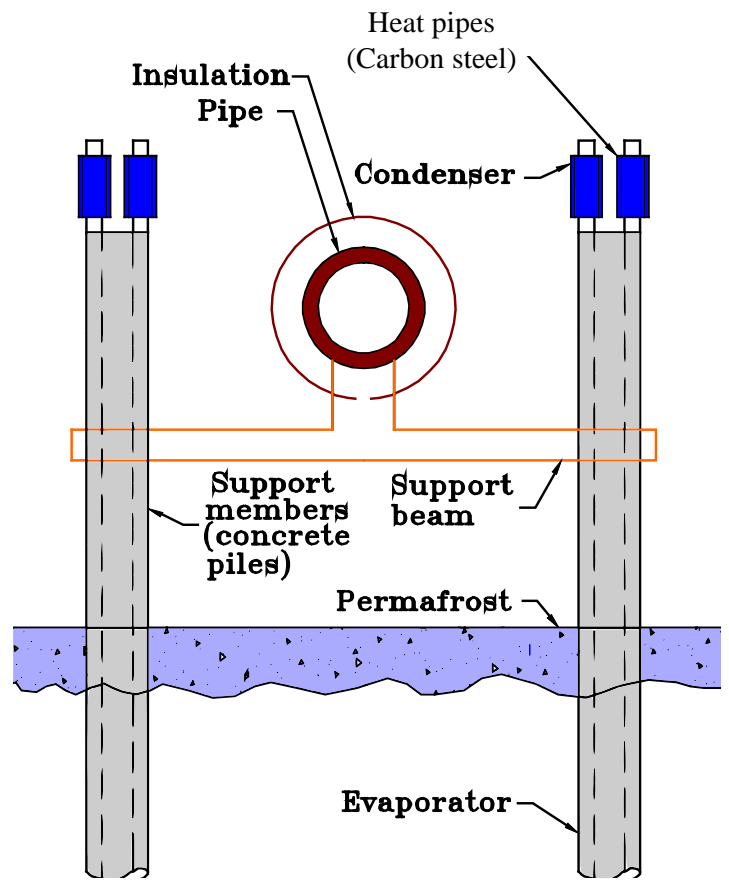

Fig. 68 Application of heat pipes for permafrost stabilization of structural supports on the Trans-Alaskan pipeline.

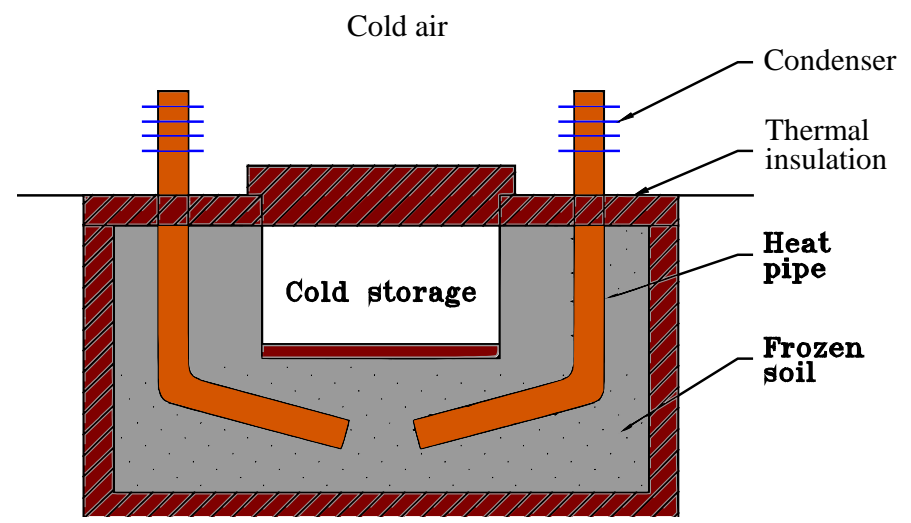

Fig. 69 Cold energy storage using heat pipes.

\section{Transportation Systems and Deicing}

Several innovations using heat pipe technology have been proposed which could improve the safety and reliability of transportation systems. Heat pipes have been used to melt the ice and snow on roadways, bridges, and aircraft runways by transporting geothermal heat stored in the ground to the pavement (Suelau et al., 1976; Bartsch et al., 1987). Shiraishi et al. (1992) presented several newly developed snow removal and deicing methods using heat pipes such as prevention of snow damage to support wires for telephone poles, a snow melting system for pavement, and a large scale snow melting system for roads in Japan. Corrugated, long heat pipes are utilized for these applications. People working on ships at sea during the winter months are plagued by the problems associated with icing. Anything exposed to the elements, such as the decks and handrails, are constantly icing over during the winter. The usual method of removing the ice is to use an axe or hatchet, which is extremely dangerous when the seas are rough. The potential for severe cuts or falling overboard is always present. To solve this problem, heat pipes have been incorporated into the decks and handrails to transport waste heat from the engine (Matsuda et al., 1981). This heat constantly melts the ice before large deposits are formed. Another similar deicing problem addressed by the use of heat pipes concerns navigation buoys (Larkin and Dubuc, 1976). Off the east coast of Canada, navigation buoys are frequently subjected to ocean spray and freezing temperatures, which results in the buoys capsizing due to the weight of the ice. Researchers have constructed a prototype buoy which was, in essence, a large ammonia thermosyphon heated from the sea. It was experimentally determined that the superstructure of the thermosyphon was kept free from ice, but that the auxiliary float seriously iced up.

\section{CONCLUSIONS}

An overview of various types of heat pipes is presented in this review. This includes heat pipe fundamentals, operations, heat transport limitations, and full simulation. This review provides a self contained document to design and simulate various types of heat pipes under different operating conditions. Numerical and analytical analyses of heat pipes have progressed significantly over the last several decades. State-of-the-art modeling is capable of predicting thermal performance under various operating conditions for conventional heat pipes. In particular, advances related to the full simulation of heat pipes under steady state, continuum transient and frozen startup operation for conventional heat pipes have been very successful, despite complex multiphase and multidomain transport phenomena in heat pipes. In general, it has been shown that heat pipe simulations must include conjugate heat transfer with the wall, wick and vapor, since these affect both the transient and steady state operating conditions. More fundamental works are needed to better understand the physical phenomena of pulsating heat pipes and loop heat pipes. An accurate simulation of liquid/vapor interface, including multiphase phenomena in various wicks, is important to accurately predict the heat transport limitation of heat pipes.

Acknowledgment: Copyright permission from ASME

\section{REFERENCES}

Anonymous, 1867, "The Paris Exhibition - Perkins' Portable Oven," The Engineer, p. 519.

Aghvami, M., and Faghri, A., 2011, "Analysis of Flat Heat Pipes with various Heating and Cooling Configurations," Applied Thermal Engineering, 31(14-15), 2645-2655.

http://dx.doi.org/10.1016/j.applthermaleng.2011.04.034 
Akbarzadeh, A., and Wadowski, T., 1996, "Heat Pipe-Based Cooling Systems for Photovoltaic Cells Under Concentrated Solar Radiation," Applied Thermal Engineering, 16(1), 81-87. http://dx.doi.org/10.1016/1359-4311(95)00012-3

Alario, J., Haslett, R., and Kosson, R., 1981, "The Monogroove High Performance Heat Pipe," AIAA-81-1156, AIAA 16th Thermophysics Conference, Palo Alto, CA.

Alario, J., Haslett, R., and Kosson, R., 1982, "The Monogroove High Performance Heat Pipe," Progress in Astronautics and Aeronautics, 83, 305-324.

Alario, J. P., 1984, "Monogrove Heat Pipe Radiator Shuttle Flight Experiment: Design, Analysis, and Testing," SAE-84-0950, Proceedings of the 14th Intersociety Conference on Environmental systems, San Diego, CA.

Alleau, T., Bricard, A., Chabanne, J., Kermorgant, H., and de Lallee, J., 1984, "Sodium Heat Pipes for Thermal Energy Supply of a Stirling Engine," Proceedings of the 5th International Heat Pipe Conference, Tsukuba, Japan, 54-58.

Alleau, T., Bricard, A., and Thouvenin, A., 1987, "Stirling Engine Coupled with a Sodium Boiler," Proceedings of the 6th International Heat Pipe Conference, Grenoble, France, 748-752.

Alonso, G., and Perez, R., 1990, "Cooling of Power Transformers with Two-Phase Thermosyphons," Proceedings of the 7th International Heat Pipe Conference, Minsk, USSR.

Ambirajan, A., Adoni, A. A., Vaidya, J. S., Rajendran, A. A., Kumar, D., and Dutta, P., 2012, "Loop Heat Pipes: A Review of Fundamentals, Operation, and Design," Heat Transfer Engineering, 33(4-5), 387-405. http://dx.doi.org/10.1080/01457632.2012.614148

Amidieu, M., Moscheti, B., and Tatry, M., 1987, "Develpement of a Space Deployable Radiator Using Heat Pipes," Proceedings of the 6th International Heat Pipe Conference, Grenoble, France, 380-385.

Anderson, W. G., Dussinger, P. M., Sarraf, D. B., and Tamanna, S., 2008, "Heat Pipe Cooling of Concentrating Photovoltaic Cells," 33rd IEEE Photovoltaic Specialists Conference, San Diego, CA. http://dx.doi.org/10.1109/PVSC.2008.4922577

Anderson, W. G., Bonner, R. W., Dussinger, P. M., Hartenstine, J. R., Sarraf, D. B., and Locci, I. E., 2007, "Intermediate temperature fluids life tests - Experiments," Collection of Technical Papers - 5th International Energy Conversion Engineering Conference, 2, 926-941.

Anderson, W. G., and Tarau, C., 2008, "Variable conductance heat pipes for radioisotope stirling systems," Proceedings of STAIF 2008, 969, 679-688.

http://dx.doi.org/10.1063/1.2845031

Andraka, C. E., Rawlinson, K. S., Moss, T. A., Adkins, D. R., Moreno, J. B., Gallup, D. R., Cordeiro, P. G., and Johansson, S., 1996, "Solar Heat Pipe Testing of the Stirling Thermal Motors 4-120 Stirling Engine," SAND96-1424C, Proceedings of the 31st Intersociety Energy Conversion Engineering Conference, 2, 1295-1300.

http://dx.doi.org/10.1109/IECEC.1996.553903

Andraka, C. E., Rawlinson, K. S., and Siegel, N. P., 2012, "Technical Feasibility of Storage on Large Dish Stirling Systems," Sandia Report SAND2012-8352.
Barthelemy, R., Jacobson, D., and Rabe, D., 1978, "Heat Pipe Mirrors for High Power Lasers," Proceedings of the 3rd International Heat Pipe Conference, Paper No. 78-391, Palo Alto, CA.

Bartsch, G., Butow, E., and Schroeder-Richter, D., 1987, "Deicing of Road Surfaces Employing Heat Pipes Installed in the Ground-Water Layer," Proceedings of the 6th International Heat Pipe Conference, Grenoble, France, 715-720.

Basiulis, A., 1976, "Follow-up on Heat Pipe Applications," Proceedings of the 2nd International Heat Pipe Conference, Bologna, Italy, 473-480.

Bassani, C., Lighthart, J., Sciamanna, G., Marcarino, P., and Fernicola, V., 1990, "Gas Controlled Heat Pipes for Primary Temperature Measurements," Proceedings of the 7th International Heat Pipe Conference, Minsk, USSR.

Benner, S., Costello, F., and Ku, J., 1989, "SINFAC Simulation of a High-Power Hybrid CPL," AIAA-89-0316, Proceedings of the 27th Aerospace Sciences Meeting, Reno, NV.

Bienert, W., 1973, "Heat Pipes for Solar Energy Collectors," Paper No. 12-1, Proceedings of the 1st International Heat Pipe Conference, Stuttgart, Federal Republic of Germany.

Bilski, W. J., and Broadbent, J., 2010, "Feel the Heat: Thermal Design Trends in Medical Devices," $M D+D I$, 32(6).

Boo, J. H., and Chung, W. B., 2004, "Thermal Performance of a SmallScale Loop Heat Pipe with PP wick," Proceedings of the 13th International Heat Pipe Conference, Shanghai, China, 259-264.

Bowman, W. J., 1987, Simulated Heat Pipe Vapor Dynamics, Ph.D. Dissertation, Air Force Institute of Technology, Dayton, OH.

Brennan, P. J., Thienel, L., Swanson, T., and Morgan, M., 1993, "Flight Data for the Cryogenic Heat Pipe (CRYOHP) Experiment," AIAA-932735.

Brost, O., Groll, M., and Mack, H., 1990, "High-Temperature Lithium Heat Pipe Furnace for Space Applications," Proceedings of the 7th International Heat Pipe Conference, Minsk, USSR.

Brost, O., Groll, M., Neuer, G., and Schubert, K., 1973, "Industrial Applications of Alkali-Metal Heat Pipes," Paper No. 11-3, Proceedings of the 1st International Heat Pipe Conference, Stuttgart, Federal Republic of Germany.

Brown, R., Gustafson, E., Gisondo, F., and Hutchison, M., 1990, "Performance Evaluation of the Grumman Prototype Space Erectable Radiator System," AIAA Paper No. 90-1766.

Brown, R., Kosson, R., and Ungar, E., 1991, "Design of the SHARE II Monogroove Heat Pipe," AIAA 91-1359, Proceedings of AIAA 26th Thermophysics Conference, Honolulu, HI.

Cao, Y., 1996, "Rotating Micro/Miniature Heat Pipes for Turbine Blade Cooling Applications," AFOSR Contractor and Grantee Meeting on Turbulence and Internal Flows, Atlanta, GA.

Cao, Y., 1997, "A Feasibility Study of Turbine Disk Cooling by Employing Radially Rotating Heat Pipes," Final Report for Summer Faculty Research Program, Air Force Research Lab, Turbine Engine Division. 
Cao, Y., 2010, "Miniature High-Temperature Rotating Heat Pipes and their Applications in Gas Turbine Cooling," Frontiers in Heat Pipes (FHP), 1, 023002.

http://dx.doi.org/10.5098/fhp.v1.2.3002

Cao, Y., and Faghri, A., 1990, "Transient Two-Dimensional Compressible Analysis for High-Temperature Heat Pipes with Pulsed Heat Input," Numerical Heat Transfer; Part A: Applications, 18(4), 483-502.

http://dx.doi.org/10.1080/10407789008944804

Cao, Y., and Faghri, A., 1991, "Transient Multidimensional Analysis of Nonconventional Heat Pipes with Uniform and Nonuniform Heat Distributions," Journal of Heat Transfer, 113(4), 995-1002. http://dx.doi.org/10.1115/1.2911233

Cao, Y., and Faghri, A., 1992, "Closed-Form Analytical Solutions of High-Temperature Heat Pipe Startup and Frozen Startup Limitation," Journal of Heat Transfer, 114(4), 1028-1035.

http://dx.doi.org/10.1115/1.2911873

Cao, Y., and Faghri, A., 1993a, "Conjugate Modeling of HighTemperature Nosecap and Wing Leading-Edge Heat Pipes," Journal of Heat Transfer, 115(3), 819-822.

http://dx.doi.org/10.1115/1.2910765

Cao, Y., and Faghri, A., 1993b, "Simulation of the Early Startup Period of High-Temperature Heat Pipes from the Frozen State by a Rarefied Vapor Self-Diffusion Model," Journal of Heat Transfer, 115(1), 239246.

http://dx.doi.org/10.1115/1.2910655

Cao, Y., and Faghri, A., 1993c, "A Numerical Analysis of HighTemperature Heat Pipe Startup from the Frozen State," Journal of Heat Transfer, 115(1), 247-254.

http://dx.doi.org/10.1115/1.2910657

Cao, Y., and Faghri, A., 1994a, "Micro/Miniature Heat Pipes and Operating Limitations," Journal of Enhanced Heat Transfer, 1(3), 265274.

Cao, Y., and Faghri, A., 1994b, "Analytical Solutions of Flow and Heat Transfer in a Porous Structure with Partial Heating and Evaporation on the Upper Surface," International Journal of Heat and Mass Transfer, 37(10), 1525-1533.

http://dx.doi.org/10.1016/0017-9310(94)90154-6

Cao, Y., and Faghri, A., 1994c, "Conjugate Analysis of a Flat-Plate Type Evaporator for Capillary Pumped Loops with Three-Dimensional Vapor Flow in the Groove," International Journal of Heat and Mass Transfer, 37(3), 401-409.

http://dx.doi.org/10.1016/0017-9310(94)90074-4

Cao, Y., Faghri, A., and Mahefkey, E. T., 1989, "The Thermal Performance of Heat Pipes with Localized Heat Input," International Journal of Heat and Mass Transfer, 32(7), 1279-1287. http://dx.doi.org/10.1016/0017-9310(89)90028-8

Cao, Y., Gao, M., Beam, J. E., and Donovan, B., 1997, "Experiments and Analyses of Flat Miniature Heat Pipes," Journal of Thermophysics and Heat Transfer, 11(2), 158-164.

http://dx.doi.org/10.2514/2.6247

Chalmers, D. R., Fredley, J., Ku, J., and Kroliczek, E. J., 1988, "Design of a Two-Phase Capillary Pumped Flight Experiment," SAE 88-1086,
Proceedings of 18th Intersociety Conference on Environmental Systems, San Francisco, CA.

Chen, M. M., and Faghri, A., 1990, "An Analysis of the Vapor Flow and the Heat Conduction through the Liquid-Wick and Pipe Wall in a Heat Pipe with Single Or Multiple Heat Sources," International Journal of Heat and Mass Transfer, 33(9), 1945-1955.

http://dx.doi.org/10.1016/0017-9310(90)90226-K

Chengsheng, H., Tinghan, L., Yaopu, W., and Zengqi, H., 1984, "Design and Performance of Low Temperature Heat Pipe Blackbody," Proceedings of the 5th International Heat Pipe Conference, Tsukuba, Japan, 74-81.

Chernysheva, M. A., and Maydanik, Y. F., 2008, "Numerical Simulation of Transient Heat and Mass Transfer in a Cylindrical Evaporator of a Loop Heat Pipe," International Journal of Heat and Mass Transfer, 51(17-18), 4204-4215.

http://dx.doi.org/10.1016/j.ijheatmasstransfer.2007.12.021

Chuang, P. A., 2003, "An Improved Steady-State Model of Loop Heat Pipe Based on Experimental and Theoretical Analyses," Ph.D. Thesis, Pennsylvania State University, State College, PA.

Cotter, T. P., 1965, "Theory of Heat Pipes," Los Alamos Scientific Laboratory Report No. LA-3246-MS.

Cotter, T. P., 1984, "Principles and Prospects for Micro Heat Pipes," Proceedings of 5th International Heat Pipe Conference, Tsukuba, Japan, 328-335.

Cullimore, B., 1991, "Startup Transient in Capillary Pumped Loops," AIAA-91-1374, Honolulu, HI.

Cullimore, B., and Bauman, J., 2000, "Steady State and Transient Loop Heat Pipe Modeling," SAE 2000-01-2316, Proceedings of the 34th International Conference on Environmental Systems (ICES), Toulouse, France.

Daniels, T. C., and Al-Jumaily, F. K., 1975, "Investigations of the Factors Affecting the Performance of a Rotating Heat Pipe," International Journal of Heat and Mass Transfer, 18(7-8), 961-973. http://dx.doi.org/10.1016/0017-9310(75)90190-8

Do, K. H., Kim, S. J., and Garimella, S. V., 2008, "A Mathematical Model for Analyzing the Thermal Characteristics of a Flat Micro Heat Pipe with a Grooved Wick," International Journal of Heat and Mass Transfer, 51(19-20), 4637-4650. http://dx.doi.org/10.1016/j.ijheatmasstransfer.2008.02.039

Dobson, R. T., 2004, "Theoretical and Experimental Modelling of an Open Oscillatory Heat Pipe Including Gravity," International Journal of Thermal Sciences, 43(2), 113-119. http://dx.doi.org/10.1016/j.ijthermalsci.2003.05.003

Dobson, R. T., 2005, "An Open Oscillatory Heat Pipe Water Pump," Applied Thermal Engineering, 25(4), 603-621. http://dx.doi.org/10.1016/j.applthermaleng.2004.07.005

Dobson, R. T., and Harms, T. M., 1999, "Lumped Parameter Analysis of Closed and Open Oscillatory Heat Pipes," Proceedings of the 11th International Heat Pipe Conference, Tokyo, Japan, 12-16.

Edwards, D. K., and Marcus, B. D., 1972, "Heat and Mass Transfer in the Vicinity of the Vapor-Gas Front in a Gas-Loaded Heat Pipe," 
Journal of Heat Transfer, Transactions ASME, 94(2), 155-162. http://dx.doi.org/10.1115/1.3449887

El-Genk, M. S., and Huang, L., 1993, "An Experimental Investigation of the Transient Response of a Water Heat Pipe," International Journal of Heat and Mass Transfer, 36(15), 3823-3830.

http://dx.doi.org/10.1016/0017-9310(93)90062-B

El-Genk, M. S., and Saber, H. H., 1999, "Determination of Operation Envelopes for Closed, Two-Phase Thermosyphons," International Journal of Heat and Mass Transfer, 42(5), 889-903. http://dx.doi.org/10.1016/S0017-9310(98)00212-9

Faghri, A., 1989, "Performance Characteristics of a Concentric Annular Heat Pipe: Part II-Vapor Flow Analysis," Journal of Heat Transfer, 111(4), 851-857.

http://dx.doi.org/10.1115/1.3250796

Faghri, A., 1990, "Thermal Energy Storage Heat Exchangers," U.S. Patent No. 4976308.

Faghri, A., 1991, "Micro Heat Pipe Energy Storage Systems," U.S. Patent No. 5000252.

Faghri, A., 1993a, "Centrifugal Heat Pipe Vapor Absorption Heat Pump," U.S. Patent No. 5201196.

Faghri, A., 1993b, "Temperature Regulation System for the Human Body using Heat Pipes," U.S. Patent No. 5269369.

Faghri, A., 1994, "Centrifugal Heat Pipe System," U.S. Patent No. 5297619.

Faghri, A., 1995, Heat Pipe Science and Technology, 1st ed., Taylor \& Francis, Washington, D.C.

Faghri, A., and Buchko, M., 1991, "Experimental and Numerical Analysis of Low-Temperature Heat Pipes with Multiple Heat Sources," Journal of Heat Transfer, 113(3), 728-734.

http://dx.doi.org/10.1115/1.2910624

Faghri, A., Buchko, M., and Cao, Y., 1991a, "A Study of HighTemperature Heat Pipes with Multiple Heat Sources and Sinks: Part I Experimental Methodology and Frozen Startup Profiles," Journal of Heat Transfer, 113(4), 1003-1009.

http://dx.doi.org/10.1115/1.2911193

Faghri, A., Buchko, M., and Cao, Y., 1991b, "A Study of HighTemperature Heat Pipes with Multiple Heat Sources and Sinks: Part II Analysis of Continuum Transient and Steady- State Experimental Data with Numerical Predictions," Transactions of the ASME Journal of Heat Transfer, 113(4), 1010-1016.

http://dx.doi.org/10.1115/1.2911194

Faghri, A., Chen, M. M., and Morgan, M., 1989a, "Heat Transfer Characteristics in Two-Phase Closed Conventional and Concentric Annular Thermosyphons," Journal of Heat Transfer, 111(3), 611-618. http://dx.doi.org/10.1115/1.3250726

Faghri, A., Gogineni, S., and Thomas, S., 1993, "Vapor Flow Analysis of an Axially Rotating Heat Pipe," International Journal of Heat and Mass Transfer, 36(9), 2293-2303.

http://dx.doi.org/10.1016/S0017-9310(05)80114-0

Faghri, A., and Guo, Z., 2009, "Vapor Feed Fuel Cells with a Passive Thermal-Fluids Management System," U.S. Patent No. 7625649B1.
Faghri, A., and Parvani, S., 1988, "Numerical Analysis of Laminar Flow in a Double-Walled Annular Heat Pipe," Journal of Thermophysics and Heat Transfer, 2(3), 165-171.

http://dx.doi.org/10.2514/3.81

Faghri, A., Reynolds, D., and Faghri, P., 1989b, "Heat Pipes for Hands," Mechanical Engineering, 111(6), 72-75.

Faghri, A., Stewart, R. J., and Rainey, C. L., 1984, "Axial Variation of Local Heat Flux Along the Condenser Section of a Double Wall Artery High Capacity Heat Pipe," Proceedings of the 5th International Heat Pipe Conference, Tsukuba, Japan, 13-17.

Faghri, A., 2012, "Review and Advances in Heat Pipe Science and Technology," Journal of Heat Transfer, 134(12), 123001.

http://dx.doi.org/10.1115/1.4007407

Faghri, A., and Guo, Z., 2005, "Challenges and Opportunities of Thermal Management Issues Related to Fuel Cell Technology and Modeling," International Journal of Heat and Mass Transfer, 48(1920), 3891-3920.

http://dx.doi.org/10.1016/j.ijheatmasstransfer.2005.04.014

Faghri, A., and Harley, C., 1994, "Transient Lumped Heat Pipe Analyses," Heat Recovery Systems and CHP, 14(4), 351-363. http://dx.doi.org/10.1016/0890-4332(94)90039-6

Faghri, A., and Khrustalev, D., 1997, "Advances in Modeling of Enhanced Flat Miniature Heat Pipes with Capillary Grooves," Journal of Enhanced Heat Transfer, 4(2), 99-109.

Faghri, A., and Thomas, S., 1989, "Performance Characteristics of a Concentric Annular Heat Pipe: Part I-Experimental Prediction and Analysis of the Capillary Limit," Journal of Heat Transfer, 111(1-4), 844-850.

http://dx.doi.org/10.1115/1.3250795

Faghri, A., 1986, "Vapor Flow Analysis in a Double-Walled Concentric Heat Pipe," Numerical Heat Transfer, 10(6), 583-595.

Faghri, A., and Guo, Z., 2008, "Integration of Heat Pipe into Fuel Cell Technology," Heat Transfer Engineering, 29(3), 232-238. http://dx.doi.org/10.1080/01457630701755902

Finlay, I., Cree, D., and Blundell, D., 1976, "Performance of a Prototype Isothermal Oven for Use with an ' $X$ ' Band Microwave Noise Standard," Proceedings of the 2nd International Heat Pipe Conference, Bologna, Italy, 545-554.

Fletcher, L. S., and Peterson, G. P., 1997, U.S. Patent No. 5591162.

Furukawa, M., 2006, "Model-Based Method of Theoretical Design Analysis of a Loop Heat Pipe," Journal of Thermophysics and Heat Transfer, 20(1), 111-121. http://dx.doi.org/10.2514/1.14675

Gao, M., Cao, Y., Beam, J. E., and Donovan, B., 2000, "Structural Optimization of Axially Grooved Flat Miniature Heat Pipes," Journal of Enhanced Heat Transfer, 7(6), 361-369.

Gaugler, R., 1944, "Heat Transfer Device," U.S. Patent No. 2350348.

Gi, K., and Maezawa, S., 2006, "Study on Solar Cell Cooling by Heat Pipe," Proceedings of the 8th International Heat Pipe Symposium, Kumamoto, Japan, 295-299. 
Giessler, F., Sattler, P., and Thoren, F., 1987, "Heat Pipe Cooling of Electrical Machines," Proceedings of the 6th International Heat Pipe Conference, Grenoble, France, 557-564.

Gray, V. H., 1969, "The Rotating Heat Pipe-A Wickless, Hollow Shaft for Transferring High Heat Fluxes," Proceedings of ASME/AIChE Heat Transfer Conference, Minneapolis, MN, 1-5.

Grover, G., 1966, "Evaporation-Condensation Heat Transfer Device," U.S. Patent No. 3229759.

Grover, G. M., Cotter, T. P., and Erickson, G. F., 1964, "Structures of very High Thermal Conductance," Journal of Applied Physics, 35(6), 1990-1991.

http://dx.doi.org/10.1063/1.1713792

Guo, Z., and Faghri, A., 2006a, "Development of Planar Air Breathing Direct Methanol Fuel Cell Stacks," Journal of Power Sources, 160(2), 1183-1194.

http://dx.doi.org/10.1016/j.jpowsour.2006.03.045

Guo, Z., and Faghri, A., 2006b, "Miniature DMFCs with Passive Thermal-Fluids Management System," Journal of Power Sources, 160(2), 1142-1155.

http://dx.doi.org/10.1016/j.jpowsour.2006.03.013

Hall, M. L., Merrigan, M. A., and Reid, R. S., 1994, "Status Report on the THROHPUT Transient Heat Pipe Modeling Code," AIP-CP-301, Proceedings of the 11th Symposium on Space Nuclear Power and Propulsion, American Institute of Physics, New York, NY, 965-970.

Hamdan, M. O., 2003, "Loop Heat Pipe (LHP) Modeling and Development by Utilizing Coherent Porous Silicon (CPS) Wicks," Ph.D. Thesis, University of Cincinnati, OH.

Harley, C., and Faghri, A., 1994a, "Transient Gas-Loaded Thermosyphon Analysis," Proceedings of the 10th International Heat Transfer Conference, Brighton, England.

Harley, C., and Faghri, A., 2000, "Transient Gas-Loaded Rotating Heat Pipes," Proceedings of the 15th National and 4th ISHMT/ASME Heat and Mass Transfer Conference, Pune, India.

Harley, C., and Faghri, A., 1994b, "Complete Transient TwoDimensional Analysis of Two-Phase Closed Thermosyphons Including the Falling Condensate Film," Journal of Heat Transfer, 116(2), 418426.

http://dx.doi.org/10.1115/1.2911414

Harley, C., and Faghri, A., 1994c, "Transient Two-Dimensional GasLoaded Heat Pipe Analysis," Journal of Heat Transfer, 116(3), 716723.

http://dx.doi.org/10.1115/1.2910927

Harley, C., and Faghri, A., 1995, "Two-Dimensional Rotating Heat Pipe Analysis," Journal of Heat Transfer, 117(1), 202-208.

http://dx.doi.org/10.1115/1.2822304

Hassan, H., and Accensi, A., 1973, "Spacecraft Application of Low Temperature Heat Pipes," Paper No. 9-1, Proceedings of the 1st International Heat Pipe Conference, Stuttgart, Federal Republic of Germany.

Hijikata, K., Chen, S. J., and Tien, C. L., 1984, "Noncondensible Gas Effect on Condensation in a Two-Phase Closed Thermosyphon,"
International Journal of Heat and Mass Transfer, 27(8), 1319-1325. http://dx.doi.org/10.1016/0017-9310(84)90059-0

Hoang, T. T., and Kaya, T., 1999, "Mathematical Modeling of Loop Heat Pipe with Two-Phase Pressure Drop," AIAA Paper No. 19993448 .

Hoang, T., and Ku, J., 2003, "Transient Modeling of Loop Heat Pipes," AIAA Paper No. 2003-6082.

Holley, B., and Faghri, A., 2005, "Analysis of Pulsating Heat Pipe with Capillary Wick and Varying Channel Diameter," International Journal of Heat and Mass Transfer, 48(13), 2635-2651.

http://dx.doi.org/10.1016/j.ijheatmasstransfer.2005.01.013

Holmes, H. R., and Field, A. R., 1986, "The Gas-Tolerant HighCapacity Tapered Artery Heat Pipe," AIAA-86-2343, Proceedings of AIAA/ASME 4th Joint Thermophysics and Heat Transfer Conference, Boston, MA.

Hopkins, R., Faghri, A., and Khrustalev, D., 1999, "Flat Miniature Heat Pipes with Micro Capillary Grooves," Journal of Heat Transfer, 121(1), 102-109.

http://dx.doi.org/10.1115/1.2825922

Hosoda, M., Nishio, S., and Shirakashi, R., 1999, "Meandering Closed Loop Heat Transport Tube (Propagation Phenomena of Vapor Plug)," AJTE99-6306, Proceedings of the 5th ASME/JSME Joint Thermal Engineering Conference, San Diego, CA, USA, 1-6.

Ivanovskii, M. N., Sorokin, V. P., and Yagodkin, I. V., 1982, The Physical Principles of Heat Pipes, Clarendon Press, Oxford.

Iwata, Z., Sakuma, S., and Koga, S., 1984, "Heat Pipes for Local Cooling of Underground Power Cables," Proceedings of the 5th International Heat Pipe Conference, Tsukuba, Japan, 153-155.

Jalilvand, A., Katsuta, M., Saito, K., Toyonaga, J., and Mochizuki, M., 2006, "The study of the thermal performance of concentric annular heat pipe with the application in the heat roll of fusing unit of copy machine," Annals of the Assembly for International Heat Transfer Conference 13.

http://dx.doi.org/10.1615/IHTC13.p22.60

Jang, J. H., Faghri, A., and Chang, W. S., 1991, "Analysis of the OneDimensional Transient Compressible Vapor Flow in Heat Pipes," International Journal of Heat and Mass Transfer, 34(8), 2029-2037. http://dx.doi.org/10.1016/0017-9310(91)90214-Y

Jang, J. H., Faghri, A., Chang, W. S., and Mahefkey, E. T., 1990, "Mathematical Modeling and Analysis of Heat Pipe Start-Up from the Frozen State," Journal of Heat Transfer, 112(3), 586-594.

http://dx.doi.org/10.1115/1.2910427

Jiao, B., Qiu, L. M., Gan, Z. H., and Zhang, X. B., 2012, "Determination of the Operation Range of a Vertical Two-Phase Closed Thermosyphon," Heat and Mass Transfer, 48(6), 1043-1055. http://dx.doi.org/10.1007/s00231-011-0954-x

Jiao, B., Qiu, L. M., Zhang, X. B., and Zhang, Y., 2008, "Investigation on the Effect of Filling Ratio on the Steady-State Heat Transfer Performance of a Vertical Two-Phase Closed Thermosyphon," Applied Thermal Engineering, 28(11-12), 1417-1426. http://dx.doi.org/10.1016/j.applthermaleng.2007.09.009 
Jouhara, H., and Robinson, A. J., 2009, "An Experimental Study of Small-Diameter Wickless Heat Pipes Operating in the Temperature Range 200c to 450c," Heat Transfer Engineering, 30(13), 1041-1048. http://dx.doi.org/10.1080/01457630902921113

Kaya, T., and Ku, J., 1999, "A Parametric Study of Performance Characteristics of Loop Heat Pipes," SAE Paper No. 2001-01-2317.

Kaya, T., and Goldak, J., 2006, "Numerical Analysis of Heat and Mass Transfer in the Capillary Structure of a Loop Heat Pipe," International Journal of Heat and Mass Transfer, 49(17-18), 3211-3220. http://dx.doi.org/10.1016/j.ijheatmasstransfer.2006.01.028

Kaya, T., and Hoang, T. T., 1999, "Mathematical Modeling of Loop Heat Pipes and Experimental Validation," Journal of Thermophysics and Heat Transfer, 13(3), 314-320.

http://dx.doi.org/10.2514/2.6461

Kaya, T., and Ku, J., 2003, "Thermal Operational Characteristics of a Small-Loop Heat Pipe," Journal of Thermophysics and Heat Transfer, 17(4), 464-470.

http://dx.doi.org/10.2514/2.6805

Kaya, T., Pérez, R., Gregori, C., and Torres, A., 2008, "Numerical Simulation of Transient Operation of Loop Heat Pipes," Applied Thermal Engineering, 28(8-9), 967-974.

http://dx.doi.org/10.1016/j.applthermaleng.2007.06.037

Kempers, R., Robinson, A. J., Ewing, D., and Ching, C. Y., 2008, "Characterization of Evaporator and Condenser Thermal Resistances of a Screen Mesh Wicked Heat Pipe," International Journal of Heat and Mass Transfer, 51(25-26), 6039-6046.

http://dx.doi.org/10.1016/j.ijheatmasstransfer.2008.04.001

Khalkhali, H., Faghri, A., and Zuo, Z. J., 1999, "Entropy Generation in a Heat Pipe System," Applied Thermal Engineering, 19(10), 10271043.

http://dx.doi.org/10.1016/S1359-4311(98)00089-1

Khandekar, S., and Gupta, A., 2007, "Embedded Pulsating Heat Pipe Radiators," Proceedings of the 14th International Heat Pipe Conference, Florianopolis, Brazil, 22-27.

Khandekar, S., Panigrahi, P. K., Lefèvre, F., and Bonjour, J., 2010, "Local Hydrodynamics of Flow in a Pulsating Heat Pipe: A Review," Frontiers in Heat Pipes (FHP), 1, 023003.

http://dx.doi.org/10.5098/fhp.v1.2.3002

Khandekar, S., Schneider, M., Schäfer, P., Kulenovic, R., and Groll, M., 2002, "Thermofluid Dynamic Study of Flat-Plate Closed-Loop Pulsating Heat Pipes," Microscale Thermophysical Engineering, 6(4), 303-317.

http://dx.doi.org/10.1080/10893950290098340

Khrustalev, D., 2010, "Advances in transient modeling of loop heat pipe systems with multiple components," AIP Conference Proceedings, 1208, 55-67.

Khrustalev, D., and Faghri, A., 1995a, "Thermal Characteristics of Conventional and Flat Miniature Axially-Grooved Heat Pipes," Journal of Heat Transfer, 117(4), 1048-1054.

http://dx.doi.org/10.1115/1.2836280

Khrustalev, D., and Faghri, A., 1994, "Thermal Analysis of a Micro Heat Pipe," Journal of Heat Transfer, 116(1), 189-198.

http://dx.doi.org/10.1115/1.2910855
Khrustalev, D., and Faghri, A., 1995b, "Heat Transfer during Evaporation on Capillary-Grooved Structures of Heat Pipes," Journal of Heat Transfer, 117(3), 740-747. http://dx.doi.org/10.1115/1.2822638

Khrustalev, D., and Faghri, A., 1995c, "Heat Transfer in the Inverted Meniscus Type Evaporator at High Heat Fluxes," International Journal of Heat and Mass Transfer, 38(16), 3091-3101. http://dx.doi.org/10.1016/0017-9310(95)00003-R

Khrustalev, D., and Faghri, A., 1996a, "Enhanced Flat Miniature Axially Grooved Heat Pipe," Journal of Heat Transfer, 118(1), 261264.

http://dx.doi.org/10.1115/1.2824057

Khrustalev, D., and Faghri, A., 1996b, "Estimation of the Maximum Heat Flux in the Inverted Meniscus Type Evaporator of a Flat Miniature Heat Pipe," International Journal of Heat and Mass Transfer, 39(9), 1899-1909.

http://dx.doi.org/10.1016/0017-9310(95)00270-7

Kiper, A. M., Feric, G., Anjum, M., and Swanson, T. D., 1990, "Transient Analysis of a Capillary Pumped Loop Heat Pipe," AIAA-901685, Proceedings of AIAA/ASME 5th Joint Thermophysics and Heat Transfer Conference, Seattle, WA.

Kirkpatrick, J. P., and Brennan, P. J., 1976, "Long Term Performance of the Advanced Thermal Control Experiment," Proceedings of the 2nd International Heat Pipe Conference, Bolgna, Italy, 629-646.

Kobayashi, Y., and Matsumoto, T., 1987, "Vapor Condensation in the Presence of Non-Condensible Gas in the Gravity Assisted Thermosyphon," Proceedings of 6th International Heat Pipe Conference, Grenoble, France.

Kroliczek, E. J., Ku, J., and Ollendorf, S., 1984, "Design, Development, and Test of a Capillary Pump Heat Pipe," AIAA-84-1720, Proceedings of AIAA 19th Thermophysics Conference, Snowmass, CO.

Ku, J., 1993, "Capillary Pump Loop for the Systems of Thermal Regulation of Spacecraft," Proceedings of ASME National Heat Transfer Conference, Atlanta, GA.

Ku, J., Kroliczek, E. J., Butler, D., Schweickart, R. B., and McIntosh, R., 1986a, "Capillary Pumped Loop GAS and Hitchhiker Flight Experiments," AIAA-86-1249, Proceedings of AIAA/ASME 4th Joint Thermophysics and Heat Transfer Conference, Boston, MA.

Ku, J., Kroliczek, E. J., McCabe, M. E., and Benner, S. M., 1988, "A High Power Spacecraft Thermal Management System," AIAA-88-2702, Proceedings of AIAA Thermophysics, Plasmadynamics, and Lasers Conference, San Antonio, TX.

Ku, J., Kroliczek, E. J., and McIntosh, R., 1987a, "Analytical Modelling of the Capillary Pumped Loop," Proceedings of the 6th International Heat Pipe Conference, Grenoble, France.

Ku, J., Kroliczek, E. J., and McIntosh, R., 1987b, "Capillary Pumped Loop Technology Development," Proceedings of the 6th International Heat Pipe Conference, Grenoble, France.

Ku, J., Kroliczek, E. J., Taylor, W. J., and McIntosh, R., 1986b, "Functional and Performance Tests of Two Capillary Pumped Loop Engineering Models," AIAA-86-1248, Proceedings of AIAA/ASME 4th Joint Thermophysics and Heat Transfer Conference, Boston, MA. 
Lamp, T., 1978, "Development of a Heat Pipe Pan Assembly for a GasFired Commercial Tilting Braiser," Paper No. 78-399, Proceedings of the 3rd International Heat Pipe Conference, Palo Alto, CA.

Larkin, B., and Dubuc, S., 1976, "Self De-icing Navigation Buoys Using Heat Pipes," Proceedings of the 2nd International Heat Pipe Conference, Bologna, Italy, 529-536.

Launay, S., Sartre, V., and Bonjour, J., 2007a, "Effects of Fluid Thermophysical Properties on Loop Heat Pipe operation," Proceedings of the 14th International Heat Pipe Conference, Florianopolis, Brazil.

Launay, S., Platel, V., Dutour, S., and Joly, J. L., 2007b, "Transient Modeling of Loop Heat Pipes for the Oscillating Behavior Study," Journal of Thermophysics and Heat Transfer, 21(3), 487-495. http://dx.doi.org/10.2514/1.26854

Launay, S., Sartre, V., and Bonjour, J., 2007c, "Parametric Analysis of Loop Heat Pipe Operation: A Literature Review," International Journal of Thermal Sciences, 46(7), 621-636.

http://dx.doi.org/10.1016/j.ijthermalsci.2006.11.007

Launay, S., Sartre, V., and Bonjour, J., 2008, "Analytical Model for Characterization of Loop Heat Pipes," Journal of Thermophysics and Heat Transfer, 22(4), 623-631.

http://dx.doi.org/10.2514/1.37439

Launay, S., Sartre, V., and Lallemand, M., 2004a, "Experimental Study on Silicon Micro-Heat Pipe Arrays," Applied Thermal Engineering, 24(2-3), 233-243.

http://dx.doi.org/10.1016/j.applthermaleng.2003.08.003

Launay, S., Sartre, V., Mantelli, M. H., De Paiva, K. V., and Lallemand, M., 2004b, "Investigation of a Wire Plate Micro Heat Pipe Array," International Journal of Thermal Sciences, 43(5), 499-507. http://dx.doi.org/10.1016/j.ijthermalsci.2003.10.006

Le Berre, M., Launay, S., Sartre, V., and Lallemand, M., 2003, "Fabrication and Experimental Investigation of Silicon Micro Heat Pipes for Cooling Electronics," Journal of Micromechanics and Microengineering, 13(3), 436-441.

http://dx.doi.org/10.1088/0960-1317/13/3/313

Lefèvre, F., Lips, S., and Bonjour, J., 2010, "Investigation of Evaporation and Condensation Processes Specific to Grooved Flat Heat Pipes," Frontiers in Heat Pipes (FHP), 1, 023001.

http://dx.doi.org/10.5098/fhp.v1.2.3001

Lefèvre, F., and Lallemand, M., 2006, "Coupled Thermal and Hydrodynamic Models of Flat Micro Heat Pipes for the Cooling of Multiple Electronic Components," International Journal of Heat and Mass Transfer, 49(7-8), 1375-1383.

http://dx.doi.org/10.1016/j.ijheatmasstransfer.2005.10.001

Liang, S. B., and Ma, H. B., 2004, "Oscillating Motions of Slug Flow in Capillary Tubes," International Communications in Heat and Mass Transfer, 31(3), 365-375.

http://dx.doi.org/10.1016/j.icheatmasstransfer.2004.02.007

Lin, L. C., and Faghri, A., 1998a, "Condensation in Rotating Stepped Wall Heat Pipes with Hysteretic Annular Flow," Journal of Thermophysics and Heat Transfer, 12(1), 94-99.

http://dx.doi.org/10.2514/2.6307

Lin, L., and Faghri, A., 1997a, "Heat Transfer Analysis of Stratified Flow in Rotating Heat Pipes with Cylindrical and Stepped Walls,"
International Journal of Heat and Mass Transfer, 40(18), 4393-4404. http://dx.doi.org/10.1016/S0017-9310(97)00060-4

Lin, L., and Faghri, A., 1997b, "Steady-State Performance in a Thermosyphon with Tube Separator," Applied Thermal Engineering, 17(7), 667-679.

http://dx.doi.org/10.1016/S1359-4311(96)00084-1

Lin, L., and Faghri, A., 1997c, "Steady-State Performance of a Rotating Miniature Heat Pipe," Journal of Thermophysics and Heat Transfer, 11(4), 513-518. http://dx.doi.org/10.2514/2.6292

Lin, L., and Faghri, A., 1998b, "An Analysis of Two-Phase Flow Stability in a Thermosyphon with Tube Separator," Applied Thermal Engineering, 18(6), 441-455.

http://dx.doi.org/10.1016/S1359-4311(97)00046-X

Lin, L., and Faghri, A., 1999, "Heat Transfer in Micro Region of a Rotating Miniature Heat Pipe," International Journal of Heat and Mass Transfer, 42(8), 1363-1369.

http://dx.doi.org/10.1016/S0017-9310(98)00270-1

Ma, H. B., Hanlon, M. A., and Chen, C. L., 2006, "An Investigation of Oscillating Motions in a Miniature Pulsating Heat Pipe," Microfluidics and Nanofluidics, 2(2), 171-179.

http://dx.doi.org/10.1007/s10404-005-0061-8

Ma, H. B., Maschmann, M. R., and Liang, S. B., 2002, "Heat Transport Capability in a Pulsating Heat Pipe," AIAA 2002-2765.

Machiroutu, S., Kluge, B., Kuroda, M., and Pokharna, H., 2006, Proceedings of the 8th International Heat Pipe Symposium, Kumamoto, Japan, 46-50.

Maezawa, S., Suzuki, Y., and Tsuchida, A., 1981, "Heat Transfer Characteristics of Disk-Shaped Rotating, Wickless Heat Pipe," Proceedings of the 4th International Heat Pipe Conference, London, UK, 725-734.

Marcus, B. D., and Fleishman, G. L., 1970, "Steady State and Transient Performance of Hot Reservoir Gas-Controlled Heat Pipes," ASME Paper No. 70-HT/SpT-11.

Mashiko, K., Okiai, R., Mochizuki, M., Ryokai, K., Tsuchiya, F., and Fukuda, M., 1989, "Development of an Artificial Permafrost Storage Using Heat Pipes," Paper No. 89-HT-15, ASME/AIChE National Heat Transfer Conference, Philadelphia, PA.

Matsuda, S., Miskolczy, G., Okihara, M., Okihara, T., Kanamori, M., and Hamada, N., 1981, "Test of a Horizontal Heat Pipe Deicing Panel for Use on Marine Vessels," Proceedings of the 4th International Heat Pipe Conference, London, UK, 3-10.

Maydanik, Y. F., 2005, "Loop Heat Pipes," Applied Thermal Engineering, 25(5-6), 635-657.

http://dx.doi.org/10.1016/j.applthermaleng.2004.07.010

Maydanik, Y. F., Fershtater, Y. G., and Solodovnik, N., 1994, "Loop Heat Pipes: Design, Investigation, Prospects of Use in Aerospace Technics," SAE Paper 941185.

Maydanik, Y. F., Ferchtater, Y. G., and Goncharov, K. A., 1991, "Capillary Pump Loop for the systems of Thermal Regulation of Spacecraft," 4th European Symposium on Space Environment and Control Systems, ESA SP-324. Florence, Italy. 
McIntosh, R., Ollendorf, S., and Harwell, W., 1976, "The International Heat Pipe Experiment," Proceedings of the 2nd International Heat Pipe Conference, Bologna, Italy, 589-592.

Meijer, R., and Khalili, K., 1990, "Design and Testing of a Heat Pipe Gas Combustion System for the STM4-120 Stirling Engine," Proceedings of the 7th International Heat Pipe Conference, Minsk, USSR.

Mingwei, T., Li, C., Hongji, Z., and Qingming, T., 1991, "Start-Up Behavior of the Frozen Two-Phase Closed Steel-Water Thermosyphons," Proceedings of the 8th International Heat Pipe Conference.

Miyazaki, Y., and Akachi, H., 1996, "Heat Transfer Characteristics of Looped Capillary Heat Pipe," Proceedings of the 5th International Heat Pipe Symposium, Melbourne, Australia, 378-383.

Miyazaki, Y., and Akachi, H., 1998, "Self Excited Oscillation of Slug Flow in a Micro Channel," Proceedings of the 3rd International Conference on Multiphase Flow, Lyon, France.

Miyazaki, Y., and Arikawa, M., 1999, "Oscillatory Flow in the Oscillating Heat Pipe," Proceedings of the 11th International Heat Pipe Conference, Tokyo, Japan, 131-136.

Mochizuki, M., Nguyen, T., Saito, Y., Kiyooka, F., and Wuttijumnong, V., 2007, "Advanced micro-channel vapor chamber for cooling high power processors," Proceedings of the ASME InterPack Conference, IPACK 2007, Vancouver, Canada, 695-702.

Mochizuki, M., Saito, Y., Kiyooka, F., and Nguyen, T., 2006, "High Power Cooling Chips by Heat Pipes and Advanced Heat Spreader," 8th International Heat Pipe Symposium, Kumamoto, Japan, 214-221.

Mochizuki, M., Nguyen, T., Mashiko, K., Saito, Y., Nguyen, T., and Wuttijumnong, V., 2011, "A Review of Heat Pipe Applications Including New Opportunities," Frontiers in Heat Pipes (FHP), 2, 013001.

http://dx.doi.org/10.5098/fhp.v2.1.3001

Momose, T., Ishimaru, H., Murase, T., Tanaka, S., and Ishida, S., 1987, "Application of Heat Pipe to Electron-Position Collider TRISTAN," Proceedings of the 6th International Heat Pipe Conference, Grenoble, France, 798-799.

Morgownik, A., and Savage, C., 1987, "Design Aspects of a Deployable $10 \mathrm{~kW}$ Heat Pipe Radiator," Proceedings of the 6th International Heat Pipe Conference, Grenoble, France, 351-356.

Muraoka, I., Ramos, F. M., and Vlassov, V. V., 2001, "Analysis of the Operational Characteristics and Limits of a Loop Heat Pipe with Porous Element in the Condenser," International Journal of Heat and Mass Transfer, 44(12), 2287-2297. http://dx.doi.org/10.1016/S0017-9310(00)00259-3

Nguyen, T., Johnson, P., Akbarzadeh, A., Gibson, K., and Mochizuki, M., 1992, "Design, Manufacture and Testing of a Closed Cycle Thermosyphon Rankine Engine," Proceedings of the 8th International Heat Pipe Conference, Beijing, China.

Nithyanandam, K., and Pitchumani, R., 2012, "Computational studies on a latent thermal energy storage system with integral heat pipes for concentrating solar power," Applied Energy, (in press).

http://dx.doi.org/10.1016/j.apenergy.2012.09.056
Oslejsek, O., and Polasek, F., 1976, "Cooling of Electrical Machines by Heat Pipes," Proceedings of the 2nd International Heat Pipe Conference, Bologna, Italy, 503-514.

Pan, Y., 2001, "Condensation Heat Transfer Characteristics and Concept of Sub-Flooding Limit in a Two-Phase Closed Thermosyphon," International Communications in Heat and Mass Transfer, 28(3), 311-322. http://dx.doi.org/10.1016/S0735-1933(01)00237-8

Peck, S., and Fleischman, G., 1987, "Lightweight Heat Pipe Panels for Space Radiators," Proceedings of the 6th International Heat Pipe Conference, Grenoble, France, 362-367.

Perkins, J., 1836, UK Patent No. 7059.

Peterson, G. P., 1992, "Overview of Micro Heat Pipe Research and Development," Applied Mechanics Reviews, 45(5), 175-189.

http://dx.doi.org/10.1115/1.3119755

Peterson, G. P., and Ma, H. B., 1999, "Temperature Response of Heat Transport in a Micro Heat Pipe," Journal of Heat Transfer, 121(2), 438-445.

http://dx.doi.org/10.1115/1.2825997

Peterson, P. F., and Tien, C. L., 1989, "Numerical and Analytical Solutions for Two-Dimensional Gas Distribution in Gas-Loaded Heat Pipes," Journal of Heat Transfer, 111(3), 598-604.

http://dx.doi.org/10.1115/1.3250724

Plesch, D., Bier, W., Seidel, D., and Schubert, K., 1991, "Miniature Heat Pipes for Heat Removal from Microelectronic Circuits," Proceedings of the ASME Winter Annual Meeting, Atlanta, GA.

Ponnappan, R., 1989, "Studies on the Startup Transients and Performance of a Gas Loaded Sodium Heat Pipe," Technical Report, WRDC-TR-89-2046.

Ponnappan, R., 1990, "Comparison of Vacuum and Gas Loaded Mode Performances of a LMHP," AIAA-90-1755, Proceedings of AIAA/ASME 5th Joint Thermophysics and Heat Transfer Conference, Seattle, WA.

Ranjan, R., Murthy, J. Y., Garimella, S. V., and Vadakkan, U., 2011, "A Numerical Model for Transport in Flat Heat Pipes Considering Wick Microstructure Effects," International Journal of Heat and Mass Transfer, 54(1-3), 153-168. http://dx.doi.org/10.1016/j.ijheatmasstransfer.2010.09.057

Rankin, J. G., 1984, "Integration and Flight Demonstration of a High Capacity Monogroove Heat Pipe Radiator," AIAA-84-1716, Proceedings of the AIAA 19th Thermopyhsics Conference, Snowmass, CO.

Reay, D., 1977, "Heat Pipes - A New Diecasting Aid," Proceedings of the 1st National Diecasters Conference, Birmingham Exhibition Centre, UK.

Rice, J., and Faghri, A., 2007, "Analysis of Porous Wick Heat Pipes, Including Capillary Dry-Out Limitations," AIAA Journal of Thermophysics and Heat Transfer, 21(3), 475-486.

http://dx.doi.org/10.2514/1.24809

Robak, C. W., Bergman, T. L., and Faghri, A., 2011, "Enhancement of Latent Heat Energy Storage using Embedded Heat Pipes," International 
Journal of Heat and Mass Transfer, 54(15-16), 3476-3484. http://dx.doi.org/10.1016/j.ijheatmasstransfer.2011.03.038

Roberts, C., 1978, "A Non-tracking Moderately Focusing Heat Pipe Solar Collectors," Paper No. 78-402, Proceedings of the 3rd International Heat Pipe Conference, Palo Alto, CA.

Rohani, A. R., and Tien, C. L., 1973, "Steady Two-Dimensional Heat and Mass Transfer in the Vapor-Gas Region of a Gas-Loaded Heat Pipe," Journal of Heat Transfer, 95(3), 377-382.

http://dx.doi.org/10.1115/1.3450067

Rosenfeld, J. H., 1987, "Modeling of Heat Transfer into a Heat Pipe for a Localized Heat Input Zone," AIChE Symposium Series, 83, 71-76.

Rosler, S., Groll, M., Supper, W., and Konev, S., 1987, "Analysis and Experimental Investigation of a Cryogenic Methane Heat Pipe," Proceedings of the 6th International Heat Pipe Conference, Grenoble, France, 219-222.

Sakulchangsatjatai, P., Terdtoon, P., Wongratanaphisan, T., Kamonpet, P., and Murakami, M., 2004, "Operation Modeling of Closed-End and Closed-Loop Oscillating Heat Pipes at Normal Operating Condition," Applied Thermal Engineering, 24(7), 995-1008.

http://dx.doi.org/10.1016/j.applthermaleng.2003.11.006

Sartre, V., Zaghdoudi, M. C., and Lallemand, M., 2000, "Effect of Interfacial Phenomena on Evaporative Heat Transfer in Micro Heat Pipes," International Journal of Thermal Sciences, 39(4), 498-504. http://dx.doi.org/10.1016/S1290-0729(00)00205-2

Schlitt, K. R., Kirkpatrick, J. P., and Brennan, P. J., 1974, "Parametric Performance of Extruded Axial Grooved Heat Pipes from $100 \mathrm{~K}$ to 300 K," AIAA-74-724, Proceedings of AIAA/ASME Thermophysics and Heat Transfer Conference.

Schmalhofer, J., and Faghri, A., 1993a, "A Study of CircumferentiallyHeated and Block-Heated Heat Pipes-I. Experimental Analysis and Generalized Analytical Prediction of Capillary Limits," International Journal of Heat and Mass Transfer, 36(1), 201-212.

http://dx.doi.org/10.1016/0017-9310(93)80080-E

Schmalhofer, J., and Faghri, A., 1993b, "A Study of CircumferentiallyHeated and Block-Heated Heat Pipes-II. Three-Dimensional Numerical Modeling as a Conjugate Problem," International Journal of Heat and Mass Transfer, 36(1), 213-226.

http://dx.doi.org/10.1016/0017-9310(93)80081-5

Schulze, T., Sodtke, C., Stephan, P., and Gambaryan-Roisman, T., 2007, "Performance of Heat Pipe Evaporation for Space Applications with Combined Re-Entrant and Micro Grooves," Proceedings of the 14th International Heat Pipe Conference, Florianopolis, Brazil.

Schweickart, R. B., and Buchko, M. T., 1991, "Development and Test Results of a Two-Phase Reservoir for Thermal Transport Systems used in Micro-Gravity," SAE (Society of Automotive Engineers) Transactions, 100, 1887-1899.

Shabgard, H., Bergman, T. L., Sharifi, N., and Faghri, A., 2010, "High Temperature Latent Heat Thermal Energy Storage using Heat Pipes," International Journal of Heat and Mass Transfer, 53(15-16), 29792988.

http://dx.doi.org/10.1016/j.ijheatmasstransfer.2010.03.035

Shabgard, H., and Faghri, A., 2011, "Performance Characteristics of Cylindrical Heat Pipes with Multiple Heat Sources," Applied Thermal
Engineering, 31(16), 3410-3419.

http://dx.doi.org/10.1016/j.applthermaleng.2011.06.026

Shabgard, H., Robak, C. W., Bergman, T. L., and Faghri, A., 2012, "Heat Transfer and Exergy Analysis of Cascaded Latent Heat Storage with Gravity-Assisted Heat Pipes for Concentrating Solar Power Applications," Solar Energy, 86(3), 816-830.

http://dx.doi.org/10.1016/j.solener.2011.12.008

Shafii, M. B., Faghri, A., and Zhang, Y., 2001, "Thermal Modeling of Unlooped and Looped Pulsating Heat Pipes," Journal of Heat Transfer, 123(6), 1159-1172.

http://dx.doi.org/10.1115/1.1409266

Shafii, M. B., Faghri, A., and Zhang, Y., 2002, "Analysis of Heat Transfer in Unlooped and Looped Pulsating Heat Pipes," International Journal of Numerical Methods for Heat and Fluid Flow, 12(5), 585609.

http://dx.doi.org/10.1108/09615530210434304

Shiraishi, M., Mochizuki, M., Mashiko, K., Ito, M., Sughiharu, S., Yamagishi, Y., and Watanabe, F., 1992, "Snow Removal and Deicing Using Flexible Long Heat Pipes," Symposium on Snow and Snow Related Problems, International Glaciological Society.

Shukla, K. N., 1981, "Transient Response of a Gas-Controlled Heat Pipe," AIAA Journal, 19(8), 1063-1070.

http://dx.doi.org/10.2514/3.7842

Singh, R., Mochizuki, M., Nguyen, T., and Akbarzadeh, A., 2011, "Applications of Heat Pipes in Energy Conservation and Renewable Energy Based Systems," Frontiers in Heat Pipes (FHP), 2, 033003. http://dx.doi.org/10.5098/fhp.v2.3.3003

Spendel, T., 1984, "Laminar Film Condensation Heat Transfer in Closed Two-Phase Thermosyphons," Proceedings of 5th International Heat Pipe Conference, Tsukuba, Japan.

Stenger, F. J., 1966, "Experimental Feasibility Study of Water-Filled Capillary Pumped Heat Transfer Loops," NASA X-1310, Nasa LeRC Report.

Suelau, H., Kroliczek, E., and Brinkman, C., 1976, "Application of Heat Pipes to Deicing Systems," Proceedings of the 2nd International Heat Pipe Conference, Bologna, Italy, 515-528.

Suman, B., and Kumar, P., 2005, "An Analytical Model for Fluid Flow and Heat Transfer in a Micro-Heat Pipe of Polygonal Shape," International Journal of Heat and Mass Transfer, 48(21-22), 44984509.

http://dx.doi.org/10.1016/j.ijheatmasstransfer.2005.05.001

Swanson, T. D., 2007, "Thermal Control Technologies for the New Age of Space Exploration," Proceedings of the 14th International Heat Pipe Conference, Florianopolis, Brazil.

Tang, X., and Park, C., 2008, "Vibration/Shock-Tolerant Capillary Two-Phase Loop Technology for Vehicle Thermal Control," Proceedings of the ASME Summer Heat Transfer Conference, Jacksonville, FL, 531-537.

http://dx.doi.org/10.1115/HT2008-56349

Tarau, C., and Anderson, W. G., 2010, "Sodium Variable Conductance Heat Pipe for Radioisotope Stirling Systems - Design and Experimental Results," IECEC 2010, 8th Annual International Energy Conversion Engineering Conference, Nashville, TN. 
Thieme, L. G., and Schreiber, J. G., 2003, "NASA GRC Stirling Technology Development Overview," AIP Conference Proceedings, 654, 613-620.

http://dx.doi.org/10.1063/1.1541346

Tournier, J. M., and El-Genk, M. S., 1994, "A Heat Pipe Transient Analysis Model," International Journal of Heat and Mass Transfer, 37(5), 753-762.

http://dx.doi.org/10.1016/0017-9310(94)90113-9

Tournier, J. M., and El-Genk, M. S., 1996, "A Vapor Flow Model for Analysis of Liquid-Metal Heat Pipe Startup from a Frozen State," International Journal of Heat and Mass Transfer, 39(18), 3767-3780. http://dx.doi.org/10.1016/0017-9310(96)00066-X

Tournier, J. M., and El-Genk, M. S., 2003, "Startup of a Horizontal Lithium-Molybdenum Heat Pipe from a Frozen State," International Journal of Heat and Mass Transfer, 46(4), 671-685.

http://dx.doi.org/10.1016/S0017-9310(02)00324-1

Trefethen, L., 1962, "On the Surface Tension Pumping of Liquids or a Possible Role of the Candlewick in Space Exploration," G.E. Tech. Info., Serial No. 615 D114.

Trovole, H. P., and Raine, J. K., 1995, "The Design and Heat Pipe Tests for a Line Focus Solar Stirling Domestic Generation System," Proceedings of the Institution of Mechanical Engineers, Part A: Journal of Power and Energy, 209(1), 27-36.

Vasiliev, L. L., 2005, "Heat Pipes in Modern Heat Exchangers," Applied Thermal Engineering, 25(1), 1-19.

http://dx.doi.org/10.1016/j.applthermaleng.2003.12.004

Vieira da Cunha, A. F., and Mantelli, M. H., 2009, "Analytical and Experimental Analysis of a High Temperature Mercury Thermosyphon," Journal of Heat Transfer, 131(9), 1-7. http://dx.doi.org/10.1115/1.3089551

Wang, Y. X., and Peterson, G. P., 2002, "Analysis of Wire-Bonded Micro Heat Pipe Arrays," Journal of Thermophysics and Heat Transfer, 16(3), 346-355.

http://dx.doi.org/10.2514/2.6711

Wang, Y., and Vafai, K., 2000, "An Experimental Investigation of the Transient Characteristics on a Flat-Plate Heat Pipe during Startup and Shutdown Operations," Journal of Heat Transfer, 122(3), 525-535. http://dx.doi.org/10.1115/1.1287725

Waters, E. D., 1976, "Heat Pipes for the Trans-Alaskan Pipeline," Proceedings of the 2nd International Heat Pipe Conference, Bolonga, Italy, 803-814.

Williams, R., 1978, "Investigation of a Cryogenic Thermal Diode," Paper No. 78-417, Proceedings of the 3rd International Heat Pipe Conference, Palo Alto, CA.

Winship, J., 1974, "Diecasting Sharpens its Edge," American Machinist, 118, 77-78.

Wong, T. N., Tong, B. Y., Lim, S. M., and Ooi, K. T., 1999, "Theoretical Modeling of Pulsating Heat Pipe," Proceedings of the 11th International Heat Pipe Conference, Tokyo, Japan, 159-163.

Wu, X. P., Mochizuki, M., Mashiko, K., Nguyen, T., Nguyen, T., Wuttijumnong, V., Cabusao, G., Singh, R., and Akbarzadeh, A., 2011, "Cold Energy Storage Systems using Heat Pipe Technology for Cooling
Data Centers," Frontiers in Heat Pipes (FHP), 2, 013005.

http://dx.doi.org/10.5098/fhp.v2.1.3005

Wu, D., and Peterson, G. P., 1991, "Investigation of the Transient Characteristics of a Micro Heat Pipe," Journal of Thermophysics and Heat Transfer, 5(2), 129-134.

http://dx.doi.org/10.2514/3.239

Xiao, B., and Faghri, A., 2008, "A Three-Dimensional Thermal-Fluid Analysis of Flat Heat Pipes," International Journal of Heat and Mass Transfer, 51(11-12), 3113-3126. http://dx.doi.org/10.1016/j.ijheatmasstransfer.2007.08.023

Yamawaki, S., Yoshida, T., Taki, M., and Mimura, F., 1998, "Fundamental Heat Transfer Experiments of Heat Pipes for Turbine Cooling," Journal of Engineering for Gas Turbines and Power, 120(3), 580-587.

http://dx.doi.org/10.1115/1.2818186

Zhang, Y., and Faghri, A., 2002, "Heat Transfer in a Pulsating Heat Pipe with Open End," International Journal of Heat and Mass Transfer, 45(4), 755-764.

http://dx.doi.org/10.1016/S0017-9310(01)00203-4

Zhang, Y., and Faghri, A., 2003, "Oscillatory Flow in Pulsating Heat Pipes with Arbitrary Numbers of Turns," Journal of Thermophysics and Heat Transfer, 17(3), 340-347.

http://dx.doi.org/10.2514/2.6791

Zhang, Y., Faghri, A., and Shafii, M. B., 2002, "Analysis of LiquidVapor Pulsating Flow in a U-Shaped Miniature Tube," International Journal of Heat and Mass Transfer, 45(12), 2501-2508.

http://dx.doi.org/10.1016/S0017-9310(01)00348-9

Zhang, Y., and Faghri, A., 2008, "Advances and Unsolved Issues in Pulsating Heat Pipes," Heat Transfer Engineering, 29(1), 20-44. http://dx.doi.org/10.1080/01457630701677114

Zhu, N., and Vafai, K., 1998a, "Analytical Modeling of the Startup Characteristics of Asymmetrical Flat-Plate and Disk-Shaped Heat Pipes," International Journal of Heat and Mass Transfer, 41(17), 2619-2637.

http://dx.doi.org/10.1016/S0017-9310(97)00325-6

Zhu, N., and Vafai, K., 1998b, "Vapor and Liquid Flow in an Asymmetrical Flat Plate Heat Pipe: A Three-Dimensional Analytical and Numerical Investigation," International Journal of Heat and Mass Transfer, 41(1), 159-174.

http://dx.doi.org/10.1016/S0017-9310(97)00075-6

Zuo, Z. J., North, M. T., and Ray, L., 1999, "Combined Pulsating and Capillary Heat Pipe Mechanism for Cooling of High Heat Flux Electronics," Proceedings of ASME Heat Transfer Device Conference, Nashville, TN, 2237-2243.

Zuo, Z. J., and Faghri, A., 1997, "Boundary Element Approach to Transient Heat Pipe Analysis," Numerical Heat Transfer; Part A: Applications, 32(3), 205-220. http://dx.doi.org/10.1080/10407789708913888

Zuo, Z. J., and Faghri, A., 1998, "A Network Thermodynamic Analysis of the Heat Pipe," International Journal of Heat and Mass Transfer, 41(11), 1473-1484.

http://dx.doi.org/10.1016/S0017-9310(97)00220-2 
Zuo, Z. J., Faghri, A., and Langston, L., 1998, "Numerical Analysis of Heat Pipe Turbine Vane Cooling," Journal of Engineering for Gas Turbines and Power, 120(4), 735-743. http://dx.doi.org/10.1115/1.2818461

Zuo, Z. J., and Gunnerson, F. S., 1995, "Heat Transfer Analysis of an Inclined Two-Phase Closed Thermosyphon," Journal of Heat Transfer,
117(4), 1073-1075.

http://dx.doi.org/10.1115/1.2836287

Zuo, Z. J., North, M. T., and Wert, K. L., 2001, "High Heat Flux Heat Pipe Mechanism for Cooling of Electronics," IEEE Transactions on Components and Packaging Technologies, 24(2), 220-225.

http://dx.doi.org/10.1109/6144.926386 